LOREN D'APRILE

A importância da família dos fatores de crescimento endotelial vascular na reprodução

São Paulo

2021 


\section{LOREN D'APRILE}

\section{A importância da família dos fatores de crescimento endotelial vascular na reprodução}

Dissertação apresentada ao Programa de Pós-Graduação em Reprodução Animal da Faculdade de Medicina Veterinária e Zootecnia da Universidade de São Paulo para a obtenção do título de Mestre em Ciências.

Departamento:

Reprodução Animal

Área de concentração:

Reprodução Animal

Orientador:

Profa. Dra. Paula de Carvalho Papa

Keohane

São Paulo

2021 
Autorizo a reprodução parcial ou total desta obra, para fins acadèmicos, desde que citada a fonte.

DADOS INTERNACIONAIS DE CATALOGAÇÃo NA PUBLICAÇÃo

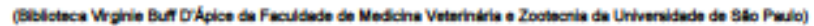

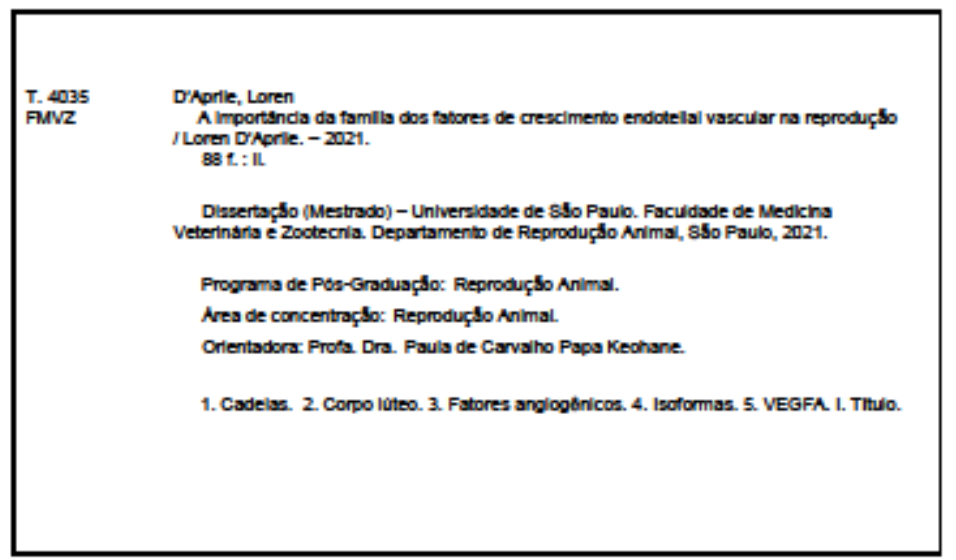

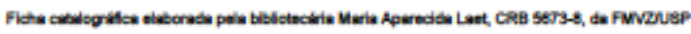




\section{Certificado da Comissão de Ética}

\section{UNIVERSIDADE DE SÃo PAULO}

Comissão de Ética no Uso de Animais

São Paulo, 01 de outubro de 2019 CEUAx N 7583011019

IImo(a). Sr(a)

Responsável: Paula De Carvalho Papa Keohane

Área: Reprodução Animal

Equipe envolvida: Loren D aprile - executor (fmvz - Usp); Paula De Carvalho Papa Keohane (orientador)

Título do projeto: "O VEGFA, sua importância na angiogênese e sua ação no corpo lúteo canino: uma revisão de literatura ".

Parecer Consubstanciado da CEUA FMVZ

A Comissão de Ética no Uso de Animais da Faculdade de Medicina Veterinária e Zootecnia da Universidade de São Paulo, na reunião de 01/10/2019, ANALISOU e APROVOU o protocolo de estudo acima referenciado. A partir desta data, é dever do pesquisador:

1. Comunicar toda e qualquer alteração do protocolo.

2. Comunicar imediatamente ao Comitê qualquer evento adverso ocorrido durante o desenvolvimento do protocolo.

3. Os dados individuais de todas as etapas da pesquisa devem ser mantidos em local seguro por 5 anos para possível auditoria dos órgãos competentes.

4. Relatórios parciais de andamento deverão ser enviados anualmente à CEUA até a conclusão do protocolo.

$$
\text { Mnneliese Tealar. }
$$

Profa. Dra. Anneliese de Souza Traldi Presidente da Comissão de Ética no Uso de Animais

Faculdade de Medicina Veterinária e Zootecnia da Universidade de São Paulo

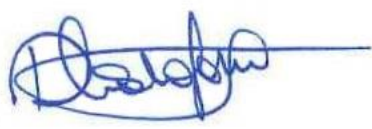

Roseli da Costa Gomes Secretária

Faculdade de Medicina Veterinária e Zootecnia da Universidade de São Paulo 
Ilimo(a). Sr(a).

Responsável: Paula De Carvalho Papa Keohane

Area: Reproduçāo Animal

Equipe envolvida: Loren DDaprile; Paula De Carvalho Papa Keohane:

Título do projeto: "A importancia da familia dos fatores de crescimento endotelial vascular na reprodução *.

Parecer Consubstanciado da Comissāo de Ética no Uso de Animais FMVZ (DD 001202)

A Comissão de Ética no Uso de Animais da Faculdade de Medicina Veterinária e Zootecnia da Universidade de São Paulo, no cumprimento das suas atribuiçōes, ANALISOU e APROVOU a Alteraçāo do cadastro (versāo de 01/abril/2021) do protocolo de estudo acima referenciado.

Resumo apresentado pelo pesquisador: "Houve alteração no título da dissertaçāo por conta do desenvolvimento do projeto de pesquisa. 0 projeto anterior era uma revisāo de literatura. A dissertação atual contém resultados que foram obtidos através da análise de amostras.

As amostras utilizadas para o desenvolvimento do projeto já estavam disponiveis no Laboratório de Estudos Morfofuncionais e Endocrinologia (laboratório coordenado pela professora Paula de Carvalho Papa Keohane) e foram suficientes para obtenção dos resultados apresentados na dissertação. São amostras que foram anteriormente coletadas com a aprovação do Comitê de Etica em Uso de Animais da Faculdade de Medicina Veterinária e Zootecnia, Universidade de Sảo Paulo, São Paulo, Brasil (número do protocolo 2719/2012). No corpo do trabalho, em materiais e métodos, é citada a procedência do material e o protocolo.

Assim sendo, não houve a necessidade do uso de animais para a realização de novas coletas e - ou obtenção de novas amostras.

.

Comentários da CEUA: "As solicitaçōes desta CEUA foram atendidas pelo Pesquisador, portanto, consideramos a alteração de titulo aprovada. Ressaltando que a demora na liberaçäo deu-se pelo fato de inconsistências no Sistema Orion. *

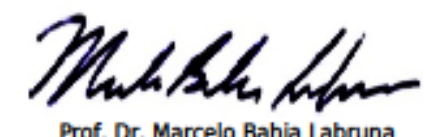

Prof. Dr. Marcelo Bahia Labruna

Coordenador da Comissāo de Ética no Uso de Animais

Faculdade de Medicina Veterinária e Zootecnia da Universidade de São Paulo

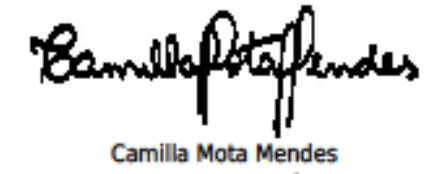

Vice-Coordenadora da Comissão de Etica no Uso de Animais

Faculdade de Medicina Veterinária e Zootecnia da Universidade de Săo Paulo

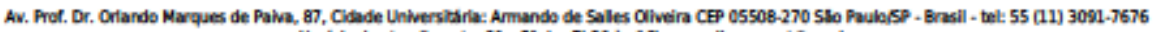

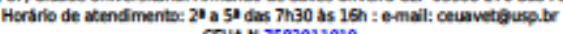




\section{FOLHA DE AVALIAÇÃO}

Autor: D’APRILE, Loren

Título: A importância da família dos fatores de crescimento endotelial vascular na reprodução

Dissertação apresentada ao Programa de Pós-Graduação em Reprodução Animal da Faculdade de Medicina Veterinária e Zootecnia da Universidade de São Paulo para obtenção do título de Mestre em Ciências.

Data:

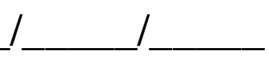

Banca Examinadora

Prof. Dr.

Instituição: Julgamento:

Prof. Dr.

Instituição: Julgamento:

Prof. Dr. Instituição: Julgamento: 


\section{DEDICATÓRIA}

A Dens, por sew infinito amor, bondade, proteção e refúgio, por todas as bênçãos maravithosas que sempre recairam sobre mim.

A todas as mulheres que vieram antes de mim e hutaram pelo direito de termos direitos. A todas as desbravadoras que, corajosamente, abriram caminho na sociedade e na ciência. : sem vocês, nada disso sería possivel.

Às mulheres que tiveram seus sonhos interrompidos ow arrancados de suas mãos pela violência doméstica e que não tiveram outra chance. Eu vejo vocês. E quando en vejo vocês, sei que essa conquista é de todas nós.

A todos que en amo e que me amam, os mens amigos, que são a minha familia de alma e estão ao meu lado.

Aos mens professores e professoras que me ensinam em todos os aspectos da vida, me guiando por caminhos de dedicação, amor e resiliência.

Ao mew amor, que é o mew maior presente e a parte mais bonita e feliz de todos os mens dias.

Aos animais, seres insubstituiveis, dotados de magnitude, pureza, esplendor, lealdade e verdade. Vocês são e sempre serã $\sigma$ men maior amor, a minha methor escotha. 


\section{AGRADECIMENTOS}

Desde $\sigma$ princípio do mestrado, até hoje, são muitas as pessoas que desejo agradecer. Se, por circunstância da memória faltha, ew me esquecer de citar alguém, peço desculpas e desejo que entendam que todos que me apoiaram, seja na parte profissional ow pessoal, são e foram importantes para que esse sonho se realizasse. Rogo, de todo meu coração, para que o methor aconteça para cada um. Que sejam abençoados com uma vida cheia de paz, amor e conquistas, em todas as áreas. Muito obrigada por tudo!

Agradeço a Deus pela vida, pela saide, pelas oportunidades, pelos aprendizados e por estar sempre comigo. Bendito é Deus que muda as horas!

Agradeço aos mens pais, por terem me dado a vida e ao men irmão por compartithar parte da minha jornada comigo.

Agradeço de forma especial à minha orientadora, Prof. Doutora Paula de Carvalho Papa Keohane, por tudo! Obrigada por confiar em mim e me permitir ter a oportunidade de ser sua orientada de mestrado e assim realizar esse sonho. Obrigada por me dar livre acesso à sua casa, sua família, sua vida e sen laboratório. Obrigada pelos ensinamentos, oportunidades e orientações profissionais e pessoais desde que nos conhecemos, por trazer a Medicina Veterináría do Coletivo para minha vida e também o Projeto Santuário, que eu tanto amo. Estamos unidas em nossas caminhadas há anos e desde que nos conhecemos passamos por 
momentos alegres e tristes, os altos e baixos da vida, mas sempre permanecemos juntas. Que nossa amizade e $\sigma$ amor que sentimos uma pela outra possa superar todo e qualquer obstáculo de tempo, distância ou adversidade, hoje e por todo o sempre! Ew amo muitovocê!

Agradeço à minha grande amiga e minha familia de alma: Fran. Amiga, por onde começar a te agradecer? Nem tenho patauras! Você me ajudou e apoiou, esteve ao meu lado, em tudo, pratudo, dentro e fora da USP, sempre. Muito obrigada por ter me acothido e cuidado de mim, por toda paciência, amor e amizade. Obrigada por ser um presente de Deus na minha vida, por ser um ponto de apoio e uma pessoa tão maravithosa! obrigada, mithões de vezes obrigada. Vocêfez muito por mim! Te amo demais!

Agradeço ao meu grande amor, Antonio Francisco da Silva Lisboa Neto, por tudo, absolutamente tudo! Você me ajudou a me reerguer, me apoiou, me amow e cuidow de mim. Eu renasci. Se não fosse por você e por sew amor nem sei o que tería sido de mim. Obrigada por me fazer acordar todos os dias feliz e com muita vontade de viver por querer estar pra sempre ao seu lado. Você é a minha pessoa, o amor da minha vida. Te amo demais fofuxo!

Agradeço à minha amiga Jéssica pela amizade de 20 anos e $\sigma$ apoio de sempre! Amore, te amo muito, você é minha irmã de alma. Muito obrigada por todo suporte e carinho! Sua amizade é muito, muito importante pra mime você é única na minha vída! 
Agradeço à tía Sônia por toda ajuda e consideração. Você e o que fez por mim fizeram toda diferença na minha vida. Serei sempre grata tia, te amo!

Agradeço à minha amiga Adriana por me ajudar a reestabelecer a minha saide, por me apoiar, me alegrar e me dar tanto carinho. Mano Dri, ew amovocê!

Agradeço à Círce, que durante um bom tempo esteve ao meu lado, me ajudando, dando forças, incentivando e me apoiando. Obrigada, lembrarei de todo bem que me que fez com amor $e$ gratidão!

Agradeço à minha amiga Otávía Mello por todo apoí que me deu durante tempos tristes e sombrios que passer. Você é muito importante pra mim!

Agradeço aos mens amigos do LEME pela compantia e por todos os momentos vívidos! A todos que passaram pelo laboratório e conviveram comigo, agradeço com amor, pois vocês fizeram parte dessa jornada, direta ow indiretamente. Muito obrigada!

Agradeço imensamente a professora Sônia Regina Pinheiro. Sônia, a homeopatia te trouxe pra minha vida, e da vida eu te trouxe pro meu coração. Muito obrigada por me ajudar, por toda preocupação e carinho comigo! Sow eternamente grata por todo 
amor, acothimento, cuidado e paciência. Sua amizade tem um imenso valor pra mim. Tenho muito amor por você!

Agradeço de todo men coração a professora Cristiane Pizzutto. Cris, fiquei muito feliz por ter tido a chance de conhecer a pessoa maravithosa que você é: amorosa, ajudadora e muito humana. Obrigada por tanta bondade. Você me dew muita força. Lembrarei de tudo, pra sempre, com muito amor e consideração!

Agradeço à Rita de Cássía María Garcia e à Vânía Plaza Nunes por serem, desde sempre, grandes inspiraçöes pra mim, como pessoas e profissionais. Vocês são maravithosas! Tenho muito amor, carinho e consideração por vocês. Obrigada por tudo que me ensinaram e por todo bem que fazem aos animais!

Agradeço à Regina e ao Renato, do serviço de pós graduação da FMVZ, pela paciência e disponibitidade em ajudar sempre. Muito obrigada!

Agradeço à Maria, da biblioteca da FMVZ, por tirar todas minhas dividas com carinho e por ser sempre muito solicita. Muito obrigada!

Agradeço à Roseli, secretáría da CEUA, por sua atenção e prestatividade de sempre. Muito obrigada!

Agradeço à Harumi, secretáría do programa de pós-graduação doVRA, por sua atenção e sua competência. Muito obrigada! 
Agradeço à Daura, secretáría do programa de pós-graduação da Anatomia, por sua ajuda e apoio.

Agradeço ao Edinaldo Farias, o Indio, por todas as palavras de força e consolo. Obrigada por orar e torcer por mim!!!

Agradeço o tio que vende roupas ali no bandejão Central, $\sigma$ sew Jorge, por sew amor, amizade e carinho durante todo esse período. Tío, obrigada por me abraçar todos os dias, por torcer por mime me fazer sorrir. Tenho muito amor por você!

Agradeço ao VRA e aos professores que me ajudaram, pelo apoio!

Agradeço à Faculdade de Medicina Veterináría e Zootecnia da Universidade de São Paulo, por proporcionar infraestrutura de quatidade para que en pudesse reatizar men projeto.

Agradeço à CAPES: "O presente trabatho foi reatizado com apoio da Coordenação de Aperfeiçoamento de Pessoal de Nivel Superior - Brasil (CAPES) - Código de Financiamento 001."

Agradeço a todos que participaram direta ow indiretamente da reatização desse trabalho, amigos queridos, saibam que tenho eterna gratidão por tudo!

A vocês, meu muito obrigada com todo amor!!! 
"O Senhor é meuPastor, nada me faltará."

Salmos 23, 1 


\section{RESUMO}

D’APRILE, L. A importância da família dos fatores de crescimento endotelial vascular na reprodução. 2021. 88 f. Dissertação (Mestrado em Ciências) Faculdade de Medicina Veterinária e Zootecnia, Universidade de São Paulo, São Paulo, 2021.

O ciclo estral da cadela difere de fêmeas de outras espécies e tem como protagonista principal o corpo lúteo, glândula endócrina transitória que secreta diversos fatores relacionados à sua manutenção e regressão. Um dos fatores chaves que regula a angiogênese é o VEGFA, fator de crescimento endotelial pertencente a uma ampla família. O objetivo do trabalho foi revisar a importância do VEGFA, de suas isoformas, seus receptores e dos fatores de crescimento na angiogênese, na reprodução e no corpo lúteo canino. Sobre as isoformas angiogênicas do VEGFA e sua estruturação em exons e introns, nada se achou na espécie canina. Sugerimos a estrutura das isoformas caninas homologas às do ser humano para posterior validação. Adicionalmente, identificamos a expressão de fatores angiogênicos durante o diestro não gestacional na espécie canina, através da técnica de RNA-seq. Para tal, foram utilizados corpos lúteos provenientes de 18 cadelas que passaram por ovariosalpingohisterectomia $(\mathrm{OSH})$ nos dias 10, 20, 30, 40, 50 e 60 após a ovulação (p.o). Os corpos lúteos coletados foram utilizados para extração de RNA total a partir do protocolo de TRIZOL e posterior análise por RNAseq, seguindo o protocolo TruSeq RNA Sample Preparation Guide, descrito por Illumina. Identificamos a expressão diferencial do VEGFA, VEGFC, VEGFD, VEGFR1, VEGFR2 e VEGFR3 nas comparações entre o período luteotrófico e regressão luteínica. Os dados demonstram maior expressão de fatores angiogênicos no dia 20 p.o, período relacionados à proliferação celular e manutenção da função do corpo lúteo canino.

Palavras-chave: Cadelas. Corpo lúteo. Fatores angiogênicos. Isoformas. VEGFA. 


\begin{abstract}
D'APRILE, L. The importance of vascular endothelial growth factor family in reproduction. 2021. 88 f. Dissertação (Mestrado em Ciências) - Faculdade de Medicina Veterinária e Zootecnia, Universidade de São Paulo, São Paulo, 2021.

The estrous cycle of bitches differs from that of other species and its main protagonist is the corpus luteum, a transient endocrine gland that secretes several factors related to its maintenance and regression. One of the main factors that regulate angiogenesis is VEGFA, an endothelial growth factor belonging to a large family. The aim of the study was to shed light on the importance of VEGFA, its isoforms and receptors in angiogenesis, reproduction and canine corpus luteum. The angiogenic isoforms of this growth factor have been investigated for its structure in exons and introns, and nothing has been found about this conformation in dogs. Here we suggest the structure of canine isoforms homologous to that of humans for further validation and we seek to identify the expression of angiogenic factors during nongestational diestrus in the canine species, using the RNA-seq technique. For this purpose, corpus luteum of 18 bitches submitted to ovariosalpingohisterectomy (OSH) were used on days 10,20,30,40, 50 and 60 after ovulation (p.o). The collected corpus luteum were used for extraction of total RNA using the TRIZOL protocol and subsequent analysis by RNA-seq, following the protocol TruSeq RNA Sample Preparation Guide, described by Illumina. We identified the differential expression of VEGFA, VEGFC, VEGFD, VEGFR1, VEGFR2 and VEGFR3 when comparing the luteotrophic and regression periods. The data demonstrate the active participation of angiogenic factors on day 20 post ovulation, a period related to cell proliferation and maintenance of canine corpus luteum function.
\end{abstract}

Keywords: Angiogenic factors. Bitches. Corpus luteum. Isoforms. VEGFA. 


\section{LISTA DE FIGURAS}

Figura 1 - Sequência dos exons das isoformas do VEGFA canino (Cf) homólogas as sequências dos exons do VEGFA humano $(\mathrm{Hs})$

Figura 2 - Análise da expressão do VEGFA, VEGFC, VEGFD, VEGFR1, VEGFR2 e

VEGFR3 no dia 20 p.o em comparação aos dias 50 e 60 p.o por RNA-seq. 49

Figura 3 - Sequência nucleotídica dos exons do VEGFA humano .78

Figura 4 - Sequência nucleotídica dos exons do VEGFA canino .80 


\section{LISTA DE TABELAS}

Tabela 1 - Dados genômicos (Ensembl) do transcrito VEGFR1 (FLT1-201) em diferentes espécies. .26

Tabela 2 - Dados genômicos (Ensembl) do transcrito VEGFR2 (KDR-201) em

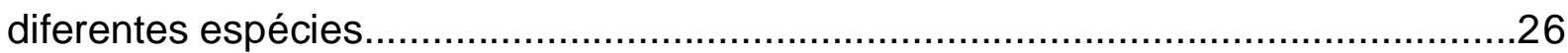

Tabela 3 - Dados genômicos (Ensembl) do transcrito VEGFR3 (FLT4-201) em

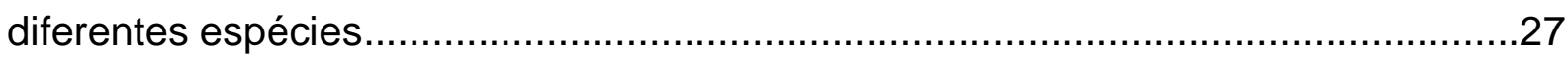

Tabela 4 - Conjuntos de GO dos processos biológicos do VEGFA, VEGFC, VEGFD, VEGFR1, VEGFR2 e VEGFR3 


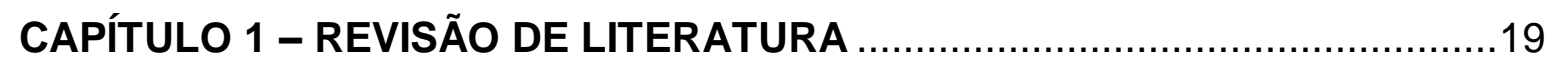

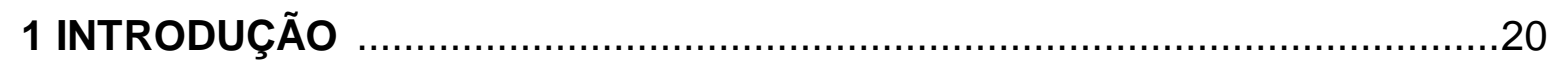

2 REVISÃO DE LITERATURA

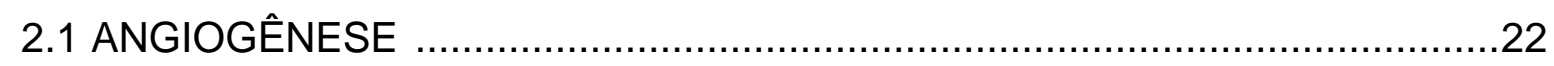

2.2 OS FATORES DE CRESCIMENTO ENDOTELIAL VASCULAR (VEGFS) ... 22

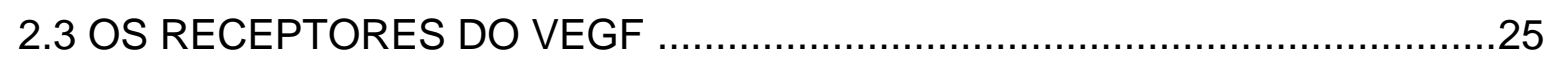

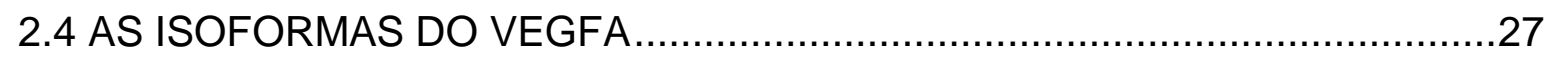

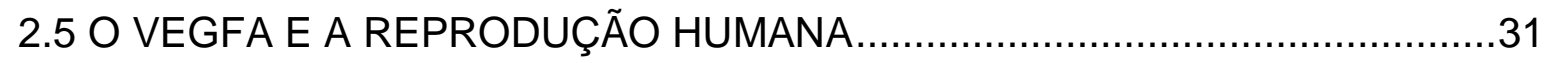

2.6 O CICLO REPRODUTIVO DA CADELA E SUA RELAÇÃO COM O VEGFA .33

CAPÍTULO 2 ANÁLISE DA EXPRESSÃO DIFERENCIAL DE FATORES ANGIOGÊNICOS NO CORPO LÚTEO CANINO NÃO GRAVÍDICO PELA

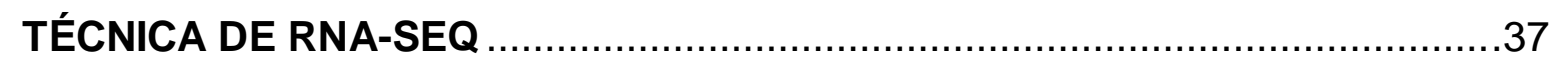

3 ANÁLISE DA EXPRESSÂO DIFERENCIAL DE FATORES ANGIOGÊNICOS NO CORPO LÚTEO CANINO NÃO GRAVÍDICO PELA TÉCNICA DE RNA-SEQ .

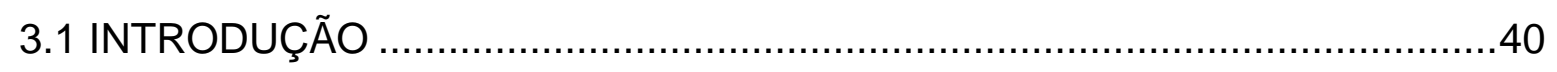

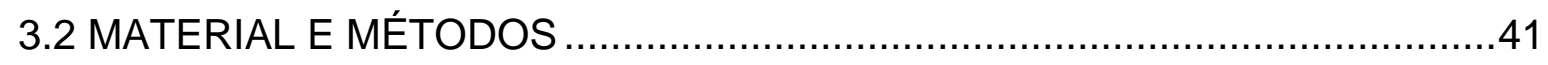

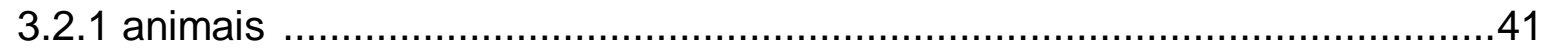

3.2.2 dosagem de progesterona e 17b-estradiol ............................................42

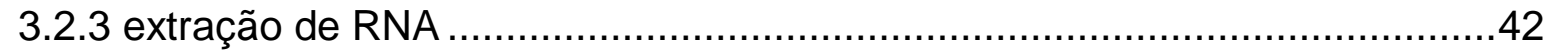

3.2.4 preparação das bibliotecas e sequenciamento …….....................................

3.2.5 análise dos dados do sequenciamento de RNA .......................................43

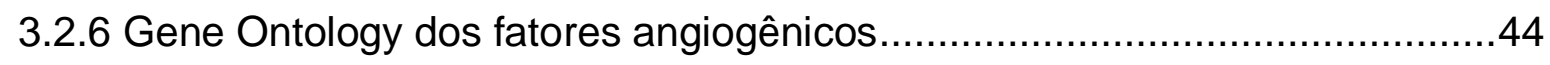

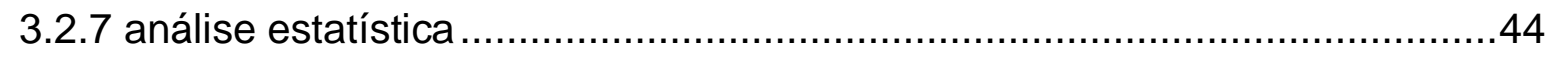

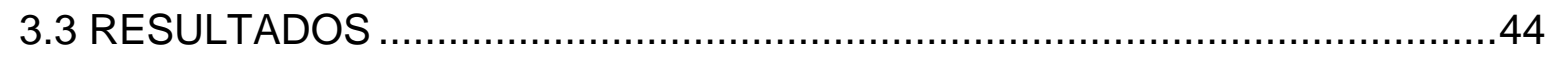

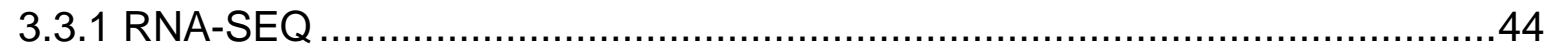

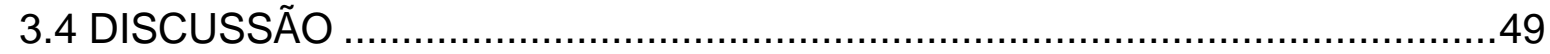

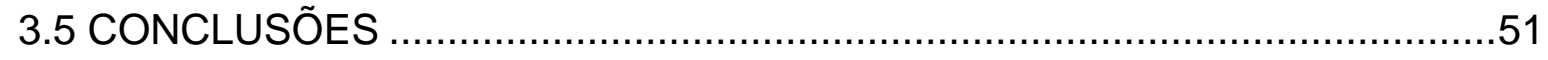

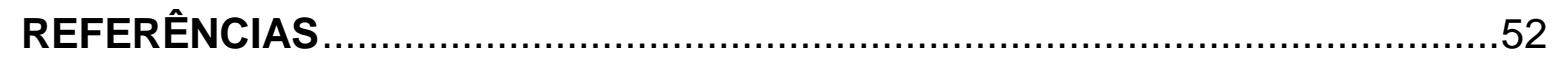


APÊNDICE - PROPOSTA DE VALIDAÇÃO DE SEQUÊNCIAS HOMÓLOGAS

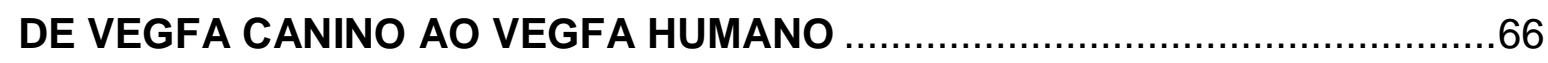

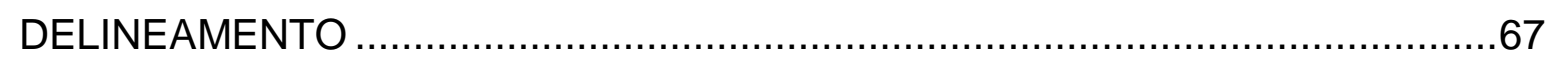

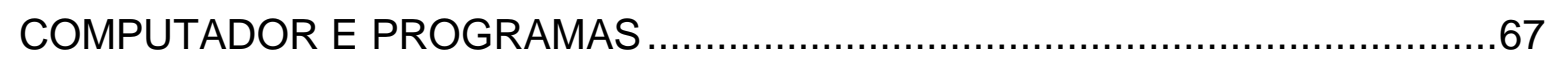

LEVANTAMENTO DAS INFORMAÇÕES E ESCOLHA DOS ARTIGOS …...........67

SELEÇÃO DOS EXONS QUE CONSTITUEM O VEGFA HUMANO ....................68

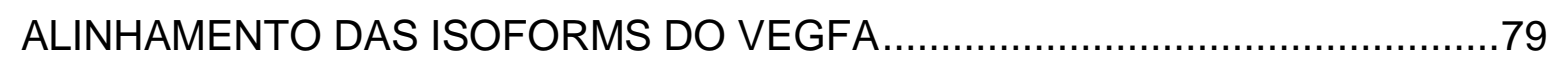

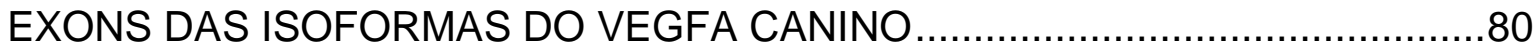

RESULTADOS ENCONTRADOS E CONSIDERAÇÕES .................................. 81

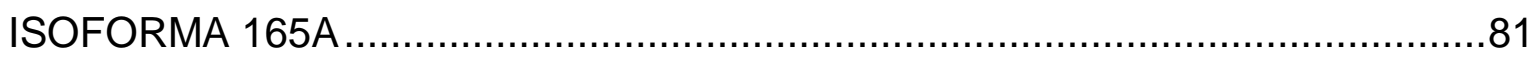

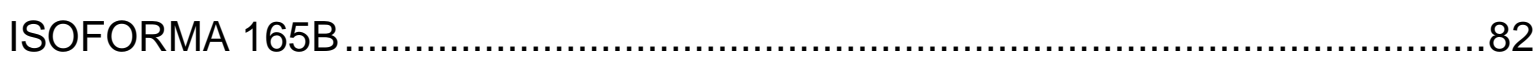

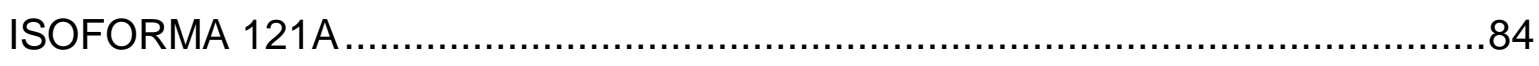

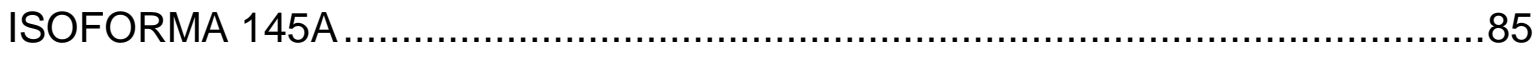

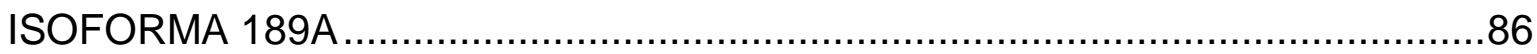

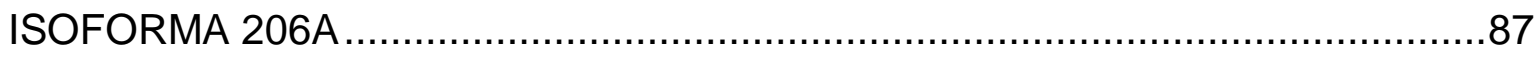


CAPÍTULO 1 - REVISÃO DE LITERATURA 


\section{INTRODUÇÃO}

Vasos sanguíneos começam a se formar oriundos de vasos já existentes, através da multiplicação e migração de células endoteliais, em um processo denominado angiogênese, que ocorre de forma complexa, mas ao mesmo tempo delicada, havendo um equilíbrio minucioso entre fatores promotores e inibidores de crescimento endotelial (SCHAMS; BERISHA, 2004). Quando esse equilíbrio é modificado, diversas alterações de ordem infecciosas, malignas, inflamatórias, imunológicas e isquêmicas se apresentam (CARMELIET, 2005).

Diretamente relacionado à angiogênese, o fator de crescimento endotelial vascular A (VEGFA) ou VEGF nativo é uma glicoproteína codificada por um único gene (FERRARA, 2004), que faz parte de uma família de proteínas muito semelhantes, identificadas por letras: VEGFA ao VEGFF (PAAVONEN et al., 1996; ACHEN et al., 1998; MEYER et al., 1999; SUTO et al., 2005; YAMAZAKI et al., 2005). Na família do VEGF também está presente o fator de crescimento placentário (PIGF) (PARK et al., 1994; HOEBEN et al., 2004). O VEGFA é o membro da família melhor caracterizado, por ser 0 fator de crescimento mais abundante na angiogênese e o mais potente estimulador dos processos angiogênicos (FERRARA et al., 1998; WOOLARD et al., 2004).

Em humanos, ao menos oito isoformas do VEGFA provenientes do mesmo gene são descritas, derivadas por splicing alternativo, com nomes que se baseiam em quantos aminoácidos cada proteína secretada tem, sendo elas: VEGFA121, VEGFA145, VEGFA148, VEGFA165, VEGFA165b, VEGFA183, VEGFA189 e VEGFA206 (LEUNG et al., 1989; HOUCK et al., 1991; TISCHER et al., 1991; POLTORAK et al., 1997; LEI; JIANG; PEI, 1998; ROBINSON; STRINGER, 2001).

Sabe-se que o ciclo estral da cadela difere de forma significativa das outras espécies domésticas, uma vez que seu período de duração é bastante longo (CONCANNON, 2009). O corpo lúteo (CL) canino é uma glândula endócrina transitória produtora de progesterona e de estradiol, hormônios com ações autócrinas e parácrinas que controlam sua função (PAPA; HOFFMANN, 2011). Diferente de outras espécies, a duração do CL funcional em cadelas gestantes e não gestantes é quase idêntica, portanto, o tempo de vida luteínico fisiológico é análogo em ambos (revisado em CONCANNON, 2009; PAPA \& KOWALEWSKI., 2020).

Em cadelas prenhes, fortes sinais apoptóticos estão associados à diminuição 
da progesterona durante a luteólise pré-parto e os níveis de prostaglandina $F 2 \alpha$ (PGF2 $\alpha$ ) aumentam no sangue materno ao mesmo tempo (KOWALEWSKI, 2014). Ao contrário do que ocorre em cadelas prenhes, a PGF2 $\alpha$ não apresenta um papel crucial na regressão do CL de cadelas não prenhes. Contudo, a prostaglandina E2 pode exercer amplo papel no CL canino, atuando na estabilização dos vasos sanguíneos, na modulação da angiogênese e como imunomoduladora (TAVARES PEREIRA et al., 2019).

O VEGFA é um dos fatores chaves que regula a angiogênese no ovário em geral (GEVA; JAFFE, 2000; AL-Zl'ABI; WATSON; FRASER, 2003; FERRARA; GERBER; LECOUTER, 2003; SHIMIZU et al., 2003; KACZMAREK; SCHAMS; ZIECIK, 2005; FRASER; DUNCAN, 2009; ROBINSON et al., 2009; MCFEE; CUPP, 2013; BERISHA et al., 2016) e já foi demonstrado no CL da cadela, juntamente a seus receptores FLT1 e KDR. Apresentam expressão variável ao longo do diestro nas células luteínicas, o que sugere papel modulatório como um fator parácrino e autócrino (MARIANI et al., 2006).

No entanto, apesar de sua provável ação durante o diestro, até o momento não foi caracterizada a conformação dos exons e introns que codificam cada isoforma do VEGFA, angiogênicas ou anti-angiogênicas em CL de cadelas. Essa sugestão de estrutura conformacional das isoformas angiogênicas está aqui apresentada para ser um início na validação e maior estudo da ação desses fatores no CL canino. Uma revisão de literatura, também presente, se fez necessária para melhor entendimento da família VEGF, do VEGFA, de seus receptores e da importância na reprodução. Adicionalmente, para elucidar quais são os fatores angiogênicos presentes no corpo lúteo canino foi realizada uma análise diferencial desses fatores pela técnica de RNAseq, reforçando a importância do VEGFA e da família VEGF no corpo lúteo canino ao longo do diestro. 


\section{REVISÃO DE LITERATURA}

\subsection{A ANGIOGÊNESE}

No processo de formação da vida, durante a fase embrionária, a vasculogênese ocorre quando as células do mesoderma se diferenciam em células precursoras endoteliais. Essas células, os angioblastos, começam a se agrupar e formam uma estrutura vascular inicial, os primeiros vasos sanguíneos (ADAMS; ALITALO, 2007; SWIFT; WEINSTEIN, 2009). A partir deles, outros vasos começam a se formar, através da multiplicação e migração de células endoteliais, em um processo denominado angiogênese (CARMELIET, 2003), fundamental para o crescimento e reparo de tecidos e órgãos, com papel vital também no ciclo estral e na placentação (FRASER; WULFF, 2003; WOOLARD et al., 2004; CARMELIET, 2005; JOHNSON; WILGUS, 2014; LAI et al., 2015). É um processo complexo, que requer um equilíbrio minucioso entre fatores promotores e inibidores do crescimento endotelial (SCHAMS; BERISHA, 2004).

O VEGFA é um regulador da angiogênese em condições fisiológicas e patológicas. A sua atuação na proliferação de células endoteliais ocorre através de dois receptores tirosina quinase, o VEGFR1 (FLT-1) e o VEGFR2 (KDR) (FERRARA; DAVIS-SMYTH, 1997; FERRARA; GERBER; LECOUTER, 2003).

O papel do VEGFA na angiogênese se mostra insubstituível, uma vez que modelos knockout, que expressam apenas uma única cópia do gene, apresentam letalidade embrionária (CARMELIET et al., 1996; FERRARA, 1996). Onde quer que a angiogênese ocorra, o VEGFA é expresso (NEUFELD et al., 1999).

\subsection{OS FATORES DE CRESCIMENTO ENDOTELIAL VASCULAR (VEGFS)}

Os fatores de crescimento endotelial vascular (VEGFs) são os principais reguladores do desenvolvimento vascular dos vasos linfáticos e sanguíneos durante a vida saudável e nos processos de doença em adultos (KOCH; CLAESSONWELSH, 2012). Por sua grande capacidade de aumentar a permeabilidade dos vasos sanguíneos, inicialmente o VEGF foi denominado de fator de permeabilidade vascular (VPF), passando a ter o nome atual quando efeitos adicionais relacionados 
à sua ação sobre as células endoteliais foram observados (SENGER et al., 1983; FERRARA et al., 1998). A família do VEGF também engloba o fator de crescimento placentário, o PIGF (PARK et al., 1994; HOEBEN et al., 2004).

A família do fator de crescimento endotelial vascular é composta por moléculas semelhantes que são codificadas por um único gene e identificadas por letras: VEGFA ao VEGFF (PAAVONEN et al., 1996; ACHEN et al., 1998; MEYER et al., 1999; SUTO et al., 2005; YAMAZAKI et al., 2005).

Esses fatores apresentam em humanos uma estrutura comum de oito resíduos de cisteína no domínio homólogo do VEGF. O VEGFA está localizado no cromossomo 6p21, codificado por 8 exons e por 7 introns (ROY; BHARDWAJ; YLÄHERTTUALA, 2006). O VEGFA ou VEGF nativo é uma glicoproteína homodimérica de $45 \mathrm{kDa}$ que se liga à heparina. A proteína é codificada por um único gene que apresenta uma ação fundamental no crescimento de células endoteliais para a formação de artérias e veias (FERRARA, 2004).

O VEGFA tem a capacidade de estimular a permeabilidade vascular, a neovascularização, a sobrevivência celular e ainda a proliferação de células vasculares e não vasculares (BYRNE, A.M.; BOUCHIER-HAYES, D.J.; HARMEY, 2005; CÉBE-SUAREZ; ZEHNDER-FJÄLLMAN; BALLMER-HOFER, 2006; CAIRES et al., 2012). Da mesma forma que o VEGFA é essencial para desencadear o processo fisiológico de desenvolvimento de veias e artérias de órgãos e tecidos, exerce forte influência em processos patológicos, como tumores diversos, entre eles o de mama, de pulmão e de boca; problemas oculares, edema cerebral, desordens inflamatórias, artrite reumatoide, osteoartrite, psoríase, lesão por isquemiareperfusão, hemangioma infantil, patologias no aparelho reprodutor feminino, diabetes mellitus, nefropatia diabética, distúrbios coronários isquêmicos, entre outros (FOLKMAN, 1972; FERRARA, 2004, 2009; WOOLARD et al., 2004; HOEBEN et al., 2004; SHIBUYA, 2013; PALLET; THERVET; TIMSIT, 2014; KIKUCHI et al., 2015; PATEL et al., 2015; FREZZETTI et al., 2016; WHITTINGTON et al., 2017; GANTA et al., 2017; MAJUMDER; ADVANI, 2017; SHIBATA et al., 2018).

Por sua ação estimulatória na angiogênese e por seu papel no câncer, tanto no seu desenvolvimento como também no tratamento, o VEGFA vem sendo amplamente estudado ao longo dos anos (RAPISARDA; MELILLO, 2012; SIA et al., 2014; FERRARA; ADAMIS, 2016). A compreensão da regulação da sinalização do VEGFA e de seus receptores é fundamental para o desenvolvimento de novas 
maneiras de direcionar os estudos de patologias através da farmacologia molecular do eixo VEGFA/VEGFR (PEACH et al., 2018). Maior expressão das isoformas próangiogênicas (melhor descritas abaixo) pode modular a sinalização do VEGFA, o que pode ser um alvo das drogas antiangiogênicas (CHESNOKOV et al., 2018).

A secreção do VEGFA ocorre por células distintas, como células endoteliais, células epiteliais, inclusive nos tecidos reprodutivos, células musculares lisas, neutrófilos, macrófagos, fibroblastos, plaquetas e células de tumores diversos, e é induzida também pela hipóxia e estímulos inflamatórios (BERSE et al., 1992; BROGI et al., 1994; GAUDRY et al., 1997; BANKS et al., 1998; NISSEN et al., 1998; SHARKEY et al., 2000; MARIANI et al., 2006; KOWALEWSKI et al., 2011; VANKLOMPENBERG et al., 2016; VEIGA et al., 2017; TREMAINE; FOULADINASHTA, 2018).

O gene do VEGFB está localizado no cromossomo 11q13, contém cerca de 4000 pb, 7 exons e 6 introns (ENHOLM et al., 1997; FERRARA; GERBER; LECOUTER, 2003; TAMMELA et al., 2005). A região promotora do VEGFB é diferente da região do VEGFA, o que pode explicar as diferenças na regulação por estímulos fisiológicos: a região promotora do VEGFB contém locais de ligação ao gene-1 de resposta rápida de crescimento (Egr-1), mas não inclui regiões ao fator-1 induzível por hipóxia (HIF-1) e sítios de ligação a AP-1 encontrados no promotor do VEGFA. Assim, a indução da expressão do VEGFA não parece regular os níveis do VEGFB em hipóxia (ENHOLM et al., 1997).

O VEGFC está localizado no cromossomo 4q34 com 7 exons. A expressão do VEGFC foi identificada no ovário, placenta, coração, intestino delgado, e na glândula tireóide em adultos. Estudos com modelo knockout mostram que o VEGFC é o principal fator de crescimento linfangiogênico e os efeitos linfangiogênicos são mediados pelo receptor VEGFR3 (ENHOLM et al., 2001; KARKKAINEN et al., 2004).

O VEGFD está localizado no cromossomo Xp22.3 e é estruturalmente idêntico ao VEGFC em 48\%. O VEGFD é expresso no endotélio vascular, músculo esquelético, coração, pulmão e intestino. O VEGFD humano se liga e ativa os receptores VEGFR2 e VEGFR3 (JELTSCH et al., 1997). Em camundongo, o VEGFD se liga apenas ao VEGFR3 e se mostrou responsável pela proliferação de células endoteliais, exibindo potencial linfangiogênico e características angiogênicas in vitro e in vivo (BALDWIN et al., 2005). 
O VEGFE foi descoberto no genoma do poxvírus que infecta cabras, ovelhas e humanos (LYTTLE et al., 1994), induzindo uma forte resposta angiogênica e capaz de estimular a mitogênese e a permeabilidade vascular (SHIBUYA, 2003).

O VEGFF foi identificado nas espécies Vipera ammodytes ammodytes e Daboia russelli russelli e contém uma curta região C-terminal. Este peptídeo promove bloqueio específico na atividade do VEGFA165 tanto in vitro quanto in vivo (YAMAZAKI et al., 2005).

\subsection{OS RECEPTORES DO VEGF}

A ação do VEGFA ocorre por meio de receptores chamados de receptores do fator de crescimento endotelial vascular, os VEGFRs. Esses receptores pertencem à classe IV da família dos receptores tirosina quinase - RTK (ALEXANDER et al., 2015) e são característicos em sua conformação com uma região transmembrânica única, uma sequência tirosina-quinase interrompida pelo domínio de inserção à quinase em sua porção intracelular e sete domínios similares à imunoglobulina em sua porção extracelular (SHIBUYA et al., 1990). Possuem semelhança com outros receptores, tais como: o receptor do fator estimulante de colônias de macrófagos (MCSFR), o receptor do fator de crescimento plaquetário do tipo III, RTKs (PDGFR), c - KIT e o fms-like tyrosine quinase 3 (FLT3) (SHIBUYA, 2013).

Os receptores do VEGF são: VEGFR1/FLT1 - Fms-like tyrosine kinase - 1(DE VRIES et al., 1992), VEGFR2/FIk1/KDR -Kinase insert domain containing region (TERMAN et al., 1992) e VEGFR3/FLT4 - Fms-like tyrosine kinase - 4 (KAIPAINEN et al., 1995; KARKKAINEN; MÄKINEN; ALITALO, 2002) e são expressos por células hematopoiéticas, endoteliais, luteínicas, placentárias, uterinas, macrófagos e por células musculares lisas (KABRUN et al., 1997; ISHIDA et al., 2001; WITMER et al., 2002; MARIANI et al., 2006; SOUSA et al., 2012; GRAM et al., 2015).

O VEGFR1 se liga ao VEGFA, VEGFB e PIGF com alta afinidade. O VEGFR1 transmite apenas sinal mitogênico fraco em células endoteliais, mas pode formar um heterodímero com o VEGFR2, que possui fortes propriedades de sinalização (HUANG et al., 2001). A expressão positiva do VEGFR1 é regulada durante a hipóxia e angiogênese, ao contrário do VEGFR2 e VEGFR3 (MAYNARD et al., 2003).

O VEGFR2 se liga ao VEGFA, VEGFC e VEGFD, é um receptor primário que 
transmite sinais do VEGF em células endoteliais (WISE et al., 1999; ZACHARY; GLIKI, 2001). A via de sinalização VEGFR2 é crucial para desencadear nas células os efeitos dos VEGFs, incluindo vasodilatação, migração e proliferação celular (FERRARA; GERBER; LECOUTER, 2003).

O VEGR3 se liga ao VEGFC e ao VEGFD. Está presente durante o desenvolvimento embrionário, mas no adulto torna-se restrito ao sistema linfático, sendo crucial no processo de linfangiogênse (KAIPAINEN et al., 1995; MÄKINEN et al., 2001).

A descoberta do VEGF e de seus receptores sugere que essas proteínas desempenham funções primordiais em um estágio inicial e desenvolvam papéis mais especializados no desenvolvimento vascular em diferentes espécies, sendo possível identificar através do Ensembl as variações genômicas de cada transcrito (Tabela 1, 2 e 3).

Tabela 1. Dados genômicos (Ensembl) do transcrito VEGFR1 (FLT1-201) em diferentes espécies.

\begin{tabular}{cccccc}
\hline Espécies & Gene ID & Cromossomo & Pares de base & Aminoácidos & Exons \\
\hline Homo sapiens & 2321 & 13 & 7123 & 1338 & 30 \\
\hline Canis lupus familiaris & 403727 & 25 & 4698 & 1337 & 30 \\
\hline Felis catus & 101088292 & 07 & 1086 & 361 & 10 \\
\hline Bos taurus & 503620 & 12 & 2664 & 708 & 15 \\
\hline Equus caballus & 100033957 & 17 & 3829 & 359 & 10
\end{tabular}

Fonte: D'APRILE, 2021.

Tabela 2. Dados genômicos (Ensembl) do transcrito VEGFR2 (KDR-201) em diferentes espécies.

\begin{tabular}{cccccc}
\hline Espécies & Gene ID & Cromossomo & Pares de base & Aminoácidos & Exons \\
\hline Homo sapiens & 3791 & 4 & 5833 & 1356 & 30 \\
\hline Canis lupus familiaris & 482154 & 13 & 4633 & 1355 & 30 \\
\hline Felis catus & 101090260 & $\mathrm{~B} 1$ & 4164 & 1336 & 30 \\
\hline Bos taurus & 407170 & 6 & 8898 & 1356 & 30 \\
\hline Equus caballus & 100033959 & 3 & 6548 & 1356 & 30
\end{tabular}

Fonte: D'APRILE, 2021. 
Tabela 3. Dados genômicos (Ensembl) do transcrito VEGFR3 (FLT4-201) em diferentes espécies.

\begin{tabular}{cccccc}
\hline Espécies & Gene ID & Cromossomo & Pares de base & Aminoácidos & Exons \\
\hline Homo sapiens & 2324 & 5 & 5833 & 1363 & 30 \\
\hline Canis lupus familiaris & 481464 & 11 & 5684 & 1278 & 30 \\
\hline Felis catus & 101094727 & $\mathrm{~A} 1$ & 5071 & 1405 & 28 \\
\hline Bos taurus & 338031 & 7 & 5882 & 1365 & 30 \\
\hline Equus caballus & 100066773 & 14 & 5029 & 1238 & 28
\end{tabular}

Fonte: D'APRILE, 2021.

\subsection{AS ISOFORMAS DO VEGFA}

Ao menos oito isoformas do VEGFA provenientes do mesmo gene são descritas em humanos. A capacidade de ligação à heparina, a solubilidade e outras características de cada molécula são definidas pela quantidade de aminoácidos que cada uma apresenta (HOUCK et al., 1991; LANGE et al., 2003). Derivadas por splicing alternativo são denominadas por VEGFA121, VEGFA145, VEGFA148, VEGFA165, VEGFA165b, VEGFA183, VEGFA189 e VEGFA206 (LEUNG et al., 1989; HOUCK et al., 1991; TISCHER et al., 1991; POLTORAK et al., 1997; LEl; JIANG; PEI, 1998; ROBINSON; STRINGER, 2001). A expressão do VEGFA111 foi identificada no endométrio humano e influencia a regulação positiva das isoformas do VEGFA na endometriose, dado que adiciona à compreensão da regulação da angiogênese endometrial (DANASTAS et al., 2018).

O splicing alternativo ocorre quando o pré-mRNA é descontinuamente transcrito entre os exons 6 e 8 (o gene possui um total de 8 exons e 7 introns). As isoformas possuem funções similares, diferindo, no entanto, em sua capacidade de ligação à matriz extracelular (BERGANTINO et al., 2015).

Em bovinos, foi observado que o VEGFA regula a sobrevivência das células germinativas no processo de estabilização da espermatogênese nos testículos desses animais (CAIRES; AVILA; MCLEAN, 2009), o que evidencia a importância desse fator de crescimento para a reprodução.

Em ratos as isoformas de VEGFA são capazes de estimular a migração de células endoteliais dentro do testículo, sendo KDR o principal mediador dessa sinalização no desenvolvimento vascular específico desse órgão (BOTT et al., 2006). Nesses animais foram identificadas isoformas homólogas às de humano, com 
apenas um aminoácido a menos (VEGFA205, VEGFA188, VEGFA164 e VEGFA120) presentes no cromossomo 17 (DE GREGORIO et al., 1997) Há expressão do VEGFA e de seus receptores por células de Leydig, Sertoli e células germinativas de uma forma que coincide com o recrutamento de células germinativas em ratos e camundongos (BOTT et al., 2006, 2010; CAIRES et al., 2012). Sargent et al. (2016), descrevem que o equilíbrio da expressão de isoformas angiogênicas e antiangiogênicas promove a autorrenovação ou morte de célulastronco espermatogoniais, que corrobora o papel fundamental desse fator de crescimento e a necessidade de pesquisas a elas relacionadas.

Foi demonstrado que a isoforma VEGFA111 e as isoformas VEGFA164 e VEGFA188 estão correlacionadas com o estágio da gestação em ratos: a expressão da isoforma VEGFA111 é maior nas membranas fetais durante a implantação do que em casos de não implantação e útero não gravídico, o que sugere a implicação dessa isoforma em perda de gestação recorrente em humanos e enfatiza sua importância para pesquisas médicas (WHITTINGTON et al., 2017).

Nas isoformas VEGFA165 e VEGFA189, faltam os exons 6 e 6b, respectivamente, e sua afinidade por heparina é maior assim como sua capacidade de ligação a moléculas da matriz extracelular. Na isoforma VEGFA121, os exons 6 e 7 estão ausentes, o que permite que a proteína alcance uma alta capacidade de difusão e não se ligue à matriz extracelular. Apenas a isoforma VEGFA206 possui o set completo dos exons 6 e 7 (BERGANTINO et al., 2015). A isoforma 189 possui uma característica adicional de localização nuclear devido à presença do exon 6a, que não está expresso nas isoformas 121 ou 165. A isoforma VEGFA145 é a mais abundante nos tecidos reprodutivos (POLTORAK et al., 1997), enquanto a 183 apresenta a expressão mais restrita ao olho.

Existem ainda as isoformas VEGFAxxxb, que apresentam funções antiangiogênicas e são geradas a partir do splice alternativo do exon 8b, em oposição às isoformas pró-angiogênicas que se formam pelo splice do exon $8 \mathrm{a}$. $\mathrm{O}$ balanço entre isoformas a e b leva ao estímulo ou inibição da angiogênese (BERGANTINO et al., 2015). Foi demonstrado que alterações no bloqueio de splicing em um desses genes VEGFA, VEGFR1 e VEGFR2, pode resultar em alterações de sinalização, como o aumento no VEGFA165a em relação ao VEGFA165b, promovendo o aumento da sinalização do VEGFR2 e o aumento da angiogênese no câncer (STEVENS; OLTEAN, 2019). Outro estudo mostrou que o 
VEGFA pró-angiogênico promove o recrutamento e o desenvolvimento folicular precoce e o VEGFA antiangiogênico inibe esses processos (MCFEE; ROZELL; CUPP, 2012). Em ovinos foram identificadas as isoformas antiangiogênicas do VEGFAxxxb na pars tuberalis da hipófise e no hipotálamo médio basal (LOMET et al., 2018).

As isoformas VEGFA165b e 121b estão melhor descritas e atuam na inibição da proliferação e migração de células endoteliais in vitro, além da redução do crescimento tumoral a partir de efeito direto nas células endoteliais (RENNEL et al., 2009). Woolard et al. (2004) relatam que o VEGFA165b inibe significativamente a ativação mediada por VEGF165 e seu principal receptor de sinalização, o VEGFR2, inibindo, portanto, a ativação da MAPK e os efeitos fisiológicos, como a angiogênese.

Em camundongos, a superexpressão do VEGF165b no ovário resultou na redução da fertilidade através de um menor número de folículos, redução de corpos lúteos e menor taxa embrionária na tuba uterina após o acasalamento (QIU et al., 2012). Além disso, outro estudo mostrou que remoção de isoformas próangiogênicas e antiangiogênicas do VEGFA em células da granulosa resultou na redução do peso ovariano, menor número de CLs e concentrações reduzidas de estrógenos, o que causou infertilidade ao interromper o sistema folicular em desenvolvimento e reduzir a taxa de ovulação (SARGENT et al., 2015). Em ovários de ratas no período perinatal, a neutralização das isoformas do VEGFA antiangiogênico levou ao aumento do desenvolvimento vascular e folicular em comparação à ação da isoforma pró-angiogênica VEGFA164 (ARTAC et al., 2009).

$\mathrm{Na}$ espécie canina foram relatadas cinco isoformas do VEGFA, a VEGF120, VEGF144, VEGF164, VEGF182 e VEGF188. Estas isoformas apresentam aproximadamente 95\% de homologia com a sequência de aminoácidos humana e, semelhança com a maioria dos mamíferos. Apenas um único resíduo de aminoácido na região N-terminal está ausente em comparação com o VEGFA humano (SCHEIDEGGER et al., 1999; JINGJING et al., 2000). Em búfalas, a expressão do VEGF 120, VEGF 164 e VEGF 188 foi identificada no CL durante o ciclo estral (CHOUHAN et al., 2013).

Embora existam poucos trabalhos que levam em consideração as diferentes isoformas do VEGFA canino, dois estudos identificaram as isoformas VEGFA120, VEGFA164 e VEGFA188 por sequenciamento de RNA e RT-PCR, como sendo as 
principais isoformas no carcinoma pulmonar canino: dados semelhantes foram obtidos para o coração dessa espécie (SCHEIDEGGER et al., 1999; JINGJING et al., 2000).

Um estudo em linfoma canino de células T mostrou que a isoforma VEGF164 estava fortemente expressa (ARICÒ et al., 2013). No endométrio canino também foram identificadas as isoformas 164, 182 e 188 do VEGFA, que se mostraram mais expressas em cadelas gestantes em comparação a não gestantes (BUKOWSKA et al., 2011).

O VEGFA está entre os fatores reguladores parácrinos e autocrinos da função luteal, uma vez que o corpo lúteo é uma glândula endócrina temporária, cujo período de atividade depende da interação de fatores luteotróficos e luteolíticos, com seu desenvolvimento e manutenção baseados na angiogênese (PAPA; KOWALEWSKI, 2020). A localização do VEGFA e de seus receptores foi observada em células endoteliais e luteais ao longo do diestro canino com sua expressão se alterando de acordo com a fase lútea (MARIANI et al., 2006). No dia 20 p.o. houve a maior expressão do mRNA do VEGFA e dos receptores VEGFR1 e VEGFR2, com um pico do receptor VEGFR2 no dia 40 p.o. (PAPA et al., 2014). A presença do VEGFA também se mostrou importante em cadelas gestantes: Gram et al. demonstraram que a expressão do VEGFA e de seu receptor VEGFR1 se manteve constante no início da gestação, com uma diminuição dessa expressão durante a fase luteínica média e sem alteração ulterior na expressão até a fase luteolítica pré-parto. Sabe-se também que 0 VEGFA pró-angiogênico promove 0 recrutamento e 0 desenvolvimento folicular precoce e o VEGFA antiangiogênico inibe esses processos (MCFEE; ROZELL; CUPP, 2012).

É possível que a ação do VEGFA canino e o do VEGFA humano sejam homólogas, uma vez são estruturalmente similares, com as mesmas propriedades biológicas e de ligação celular; e os receptores do VEGF canino se assemelham muito aos do ser humano (SCHEIDEGGER et al., 1999). 
Figura 1 - Sequência dos exons das isoformas do VEGFA canino (Cf) homólogas as sequências dos exons do VEGFA humano (Hs)

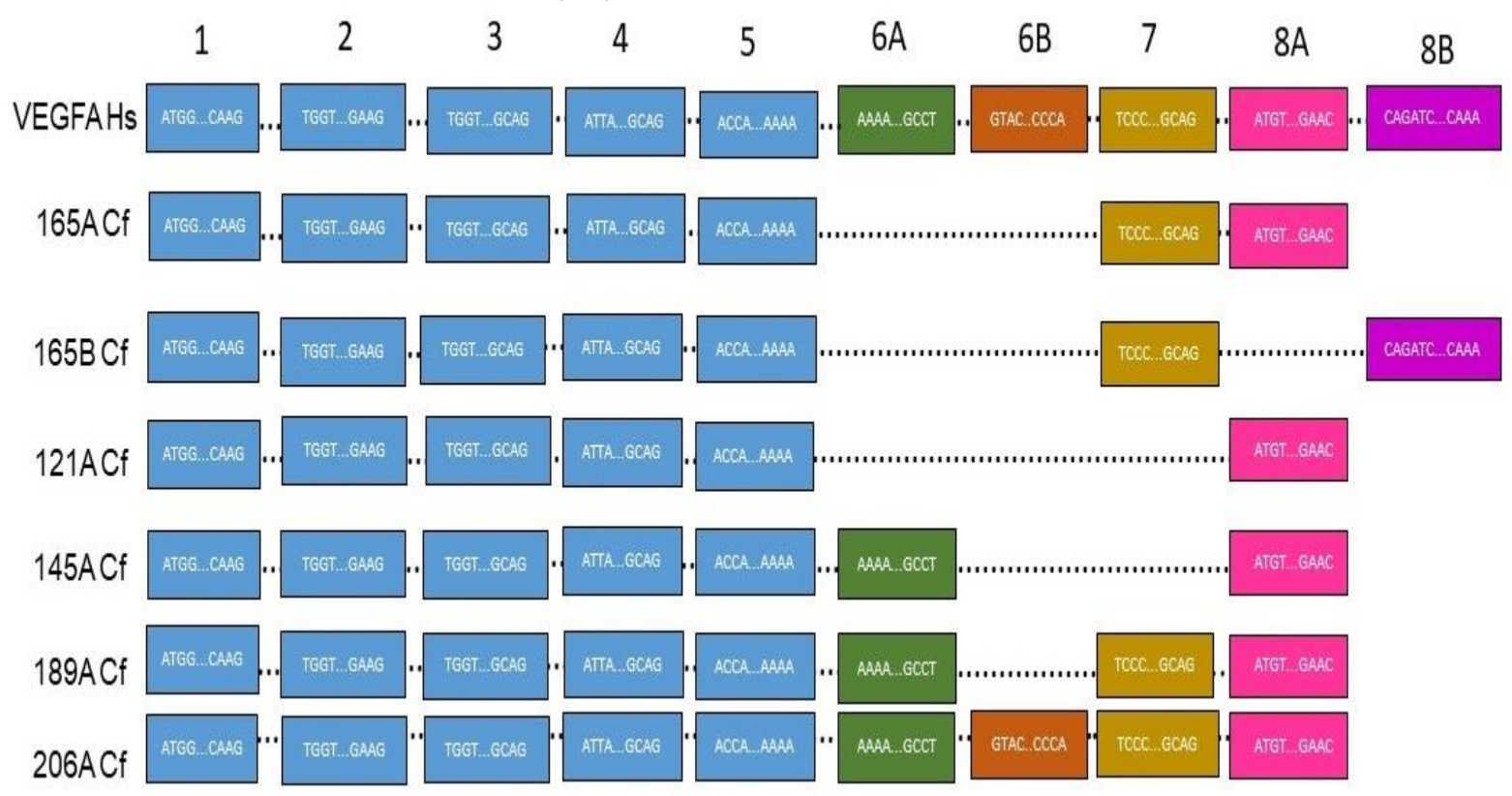

Fonte: D'APRILE, 2021.

\subsection{O VEGFA E A REPRODUÇÃO HUMANA}

Fatores de crescimento endotelial vascular, os VEGFs, bem como as citocinas são de grande importância na gestação humana, com envolvimento e atuação em todas as fases da formação da vida: da placentação até o parto, incluindo o desenvolvimento fetal, o desenvolvimento placentário e também os resultados neonatais, como nascimento prematuro (KRUKIER; POGORELOVA, 2006; KALAGIRI et al., 2016). Observa-se que falhas no que se refere a expressão do VEGF ou em sua sinalização durante a gestação impactam negativamente a saúde, associando essas falhas a doenças e a condições indesejáveis, como a restrição de crescimento intra-uterino - RCIU (PADAVALA et al., 2006), a préeclampsia (BAKER et al., 1995; BÁNYÁSZ et al., 2006; JIM; KARUMANCHI, 2017) o diabetes gestacional (LEACH, 2011), a hipertensão arterial (BHAVINA; RADHIKA; PANDIAN, 2014), o nascimento prematuro do bebê (KRUKIER; POGORELOVA, 2006) e até a perda recorrente de gestação (LI et al., 2013; BEN ALI GANNOUN et al., 2017; SUN et al., 2017). Os fatores angiogênicos mais intensamente estudados no desenvolvimento placentário humano são os fatores relacionados à família VEGF, incluindo o VEGFA, o PIGF e os seus receptores (MAYHEW; CHARNOCKJONES; KAUFMANN, 2004; HUPPERTZ; PEETERS, 2005; DEMIR; SEVAL; 
HUPPERTZ, 2007), uma vez que se busca elucidar a importância e atuação desses fatores na conformação normal e alterada da placenta.

No endométrio há a sinalização do VEGF em células estromais, epiteliais e vasculares, demonstrando sua importância na regulação da remodelação vascular endometrial e a sua ação durante o ciclo menstrual (MÖLLER et al., 2001; GIRLING; ROGERS, 2009). É sabido que o VEGFA e suas isoformas também estão associadas a endometriose, doença ginecológica de ordem não maligna que acomete mulheres em fase reprodutiva (REN et al., 2011; YERLIKAYA et al., 2016; DANASTAS et al., 2018). O VEGFA estimula a integrina avß3, um marcador da receptividade uterina e também molécula de adesão na fase de implantação do embrião (LESSEY, 2002; ILLERA et al., 2003), aumentando a atividade mitogênica das células endoteliais (SOLDI et al., 1999).

Hannan et al. (2011) ao analisar os mediadores solúveis que se relacionam à fertilidade no fluido uterino humano demonstraram que o VEGFA é um regulador da implantação de embriões, induz aumento da adesão de células epiteliais endometriais e aumento significativo no crescimento do blastocisto. Em mulheres com infertilidade idiopática foi possível observar que os níveis de VEGFA estavam significativamente reduzidos quando comparados com os níveis de mulheres férteis no período que corresponde à janela de implantação, o que sugere participação do VEGFA nesta fase.

O VEGFA possui amplo efeito sobre a fisiologia ovariana (KACZMAREK; SCHAMS; ZIECIK, 2005) e sua ação desregulada está associada a patologias, como a Síndrome dos Ovários Policísticos (ALMAWI et al., 2016; BEN SALEM et al., 2016; BAO; SYED; ALOAHD, 2019), doença que além de causar alterações reprodutivas, está relacionada a obesidade, tolerância à glicose alterada, dislipidemia e resistência à insulina (NORMAN et al., 2007; HURD et al., 2011; CARMINA, 2013; NADERPOOR et al., 2015; CASSAR et al., 2016; GLUECK; GOLDENBERG, 2019).

Assim, é importante ressaltar que o VEGFA é fator indispensável quando se pensa em reprodução, seja por sua atuação na angiogênese e na fisiologia do aparelho reprodutor feminino, seja pelo impacto negativo que as doenças a ele associadas e co-associadas apresentam na reprodução humana. 


\subsection{O CICLO REPRODUTIVO DA CADELA E SUA RELAÇÃO COM O VEGFA}

O ciclo reprodutivo da cadela (Canis lupus familiaris) possui características específicas, o que a diferencia das fêmeas de outras espécies, uma vez que se desenvolve por um período que varia de 5 a 12 meses (CONCANNON, 2009). O estro ocorre uma vez a cada ciclo e não está relacionado a uma determinada estação do ano, o que configura a cadela como monoéstrica não estacional. A ovulação ocorre de forma espontânea e seu ciclo reprodutivo é dividido em quatro fases distintas: anestro (fase sem atividade ovariana), proestro (fase folicular), estro (fase reprodutiva) e diestro (fase luteínica) com média de 60 dias, podendo chegar até a 100 dias, caracterizado pela alta produção de progesterona pelo $\mathrm{CL}$ (CONCANNON; MCCANN; TEMPLE, 1989; HOFFMANN et al., 2004). O ciclo é controlado através do eixo hipotálamo-hipófise-gonadal, com atuação do hormônio folículo estimulante (FSH), do hormônio luteinizante (LH), do hormônio 17b estradiol (E2) e da progesterona (P4) (CONCANNON, 2009).

$\mathrm{O}$ anestro é chamado de período de quiescência do aparelho reprodutivo, com ação hormonal flutuante e de forma pulsátil controlada pelo FSH, LH e E2, e também pela progesterona. Os valores de FSH são de $50-400 \mathrm{ng} / \mathrm{ml}$, com um valor médio de $140 \mathrm{ng} / \mathrm{ml}$, entre pulsos esporádicos que são tipicamente concomitantes com os pulsos de LH. O LH basal apresenta valores baixos de $<1-$ $2 \mathrm{ng} / \mathrm{ml}$ em pulsos esporádicos, com valores de altura variável e frequentemente grandes $(3-30 \mathrm{ng} / \mathrm{ml})$ em intervalos de horas, de $7-18$ ou mais. Os valores de E2 sérico possuem uma variação que pode ser de $5-10 \mathrm{pg} / \mathrm{ml}(\sim 15-35 \mathrm{pmol} / \mathrm{l})$. Quanto a progesterona, os valores permanecem abaixo de $1 \mathrm{ng} / \mathrm{ml}$ (abaixo de $\sim 4$ $\mathrm{nmol} / \mathrm{ml}$ ). Essa fase tem duração de 15 a 165 dias e termina com aumento na secreção pulsátil de LH (CONCANNON; MCCANN; TEMPLE, 1989; CONCANNON, 2011).

O proestro é a fase do ciclo estral na qual ocorre o desenvolvimento e amadurecimento dos folículos ovarianos. Há redução gradual da concentração de $\mathrm{FSH}$, juntamente com uma elevação dos níveis séricos de E2, o qual apresenta um pico no final do proestro, declinando rapidamente antes da onda de LH e início do estro. $\mathrm{O}$ aumento da concentração de $\mathrm{P} 4$ e redução de E2 caracteriza o fim do proestro, que possui duração de 1-3 (uma a três) semanas (média de 9 dias) (CONCANNON; MCCANN; TEMPLE, 1989). 
O estro, período em que a fêmea passa a aceitar o macho, ocorre de 5 a 10 dias (média de 7 dias) e é uma fase marcada por uma queda da concentração sérica de E2, que estimula tanto um período de onda pré-ovulatória de $L H$, indicando o início da ovulação, quanto a liberação pulsátil de FSH, que aumenta sua amplitude antes da ovulação. Antes da ovulação, ocorre um aumento da concentração da P4 devido à luteinização dos folículos, em conjunto com o pico de LH (CONCANNON, 2009).

O diestro é a chamada fase luteínica, caracterizada por uma alta atividade proliferativa durante a formação do $\mathrm{CL}$. Diferente da maioria das espécies de mamíferos, a fase luteínica é muito semelhante em cadelas gestantes e não gestantes (ONCLIN; VERSTEGEN, 1997): pode-se citar a diminuição nas concentrações pré-parto de prolactina (PRL) (KOWALEWSKI et al., 2011) e a diminuição gradual de $\mathrm{P} 4$ se transforma em um declínio acentuado em cadelas gestantes, o que indica o começo do parto (CONCANNON, 2011). Até 25 dias após a ovulação, o $\mathrm{CL}$ é independente do apoio gonadotrófico para a sua manutenção (OKKENS et al., 1986; CONCANNON; MCCANN; TEMPLE, 1989).

O destino do corpo lúteo canino, bem como sua modulação, manutenção e regressão é determinado por diversos fatores, os quais contribuem potencialmente para que ocorra, ou não, a gestação em cadelas. Esses fatores podem ser divididos em: reguladores endócrinos clássicos da função lútea, reguladores endócrinos não clássicos da função lútea e reguladores parácrinos e autócrinos da função lútea. Neste último grupo estão inclusos os fatores de crescimento, como o VEGF (PAPA; KOWALEWSKI, 2020).

O CL canino é uma glândula endócrina transitória produtora de P4 e de E2, hormônios com ações autócrinas e parácrinas que controlam a função luteínica (PAPA; HOFFMANN, 2011). A progesterona é o principal produto do $\mathrm{CL}$ e tem um papel luteotrófico, ao aumentar a expressão de seus próprios receptores. O LH e o E2 são também considerados fatores luteotróficos, pois aumentam respectivamente a maquinaria esteroidogênica e a proliferação celular (OKKENS et al., 1990; HOFFMANN et al., 2004; MAYBIN; DUNCAN, 2004; PAPA; HOFFMANN, 2011; CARDOSO, 2016). Em cadelas gestantes fortes sinais apoptóticos estão associados à diminuição da progesterona durante a luteólise pré-parto e os níveis de prostaglandina $\mathrm{F} 2 \alpha$ (PGF2 $\alpha$ ) aumentam no sangue materno ao mesmo tempo (KOWALEWSKI, 2014). Ao contrário do que ocorre em cadelas gestantes, a PGF2 $\alpha$ 
não apresenta um papel crucial na regressão do corpo lúteo de cadelas não gestantes.

As mudanças morfofuncionais do CL são acompanhadas e/ou precedidas por expressão diferencial de fatores de crescimento, citocinas, prostaglandinas, todos produzidos localmente (HOFFMANN et al., 2004), dentre eles o VEGFA.

Sabe-se que a insulina tem um papel fundamental no desenvolvimento do CL, uma vez que induz a translocação do GLUT4 para que as células luteínicas possam ter um suprimento ideal de glicose para crescimento e manutenção, de modo a exercer sua função endócrina de maneira adequada (SOUSA et al., 2016). Uma vez que a sinalização da insulina pode afetar a resposta esteroidogênica das células luteínicas (SOUSA et al., 2016) e que o E2 afeta diretamente a expressão do VEGFA (APPLANAT et al., 2008), é possível que a insulina também possua um papel modulador da expressão do VEGFA e algumas de suas isoformas no CL canino. Esta modulação pode acontecer de maneira direta, via aumento da resposta celular à cascata de fosforilação da tirosina quinase, resposta clássica da ativação do receptor do VEGF por seu ligante, como demonstrado por Wang et al. (2015).

Os receptores de 17b-estradiol, ERa e ER $\beta$, desencadeiam ações diferentes durante o diestro. Cardoso, (2016) demonstra que o E2 exerce seu papel na regulação por meio do receptor $E R \alpha$, por vias de interação com o sistema IGF e através da sinalização Wnt/ß-catenina em células luteínicas caninas. Por outro lado, foi demostrado em humanos que o E2 aumenta a expressão do VEGFR2, promovendo a proliferação de células endoteliais com um efeito que varia entre os indivíduos e parece ser mediado principalmente por ERa (GARGETT et al., 2002).

Um estudo em células estromais do endométrio humano mostrou que o E2 pode promover a expressão de ERa, $\beta$-catenina e o VEGF. Os ensaios revelaram que E2 regulou positivamente a expressão de $\beta$-catenina e sua estabilização leva à ativação da sinalização $\mathrm{Wnt} / \beta$-catenina, que tem um efeito transcricional direto na expressão do gene VEGF (ZHANG et al., 2016).

Papa e Hoffmann, (2011) relataram uma coloração positiva por imunohistoquimica para ERß em 75 a 100\% das células luteínicas caninas, sem alterações significativas no que se refere ao período no diestro. Já as células luteínicas foram coradas positivamente para ERa, porém esta expressão qualitativa se mostrou dependente do período do diestro e apresentou um aumento crescente a partir do dia 25 ao 65 após a ovulação, indicando alta atividade proliferativa. Os 
autores concluíram que o CL responde à ação desse hormônio para sua manutenção e regressão, uma vez que há a presença dos receptores de E2 por expressão proteica.

Assim, tanto por expressão proteica quanto por expressão gênica ocorre o aumento da relação ER $\beta$-ERa ao longo do diestro, o que sugere que durante a regressão do CL uma ação antiproliferativa é desencadeada. De acordo com Vivar et al. (2010), o ER $\beta$ possui potentes propriedades antiproliferativas e anti-inflamatórias, além da capacidade de regular genes através da ausência de ligante, sendo um importante agente terapêutico se sua produção celular puder ser estimulada.

A participação da hipóxia na regressão luteínica em cadelas não prenhes foi demonstrada através de um estudo em que a indução da hipóxia pelo $\mathrm{CoCl} 2$ no cultivo primário de células luteínicas diminuiu a produção de P4 e E2, e estimulou a expressão do VEGFA, HIF1A, SLC2A1 e SLC2A4 (SOUSA et al., 2012). Adicionalmente, células de adenoma com produção predominante do VEGFAxxxb expostas à hipóxia mudaram sua expressão para predominantemente VEGFAxxxa (VAREY et al., 2008).

De acordo com o descrito, é possível sugerir que há ação das isoformas no desenvolvimento do CL de cadelas, uma vez que na fase inicial do diestro ocorre o aumento da vascularização, e na fase de regressão do CL, diminui. Embora, a expressão do VEGFA e dos receptores FLT1 e KDR tenham sofrido pouca variação ao longo do diestro, o papel do VEGFA na regulação luteínica indica a presença de isoformas pró-angiogênicas e antiangiogênicas no CL canino (HOFFMANN et al., 2004; MARIANI et al., 2006). 
CAPÍTULO 2 - ANÁLISE DA EXPRESSÃO DIFERENCIAL DE FATORES ANGIOGÊNICOS NO CORPO LÚTEO CANINO NÃO GRAVÍDICO PELA TÉCNICA DE RNA- SEQ 


\section{ANÁLISE DA EXPRESSÂO DIFERENCIAL DE FATORES ANGIOGÊNICOS NO CORPO LÚTEO CANINO NÃO GRAVÍDICO PELA TÉCNICA DE RNA-SEQ}

\section{RESUMO}

A angiogênese está envolvida como um dos fatores chaves na proliferação e modulação no corpo lúteo canino. O VEGF é um fator angiogênico e membro de um grupo de glicoproteínas que contém o fator de crescimento placentário (PIGF), VEGFA, VEGFB, VEGFC, VEGFD, VEGFE e VEGFF, que podem atuar direta e seletivamente através dos receptores VEGFR1, VEGFR2 e VEGFR3. O objetivo do trabalho foi identificar a expressão de fatores angiogênicos durante o diestro não gestacional na espécie canina, através da técnica de RNA-seq. Para tal, foram utilizados corpos lúteos provenientes de 18 cadelas que passaram por ovariosalpingohisterectomia (OSH) nos dias 10, 20, 30, 40, 50 e 60 após a ovulação (p.o). Os corpos lúteos coletados foram utilizados para extração de RNA total a partir do protocolo de TRIZOL e posterior análise por RNA-seq, seguindo o protocolo TruSeq RNA Sample Preparation Guide, descrito por Illumina. Identificamos a expressão diferencial em ao menos uma das comparações entre os dias 20 p.o e 50 ou 60 p.o para o VEGFA (20x50:FC=1,44, $p<0,01 ; 20 \times 60: F C=1,24 ; p<0,01)$, VEGFC (20x50:FC=1,27, $p<0,01 ; 20 \times 60: F C=1,94, \quad p<0,01)$, VEGFD (20x60:FC=1,37, $p<0,01)$, VEGFR1 (20x50:FC= 1,03, $p<0,01 ; 20 \times 60: F C=1,89, p<0,01)$, VEGFR2 $(20 \times 50: F C=1,51, p<0,01 ; 20 \times 60: F C=2,55, p<0,01)$ e VEGFR3 (20x60:FC=1,06, $p<0,01)$ do período luteotrófico e luteolítico. Os dados sugerem um aumento dos fatores angiogênicos no dia 20 p.o, período relacionado à proliferação celular e manutenção da função do corpo lúteo canino.

Palavras-chave: Cadelas. Corpo lúteo. Diestro. Fator de crescimento endotelial vascular. VEGFRs. 


\begin{abstract}
Angiogenesis is involved as one of the key factors in proliferation and modulation in the canine corpus luteum. VEGF is an angiogenic factor and a member of a group of glycoproteins that contains placental growth factor (PIGF), VEGFA, VEGFB, VEGFC, VEGFD, VEGFE and VEGFF that can act directly and selectively through the VEGFR1, VEGFR2 and VEGF3 receptors. The aim of the study was to identify the expression of angiogenic factors during non-gestational diestrus in the canine species, using the RNA-seq technique. For this purpose, corpus luteum from 18 bitches that underwent ovariosalpingohisterectomy (OSH) on days 10, 20, 30, 40, 50 and 60 after ovulation (p.o) were used. The collected corpus luteum were used for extraction of total RNA using the TRIZOL protocol and subsequent analysis by RNAseq, following the protocol TruSeq RNA Sample Preparation Guide, described by Illumina. We identified the differential expression in at least one of the comparisons between days 20 po and 50 or 60 po for VEGFA (20x50: $F C=1.44, p<0.01 ; 20 \times 60$ : $F C=1.24 ; p<0,01)$, VEGFC $(20 \times 50: F C=1.27, p<0.01 ; 20 \times 60: F C=1.94, p<0.01)$, VEGFD (20x60: FC=1.37, p <0.01), VEGFR1 (20x50: $F C=1.03, p<0.01 ; 20 \times 60$ : $F C=1.89, p<0.01)$, VEGFR2 (20x50: $F C=1.51, p<0.01 ; 20 \times 60: F C=2.55, p<0.01)$ and VEGFR3 (20x60: $F C=1.06, p<0.01)$ from the luteotrophic and luteolytic period. The data suggest an increase in angiogenic factors on day 20 p.o, a period related to cell proliferation and the maintenance of canine corpus luteum function.
\end{abstract}

Keywords: Bitches. Corpus luteum. Diestrus. Vascular endothelial growth factor. VEGFRs. 


\subsection{INTRODUÇÃO}

O fator de crescimento endotelial vascular (VEGF) é um dos fatores regulatórios da angiogênese no ovário (FERRARA, 2004; MCFEE; CUPP, 2013) e pertence a um grupo de glicoproteínas compostas pelo VEGFA, VEGFB, VEGFC, VEGFD, VEGFE, VEGFF e o fator de crescimento de placenta (PIGF) (SHIBUYA, 2001; YAMAZAKI et al., 2005). A angiogênese ocorre através da ligação do VEGF aos receptores de atividade tirosina quinase que estão presentes na superfície de células hematopoiéticas, endoteliais, luteínicas, placentárias, uterinas, macrófagos e em células musculares lisas endoteliais, sendo denominados por VEGFR1, VEGFR2 e VEGFR3 (DE VRIES et al., 1992; TERMAN et al., 1992; KAIPAINEN et al., 1995; KABRUN et al., 1997; VEIKKOLA et al., 2000; ISHIDA et al., 2001; KARKKAINEN; MÄKINEN; ALITALO, 2002; WITMER et al., 2002; ALEXANDER et al., 2015).

O VEGFA é o membro melhor caracterizado, o fator de crescimento mais abundante e potente estimulador dos processos angiogênicos (FERRARA et al., 1998; PEACH et al., 2018). No corpo lúteo canino, o VEGFA demonstra ter um importante papel nos mecanismos modulatórios, agindo de forma parácrina e autócrina durante o diestro de cadelas não gestantes (MARIANI et al., 2006). Adicionalmente, também como demostrado por Gram et al. (2015) em cadelas gestantes, a expressão do VEGFA e de VEGFR1 se manteve no inicio da gestação, diminuindo na fase lútea média e permanecendo sem alteração na expressão até a fase luteolítica pré-parto.

Os receptores VEGFR1 e VEGFR2 foram caracterizados nos componentes vasculares lúteos. Isto indica a participação em um feedback auto-regulatório no $\mathrm{CL}$ canino, uma vez que o fator modulador do VEGFA, o HIF1a sensível à hipóxia foi detectável do CL canino (PAPA et al., 2014).

O VEGFR3 é expresso nos endotélios embrionários, mas sua expressão diminui no endotélio dos vasos sanguíneos durante o desenvolvimento e permanece restrito ao endotélio linfático de adultos (KAIPAINEN et al., 1995).

Em relação ao VEGFB, este não parece desempenhar um papel direto na angiogênese em condições normais, mas pode influenciar indiretamente $O$ crescimento vascular por interferir na ação do VEGFA, promovendo a sobrevivência celular (LAL; PURI; RODRIGUES, 2018). O VEGFC e VEGFD foram detectados em células da granulosa de folículos ovulatórios de primatas e estão envolvidos nos 
processos angiogênicos da espécie (KIM; TRAU; DUFFY, 2017), além disso, são os dois ligantes do VEGFR3, no qual o VEGFC mostra ser um fator de crescimento para os vasos linfáticos em desenvolvimento, mesmo que possa se ligar ao VEGFR2 expresso no endotélio dos vasos sanguíneos e induzir a migração de células endoteliais capilares (JOUKOV et al., 1996, 1997; OH et al., 1997). O VEGFD ativa o VEGFR2 e o VEGFR3, é um mitógeno para células linfáticas e endoteliais vasculares, além de estar relacionado ao VEGFC no aspecto estrutural (ACHEN et al., 1998; DAVYDOVA et al., 2016).

O VEGFE está presente no genoma do poxvírus e mostrou se ligar em apenas um dos receptores, o VEGFR2, induzindo a autofosforilação (LYTTLE et al., 1994, OGAWA et al, 1998). O VEGFF, identificado no veneno de cobra, demonstra que o compartilhamento de uma estrutura comum com VEGFs de mamíferos são capazes de induzir a permeabilidade vascular e reduzir a pressão arterial (SUTO et al., 2005; YAMAZAKI et al., 2005; MATSUNAGA et al., 2009).

A caracterização das expressões de fatores angiogênicos ao longo do diestro é um fator importante e que deve ser aprofundado para compreensão da funcionalidade do CL canino. Desta forma, os agentes envolvidos na formação e manutenção do corpo lúteo, inclusive em processos ligados à sua regressão devem ser identificados.

Os mecanismos que influenciam os processos luteotróficos e luteolíticos estão sendo amplamente estudados. A partir das análises da expressão diferencial dos fatores angiogênicos durante o diestro de cadelas não gestantes podemos sugerir de que forma esses fatores estão envolvidos na fase de proliferação e de regressão no corpo lúteo.

\subsection{MATERIAL E MÉTODOS}

\subsubsection{Animais}

Para o desenvolvimento do experimento foram utilizados corpos lúteos provenientes de 18 cadelas sadias, de diferentes idades e sem definição do padrão racial. O trabalho obteve aprovação do Comitê de Ética em Uso de Animais da Faculdade de Medicina Veterinária e Zootecnia, Universidade de São Paulo, São Paulo, Brasil (número do protocolo 2719/2012). Os animais passaram por 
ovariosalpingohisterectomia (OSH) nos dias 10, 20, 30, 40, 50 e 60 após a ovulação (p.o) ( $n=3 /$ grupo). O dia da ovulação (dia 0) foi definido como o dia em que a concentração da progesterona periférica atingiu $\geq 5 \mathrm{ng} / \mathrm{mL}$ (CONCANNON; MCCANN; TEMPLE, 1989). No momento da OSH, amostras de corpo lúteo foram coletadas e congeladas imediatamente em nitrogênio líquido e armazenadas em freezer $-80^{\circ} \mathrm{C}$ para a extração do RNA.

\subsubsection{Dosagem de progesterona e 17b-estradiol}

As amostras foram coletadas, em tubos não heparinizados, para a dosagem hormonal. A concentração de estradiol e progesterona sérica foi determinada pelo Laboratório Hermes Pardini divisão de Medicina Veterinária (Belo Horizonte, MG) através de um sistema automatizado de quimioluminescência (Acess $®$ Imunoassay Systems, Beckman Coulter®, Fullerton, CA, USA). As amostras foram adicionadas a um recipiente de reação contendo anticorpo de coelho anti-progesterona e antiestradiol, após ao conjugado a progesterona-fosfatase alcalina e estradiol-fosfatase alcalina, respectivamente. Os complexos antígeno-anticorpo resultantes ligam-se ao anticorpo de captura na fase sólida. A produção de luz é inversamente proporcional à concentração de progesterona e estradiol na amostra. As concentrações de progesterona e estradiol presentes na amostra foram determinadas a partir de uma curva de calibração multiponto armazenada no sistema.

\subsubsection{Extração de RNA}

A extração de RNA total dos corpos lúteos foi realizada a partir do protocolo de TRIZOL (Life Technologies, Carlsbad, CA, USA). A quantificação do RNA e determinação da razão A260/A280 foi efetuada no aparelho Biophotometer (Eppendorf, Hamburg, Germany) e a qualidade do RNA foi avaliada no Agilent 2100 Bioanalyser (Agilent Technologies, USA). 


\subsubsection{Preparação das bibliotecas e sequenciamento do RNA}

As etapas de preparação e sequenciamento de mRNA foram estabelecidas a partir do protocolo TruSeq RNA Sample Prep Guide, descrito pela Illumina, disponível em http://grcf.jhmi.edu/hts/protocols/mRNA-Seq SamplePrep 1004898 D.pdf.

A qualidade das bibliotecas produzidas foi avaliada usando o Agilent 2100 Bioanalyser (Agilent Technologies) com o auxílio de um chip de DNA 1000.

Posteriormente, a quantificação individual das bibliotecas foi realizada por meio da técnica de PCR em tempo real com o Kit KAPA Library Quantification (KAPA Biosystems). O sequenciamento do mRNA foi realizado pelo aparelho o HiScanSQ (Illumina - San Diego, EUA), de acordo com as instruções do fabricante, utilizando o protocolo de reads paired-end.

\subsubsection{Análise dos dados do sequenciamento de RNA}

As análises dos dados obtidos ocorreram em quatro etapas principais: préprocessamento, montagem, mapeamento e análise de expressão diferencial (DE). Para obtenção dos dados brutos, foi utilizado o software CASAVA. 8.2 fornecido pela Illumina que faz a conversão dos traçados fluorescentes em uma sequência de bases nitrogenadas, no formato fastq. Durante este processo, um fator de qualidade foi associado a cada base da sequência (qualidade phred). Esta qualidade phred varia de 1 a 60 para cada base, quanto maior o número, maior a probabilidade da inserção correta da base. Para análise de qualidade do sequenciamento foi utilizado a ferramenta "FAST QC" e para filtrar os reads que tivessem menos que $50 \mathrm{pb}$ utilizamos a ferramenta "Trimmomatic" do "Our Galaxy".Os reads foram mapeados contra o genoma de referência (Canis_familiaris.CanFam3.1.75.dna.toplevel.fa) usando o programa Hisat ("Our Galaxy"- ETH-Zurique) .

Para análise dos genes diferencialmente expressos foi utilizado o software R_Studio. A expressão diferencial no dia 20 p.o em relação aos dias 50 (20x50) e 60 (20x60) p.o, foram analisadas pelo valor de "fold change" (FC) e pelo valor de razão de falsas descobertas $(F D R)<0,01$. As comparações entre os dias $20 \times 50$ e $20 \times 60$ foram selecionadas, pois são períodos correspondentes a fase de formação e de regressão do $\mathrm{CL}$ canino. A expressão foi considerada diferencial para o FC maior 
que 1 (FC>1) ou menor que $1(\mathrm{FC}<1)$, o que representa aumento ou diminuição da expressão, respectivamente (ZUGAIB, 2017).

3.2.6 Gene Ontology dos fatores angiogênicos

Os 'genes ID' canino do VEGFA, VEGFC, VEGFD, VEGFR1, VEGFR2 e VEGFR3 foram submetidos ao programa DAVID 6.8 (Database for Annotation Visualization and Integrated Discovery) para análise de categoria do gene ontology (GO) dos processos biológicos (PB).

\subsubsection{Análise estatística}

Os resultados foram apresentados com a referente ao FC e para a análises dos dados de expressão diferencial foi considerado o valor de fold-change sendo $>1,0$ de regulação positiva e <1,0 de regulação negativa (ZUGAIB, 2017; BIFFI, 2018), valor de $\mathrm{P}<0,05$ foi corrigido e definido pela FDR.

\subsection{RESULTADOS}

\subsubsection{RNA-SEQ}

Um total de 771.208 .718 reads foram gerados pelo Illumina HiScanSQ e através do software Hisat, 203.923.337 reads foram mapeados pelo genoma canino de referência (Canis_familiaris.CanFam3.1.75.dna.toplevel.fa). Pelo QuasR QCount foi gerada uma lista de genes diferencialmente expressos (DE) e através do programa R-Studio foi possível realizar as comparações e análises estatísticas entre os diferentes grupos.

Pelo programa DAVID os genes ID dos genes caninos do sistema VEGF, o VEGFA, VEGFC, VEGFD, VGFR1, VEGFR2 e o VEGFR3, estão envolvidos no termo da categoria GO 'positive regulation of endothelial cell proliferation' $\left(p=9,3.10^{-}\right.$ ${ }^{10}$ ) e na 'positive regulation of angiogenesis' $\left(p=7,8.10^{-9}\right)$ dos processos biológicos no enrichment score de 7,22. Além disso, foi possível identificar o gene ontology (GO) para a análise funcional dos genes (Tabela 4), no qual estão envolvidos com processos regulatórios da angiogênese. 
Tabela 4 - Conjuntos de GO dos processos biológicos do VEGFA, VEGFC, VEGFD, VEGFR1, VEGFR2 e VEGFR3

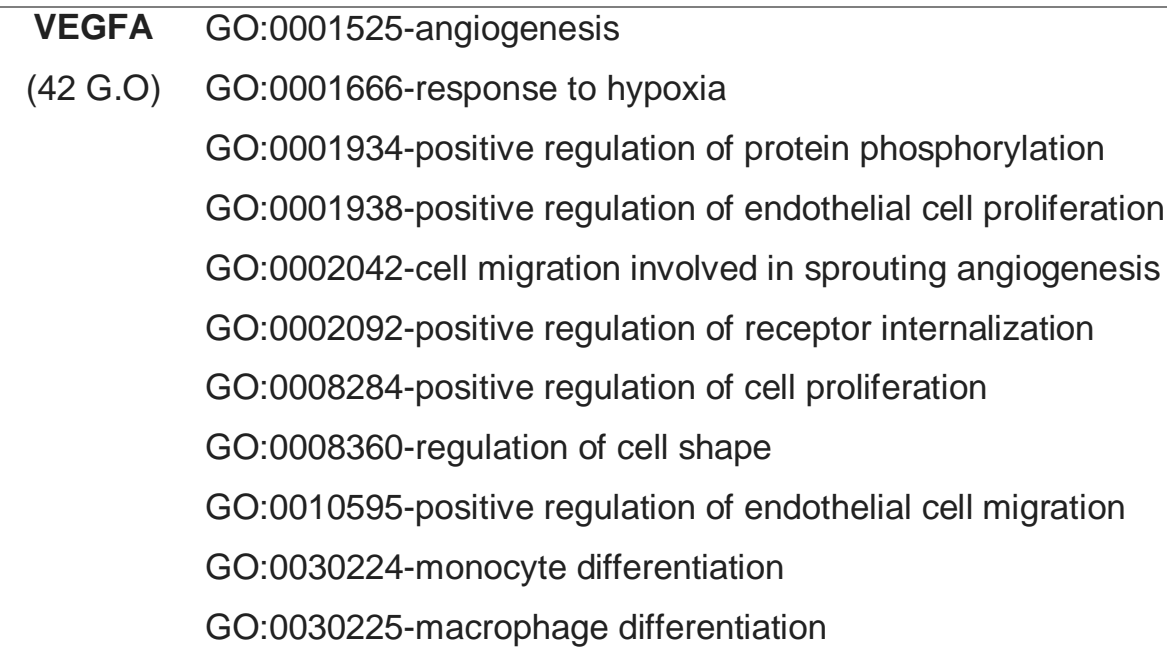

GO:0030949-positive regulation of vascular endothelial growth factor receptor signaling pathway

GO:0031334-positive regulation of protein complex assembly

GO:0031954-positive regulation of protein autophosphorylation

GO:0032147-activation of protein kinase activity

GO:0032793-positive regulation of CREB transcription factor activity

GO:0033138-positive regulation of peptidyl-serine phosphorylation

GO:0035148-tube formation

GO:0035767-endothelial cell chemotaxis

GO:0035924-cellular response to vascular endothelial growth factor stimulus

GO:0038033-positive regulation of endothelial cell chemotaxis by VEGF-activated vascular endothelial growth factor receptor signaling pathway

GO:0038091-positive regulation of cell proliferation by VEGF-activated platelet derived growth factor receptor signaling pathway

GO:0043066-negative regulation of apoptotic process

GO:0043406-positive regulation of MAP kinase activity

GO:0043536-positive regulation of blood vessel endothelial cell migration

GO:0045766-positive regulation of angiogenesis

GO:0045785-positive regulation of cell adhesion

GO:0045944-positive regulation of transcription from RNA polymerase II promoter

GO:0048010-vascular endothelial growth factor receptor signaling pathway

GO:0050731-positive regulation of peptidyl-tyrosine phosphorylation

GO:0050918-positive chemotaxis

GO:0050927-positive regulation of positive chemotaxis

GO:0050930-induction of positive chemotaxis

GO:0051272-positive regulation of cellular component movement

GO:0051781-positive regulation of cell division 
GO:0051894-positive regulation of focal adhesion assembly

GO:0060754-positive regulation of mast cell chemotaxis

GO:0071456-cellular response to hypoxia

GO:0090037-positive regulation of protein kinase C signaling

GO:0090050-positive regulation of cell migration involved in sprouting angiogenesis

GO:1900086-positive regulation of peptidyl-tyrosine autophosphorylation

GO:1903572-positive regulation of protein kinase D signaling

VEGFC GO:0001525-angiogenesis

(13 G.O) GO:0001666-response to hypoxia

GO:0001938-positive regulation of endothelial cell proliferation

GO:0001954-positive regulation of cell-matrix adhesion

GO:0008285-negative regulation of cell proliferation

GO:0009887-organ morphogenesis

GO:0016331-morphogenesis of embryonic epithelium

GO:0045766-positive regulation of angiogenesis

GO:0048010-vascular endothelial growth factor receptor signaling pathway

GO:0050731-positive regulation of peptidyl-tyrosine phosphorylation

GO:0050930-induction of positive chemotaxis

GO:0060754-positive regulation of mast cell chemotaxis

GO:1901492-positive regulation of lymphangiogenesis

VEGFD GO:0001525-angiogenesis

(09 G.O) GO:0001666-response to hypoxia

GO:0001938-positive regulation of endothelial cell proliferation

GO:0008283-cell proliferation

GO:0045766-positive regulation of angiogenesis

GO:0048010-vascular endothelial growth factor receptor signaling pathway

GO:0050930-induction of positive chemotaxis

GO:0060754-positive regulation of mast cell chemotaxis

GO:0071542-dopaminergic neuron differentiation

VGFR1 GO:0002548-monocyte chemotaxis

(09 G.O) GO:0010863-positive regulation of phospholipase $C$ activity

GO:0014068-positive regulation of phosphatidylinositol 3-kinase signaling

GO:0030335-positive regulation of cell migration

GO:0030949-positive regulation of vascular endothelial growth factor receptor signaling 
pathway

GO:0043406-positive regulation of MAP kinase activity

GO:0043552-positive regulation of phosphatidylinositol 3-kinase activity

GO:0045766-positive regulation of angiogenesis

GO:0046777-protein autophosphorylation

VEGFR2 GO:0001938-positive regulation of endothelial cell proliferation

(15 G.O) GO:0008360-regulation of cell shape

GO:0014068-positive regulation of phosphatidylinositol 3-kinase signaling

GO:0016239-positive regulation of macroautophagy

GO:0035584-calcium-mediated signaling using intracellular calcium source

GO:0038033-positive regulation of endothelial cell chemotaxis by VEGF-activated vascular endothelial growth factor receptor signaling pathway

GO:0045766-positive regulation of angiogenesis

GO:0046777-protein autophosphorylation

GO:0050927-positive regulation of positive chemotaxis

GO:0051770-positive regulation of nitric-oxide synthase biosynthetic process

GO:0051894-positive regulation of focal adhesion assembly

GO:0051901-positive regulation of mitochondrial depolarization

GO:0070374-positive regulation of ERK1 and ERK2 cascade

GO:0090141-positive regulation of mitochondrial fission

GO:2000352-negative regulation of endothelial cell apoptotic process

VEGFR3 GO:0001938-positive regulation of endothelial cell proliferation

(14 G.O) GO:0001946-lymphangiogenesis

GO:0002040-sprouting angiogenesis

GO:0003016-respiratory system process

GO:0010575-positive regulation of vascular endothelial growth factor production

GO:0010595-positive regulation of endothelial cell migration

GO:0043066-negative regulation of apoptotic process

GO:0046330-positive regulation of JNK cascade

GO:0046777-protein autophosphorylation

GO:0048010-vascular endothelial growth factor receptor signaling pathway

GO:0048286-lung alveolus development

GO:0060312-regulation of blood vessel remodeling

GO:0070374-positive regulation of ERK1 and ERK2 cascade

GO:0090037-positive regulation of protein kinase $\mathrm{C}$ signaling 
A expressão diferencial do VEGFA, VEGFC, VEGFD, VEGFR1, VEGFR2 e VEGFR3 foi analisada nas comparações entre os dias $20 \times 50$ e 20x60, por valores de FC (Figura 2).

O VEGFA apresentou expressão diferencial nas comparações dos dias $20 \times 50$ ( $F C=1,44, p<0,01$ e $F D R<0,01)$ e $20 \times 60$ ( $F C=1,24, p<0,01$ e $F D R<0,01)$, sendo observada uma regulação positiva no dia 20 p.o em comparação aos dias 50 e 60 p.o. Assim como a expressão dos receptores VEGFR1 e VEGFR2, nas comparações 20X50 ( $F C=1,03, p<0,01$ e $F D R<0,01 / F C=1,51, p<0,01$ e $F D R=0,03$, respectivamente) e 20X60 ( $F C=1,89, p<0,01$ e $F D R<0,01 / F C=2,55, p<0,01$ e FDR $<0,01$, respectivamente) mostraram um aumento no dia 20 p.o em comparação aos dias 50 e 60 p.o..

O VEGFR3 somente apresentou regulação positiva no dia 20 ( $F C=1,06$, $p<0,01$ e $F D R=0,04)$ em sua comparação no dia 60 p.o, não sendo observado diferença significativa entre os períodos na comparação 20x50 ( $F C=0,16, p=0,65$ e $\mathrm{FDR}=0,85)$.

O VEGFC apresentou regulação positiva no dia 20 em suas comparações no dia 50 ( $F C=1,27, p<0,01$ e $F D R<0,01)$ e no dia 60 ( $F C=1,94, p<0,01$ e $F D R<0,01)$. Já o VEGFD apresentou regulação positiva apenas no dia 20 em sua comparação ao dia 50 ( $F C=1,36, p<0,01$ e $F D R<0,05)$.

A expressão do VEGFB foi identificada nos dados do RNA-seq, mas sem expressão diferencial significativa. 
Figura 2 - Análise da expressão do VEGFA, VEGFC, VEGFD, VEGFR1, VEGFR2 e VEGFR3 no dia 20 p.o em comparação aos dias 50 e 60 p.o por RNA-seq. A linha vermelha tracejada representa um fold change > 1 para cada gene nas comparações.

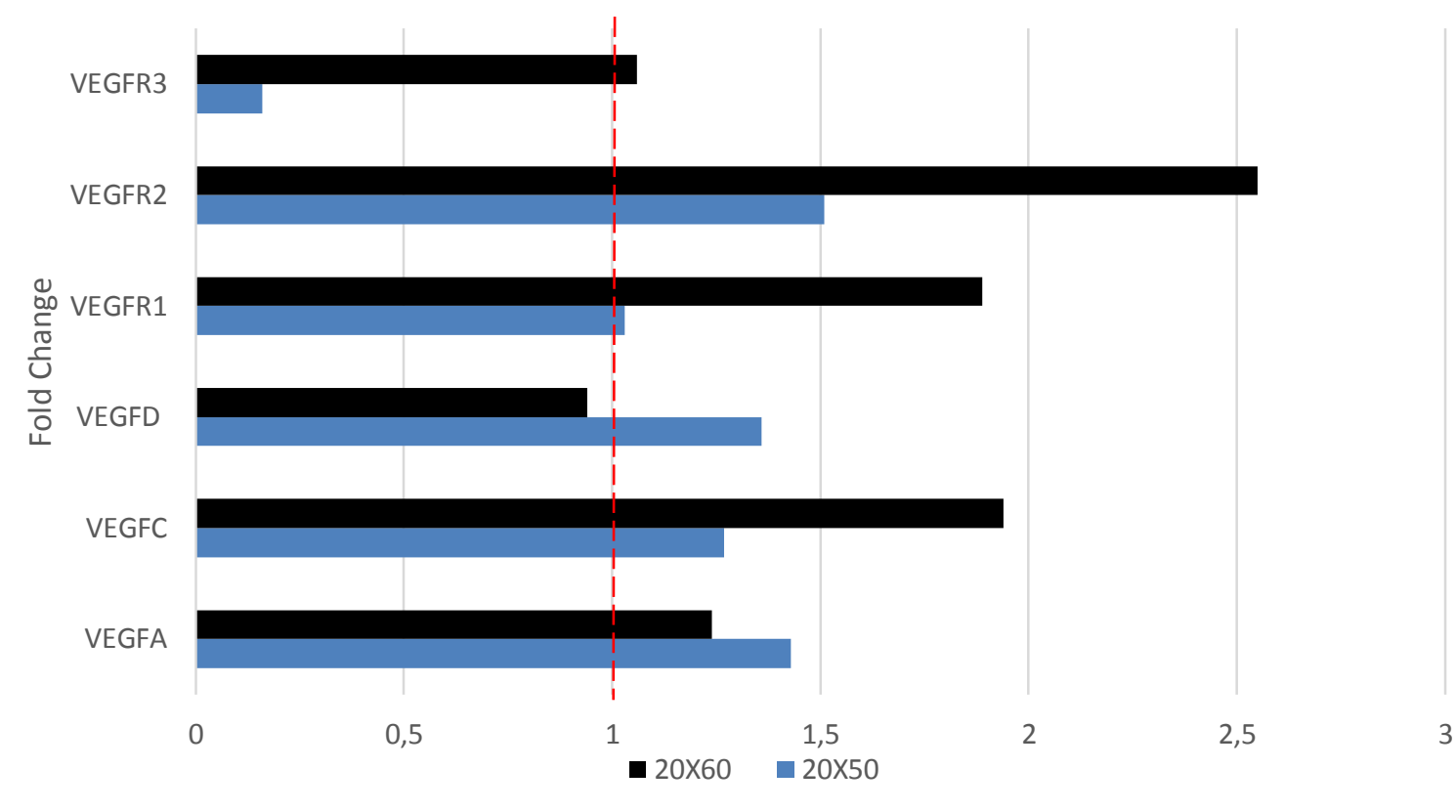

Comparação entre os dias após a ovulação

Fonte: D'APRILE, 2021.

\subsection{DISCUSSÃO}

O estudo indica que fatores angiogênicos atuam de forma distinta nos períodos do diestro canino, uma vez que houve um aumento no dia 20 p.o em comparação aos dias 50 e 60 p.o. Os resultados do RNA-seq sugerem que o VEGFA, o VEGFC, o VEGFD e seus receptores, estejam envolvidos com os processos de proliferação, manutenção e regressão do corpo lúteo canino, pela alteração da expressão nos períodos do diestro.

Uma vez que o 17ß-estradiol (E2) afeta diretamente a expressão do VEGFA (APPLANAT et al., 2008) e a produção de progesterona (P4) é maior no dia 20, os nossos dados de fold change indicam uma regulação positiva do VEGFA, VEGFC e VEGFD no início da fase luteínica e diminuição após este período (FRASER; LUNN, 2000). 
A regulação positiva dos fatores angiogênicos no dia 20 também pode estar relacionada a insulina, pois esta tem um papel fundamental nos corpos lúteos caninos pela indução da translocação de GLUT4 para que as células tenham suprimento de glicose e exerçam sua função endócrina de maneira adequada (SOUSA et al., 2016). Adicionalmente, os mecanismos de ação da insulina podem agir de maneira direta, via aumento da resposta celular à cascata de fosforilação da tirosina quinase, que é uma resposta clássica de ativação do receptor do VEGF por seu ligante, como demonstrado por Wang et al. (2015) e isto corrobora com o aumento do fold change dos fatores angiogênicos durante o período inicial do diestro.

O VEGFA tem alta afinidade ao VEGFR1 e a ativação dos mecanismos de sinalização pró-angiogênica são gerados pela ligação ao VEGFR2 (SHIBUYA, 2011). Desta forma, a regulação negativa do VEGFA e dos receptores VEGFR1 e VEGFR2 nos dias 50 e 60 p.o nos mostram esses mecanismos de sinalização no corpo lúteo canino. Em bovinos, os resultados foram similares, pois a expressão gênica do VEGF e do VEGFR2 indicou um aumento da expressão durante a fase inicial do desenvolvimento do corpo lúteo (BERISHA et al., 2000), mas não em relação a expressão do VEGFR1, que não se alterou durante o desenvolvimento luteínico (SCHAMS; BERISHA, 2004).

O VEGFC e o VEGFD apresentaram regulação positiva no dia 20 em relação ao dia 50 do diestro, e o VEGFC na comparação 20x60. O receptor VEGFR3 apresentou FC significativo apenas na comparação 20x60, sendo considerado um regulador negativo da expressão do VEGFD (SECKER; HARVEY, 2015), uma vez que estão associados à linfangiogênese e angiogênese (LAAKKONEN et al., 2007; ANISIMOV et al., 2009).

Foi relatado que o VEGFC e o VEGFD também atuam via VEGFR2 e VEGFR3 para promover a angiogênese e a linfangiogênese (JOUKOV et al.,1997; ACHEN et al., 1998; GOLDMAN et al., 2007) e isto corrobora com um trabalho que indica que o VEGFC e VEGFD são expressos por células foliculares para apoiar o desenvolvimento linfático, que são essenciais para o funcionamento adequado do corpo lúteo (KIM, TRAU, DUFFY,2017).

O VEGFC e VEGFD são fatores linfangiogênicos e sua expressão, regulação e funcionalidade dentro do CL não foram caracterizadas até o momento. $O$ nosso trabalho mostra um dado primordial sobre a evidência do VEGFC e VEGFD durante 
os períodos do dia 20, 50 e 60 p.o, o que sugere ativação da linfangiogênese, como descrito em vacas: foi demonstrado que a proteína de reconhecimento do concepto foi amplificada na linfangiogênese via sinalização de VEGFC no período de manutenção do $\mathrm{CL}$ e também quando o $\mathrm{CL}$ alcança sua fase de maior produção para sustentação da gestação (NITTA et al., 2011).

Os dados mostram um aumento do fold change principalmente no dia 20 p.o, o que indica mudanças significativas na expressão gênica, considerando o fato de que a variabilidade de fold change é diretamente relacionada à intensidade sinal (LI et al, 2005).

\subsection{CONCLUSÕES}

Os resultados nos oferecem perspectivas importantes sobre os fatores relacionados ao processo de proliferação e regressão do corpo lúteo. O VEGFA não é o único fator angiogênico expresso diferencialmente no corpo lúteo canino e o conjunto de fatores angiogênicos pode atuar de forma distinta e coordenada.

O VEGFA, VEGFC, VEGFD, VEGFR1, VEGFR2 e VEGFR3 estão expressos ao longo do diestro o que sugere sua participação nos processos de maturação e regressão do CL canino.

\section{AGRADECIMENTOS}

O presente trabalho foi realizado com apoio da Coordenação de Aperfeiçoamento de Pessoal de Nível Superior - Brasil (CAPES) - Código de Financiamento 001. 


\section{REFERÊNCIAS}

ACHEN, M. G. et al. Vascular Endothelial Growth Factor D (VEGF-D) Is a Ligand for the Tyrosine Kinases VEGF Receptor 2 (Flk1) and VEGF Receptor 3 (Flt4). Proceedings of the National Academy of Sciences of the United States of America, v. 95, n. 2, p. 548-553, jan. 1998.

ADAMS, R. H.; ALITALO, K. Molecular regulation of angiogenesis and lymphangiogenesis. Nature Reviews Molecular Cell Biology, v. 8, n. 6, p. 464478, 2007.

AL-Zl'ABI, M. O.; WATSON, E. D.; FRASER, H. M. Angiogenesis and Vascular Endothelial Growth Factor Expression in the Equine Corpus Luteum. Reproduction (Cambridge, England), v. 125, n. 2, p. 259-270, fev. 2003.

ALEXANDER, S. P. H. et al. The Concise Guide to PHARMACOLOGY 2015/16: Catalytic receptors. British Journal of Pharmacology, v. 172, n. 24, p. 5979-6023, 2015.

ALMAWI, W. Y. et al. Analysis of VEGFA variants and changes in VEGF levels underscores the contribution of VEGF to polycystic ovary syndrome. PLoS ONE, v. 11, n. 11, p. 1-12, 2016.

ANISIMOV, A. et al. Activated forms of VEGF-C and VEGF-D provide improved vascular function in skeletal muscle. Circulation Research, v. 104, n. 11, p. 13021312, 2009.

APPLANAT, M. P. et al. Vascular Endothelial Growth Factor Is a Target Gene for Estrogen Receptor and Contributes to Breast Cancer Progression. Advances in experimental medicine and biology, v. 617, p. 437-444, 2008.

ARICÒ, A. et al. The role of vascular endothelial growth factor and matrix metalloproteinases in canine lymphoma: In vivo and in vitro study. BMC Veterinary Research, v. 9, p. 1-10, 2013.

ARTAC, R. A. et al. Neutralization of Vascular Endothelial Growth Factor Antiangiogenic Isoforms Is More Effective than Treatment with Proangiogenic Isoforms in Stimulating Vascular Development and Follicle Progression in the Perinatal Rat Ovary. Biology of reproduction, v. 81, n. 5, p. 978-988, nov. 2009.

BAKER, P. N. et al. Elevated serum levels of vascular endothelial growth factor in patients with preeclampsia. Obstetrics and Gynecology, v. 86, n. 5, p. 815-821, 1995.

BALDWIN, M. E. et al. Vascular Endothelial Growth Factor D Is Dispensable for Development of the Lymphatic System. Molecular and cellular biology, v. 25, n. 6, p. 2441-2449, mar. 2005.

BANKS, R. E. et al. Release of the Angiogenic Cytokine Vascular Endothelial Growth Factor (VEGF) from Platelets: Significance for VEGF Measurements and Cancer Biology. British journal of cancer, v. 77, n. 6, p. 956-964, mar. 1998.

BÁNYÁSZ, I. et al. Genetic polymorphisms of vascular endothelial growth factor in 
severe pre-eclampsia. Molecular Human Reproduction, v. 12, n. 4, p. 233-236, 1 abr. 2006.

BAO, L.; SYED, R.; ALOAHD, M. S. Analysis of VEGF Gene Polymorphisms and Serum VEGF Protein Levels Contribution in Polycystic Ovary Syndrome of Patients. Molecular biology reports, v. 46, n. 6, p. 5821-5829, dez. 2019.

BEN ALI GANNOUN, M. et al. Vascular endothelial growth factor single nucleotide polymorphisms and haplotypes in pre-eclampsia: A case-control study. Cytokine, v. 97, p. 175-180, 2017.

BEN SALEM, A. et al. Vascular Endothelial Growth Factor (VEGFA) Gene Variation in Polycystic Ovary Syndrome in a Tunisian Women Population. BMC genomics, v. 17, n. Suppl 9, p. 748, 17 out. 2016.

BERGANTINO, F. et al. Structure-fluctuation-function relationships of seven proangiogenic isoforms of VEGFA, important mediators of tumorigenesis. Biochimica et Biophysica Acta - Proteins and Proteomics, v. 1854, n. 5, p. 410-425, 2015. Disponível em: <http://dx.doi.org/10.1016/j.bbapap.2015.01.005>.

BERISHA, B. et al. Expression and localisation of vascular endothelial growth factor and basic fibroblast growth factor during the final growth of bovine ovarian follicles. $p$. 371-382, 2000.

BERISHA, B. et al. Angiogenesis in The Ovary - The Most Important Regulatory Event for Follicle and Corpus Luteum Development and Function in Cow - An Overview. Journal of Veterinary Medicine Series C: Anatomia Histologia Embryologia, v. 45, n. 2, p. 124-130, 2016.

BERSE, B. et al. Vascular Permeability Factor (Vascular Endothelial Growth Factor) Gene Is Expressed Differentially in Normal Tissues, Macrophages, and Tumors. Molecular biology of the cell, v. 3, n. 2, p. 211-220, fev. 1992.

BHAVINA, K.; RADHIKA, J.; PANDIAN, S. S. VEGF and eNOS Expression in Umbilical Cord from Pregnancy Complicated by Hypertensive Disorder with Different Severity. BioMed Research International, v. 2014, p. 982159, 2014.

BIFFI, K. Avaliação de assinaturas gênicas relacionadas ao perfil de resistência e suscetibilidade às infestações por carrapatos Rhipicephalus microplus. 2018.

BOTT, R. C. et al. Vascular Endothelial Growth Factor and Kinase Domain Region Receptor Are Involved in Both Seminiferous Cord Formation and Vascular Development During Testis Morphogenesis in the Rat 1. v. 67, n. May, p. 56-67, 2006.

BOTT, R. C. et al. KDR-LacZ-expressing cells are involved in ovarian and testisspecific vascular development, suggesting a role for VEGFA in the regulation of this vasculature. p. 117-130, 2010.

BROGI, E. et al. Indirect Angiogenic Cytokines Upregulate VEGF and BFGF Gene Expression in Vascular Smooth Muscle Cells, Whereas Hypoxia Upregulates VEGF Expression Only. Circulation, v. 90, n. 2, p. 649-652, ago. 1994.

BUKOWSKA, D. et al. Analysis of integrins and vascular endothelial growth factor isoforms mRNA expression in the canine uterus during perimplantation period. 
Polish Journal of Veterinary Sciences, v. 14, n. 2, p. 253-258, 2011.

BYRNE, A.M.; BOUCHIER-HAYES, D.J.; HARMEY, J. H. Angiogenic and cell survival functions of Vascular Endothelial Growth Factor (VEGF). AORN journal, v. 81, n. 4, p. 777-778, 2005.

CAIRES, K. C. et al. VEGFA Family Isoforms Regulate Spermatogonial Stem Cell Homeostasis in Vivo. Endocrinology, v. 153, n. 2, p. 887-900, fev. 2012.

CAIRES, K. C.; AVILA, J. De; MCLEAN, D. J. Vascular endothelial growth factor regulates germ cell survival during establishment of spermatogenesis in the bovine testis. Reproduction, v. 138, p. 667-677, 2009.

CARDOSO, A. P. M. M. Mecanismo de ação do 17b-estradiol no corpo lúteo de cadelas não prenhes. 2016.

CARMELIET, P. et al. Abnormal Blood Vessel Development and Lethality in Embryos Lacking a Single VEGF Allele. Nature, v. 380, n. 6573, p. 435-439, abr. 1996.

CARMELIET, P. Angiogenesis in Health and Disease. Nature medicine, v. 9, n. 6, p. 653-660, jun. 2003.

CARMELIET, P. Angiogenesis in Life, Disease and Medicine. Nature, v. 438, n. 7070, p. 932-936, dez. 2005.

CARMINA, E. Obesity, Adipokines and Metabolic Syndrome in Polycystic Ovary Syndrome. Frontiers of hormone research, v. 40, p. 40-50, 2013.

CASSAR, S. et al. Insulin Resistance in Polycystic Ovary Syndrome: A Systematic Review and Meta-Analysis of Euglycaemic-Hyperinsulinaemic Clamp Studies. Human reproduction (Oxford, England), v. 31, n. 11, p. 2619-2631, nov. 2016.

CÉBE-SUAREZ, S.; ZEHNDER-FJÄLLMAN, A.; BALLMER-HOFER, K. The role of VEGF receptors in angiogenesis; complex partnerships. Cellular and Molecular Life Sciences, v. 63, n. 5, p. 601-615, 2006.

CHESNOKOV, M. S. et al. Shift in VEGFA isoform balance towards more angiogenic variants is associated with tumor stage and differentiation of human hepatocellular carcinoma. PeerJ, v. 2018, n. 6, p. 1-17, 2018.

CHOUHAN, V. S. et al. Expression and localization of vascular endothelial growth factor and its receptors in the corpus luteum during oestrous cycle in water buffaloes (Bubalus bubalis). Reproduction in Domestic Animals, v. 48, n. 5, p. 810-818, 2013.

CONCANNON, P. W. Endocrinologic Control of Normal Canine Ovarian Function. Reproduction in domestic animals = Zuchthygiene, v. 44 Suppl 2, p. 3-15, jul. 2009.

CONCANNON, P. W. Reproductive Cycles of the Domestic Bitch. Animal reproduction science, v. 124, n. 3-4, p. 200-210, abr. 2011.

CONCANNON, P. W.; MCCANN, J. P.; TEMPLE, M. Biology and Endocrinology of Ovulation, Pregnancy and Parturition in the Dog. Journal of reproduction and fertility. Supplement, v. 39, p. 3-25, 1989. 
DANASTAS, K. et al. Expression of Vascular Endothelial Growth Factor A Isoforms Is Dysregulated in Women with Endometriosis. Reproduction, fertility, and development, v. 30, n. 4, p. 651-657, mar. 2018.

DAVYDOVA, N. et al. Differential receptor binding and regulatory mechanisms for the lymphangiogenic growth factors vascular endothelial growth factor (VEGF)-C and -D. Journal of Biological Chemistry, v. 291, n. 53, p. 27265-27278, 2016.

DE GREGORIO, L. et al. Genetic mapping of the vascular endothelial growth factor (Vegf) gene to mouse Chromosome 17. Mammalian Genome, v. 8, p. 451-452, 1997.

DE VRIES, C. et al. The Fms-like Tyrosine Kinase, a Receptor for Vascular Endothelial Growth Factor. Science (New York, N.Y.), v. 255, n. 5047, p. 989-991, fev. 1992.

DEMIR, R.; SEVAL, Y.; HUPPERTZ, B. Vasculogenesis and Angiogenesis in the Early Human Placenta. Acta histochemica, v. 109, n. 4, p. 257-265, 2007.

ENHOLM, B. et al. Comparison of VEGF, VEGF-B, VEGF-C and Ang-1 mRNA regulation by serum, growth factors, oncoproteins and hypoxia. Oncogene, v. 14, n. 20, p. 2475-2483, 1997. Disponível em: <https://doi.org/10.1038/sj.onc.1201090>.

ENHOLM, B. et al. Adenoviral expression of vascular endothelial growth factor-C induces lymphangiogenesis in the skin. Circulation Research, v. 88, n. 6, p. 623629, 2001.

FERRARA, N. et al. Vascular Endothelial Growth Factor Is Essential for Corpus Luteum Angiogenesis. Nature medicine, v. 4, n. 3, p. 336-340, mar. 1998.

FERRARA, N. Vascular endothelial growth factor: Basic science and clinical progress. Endocrine Reviews, v. 25, n. 4, p. 581-611, 2004.

FERRARA, N. VEGF-A: A Critical Regulator of Blood Vessel Growth. European cytokine network, v. 20, n. 4, p. 158-163, dez. 2009.

FERRARA, N.; ADAMIS, A. P. Ten years of anti-vascular endothelial growth factor therapy. Nature Reviews Drug Discovery, v. 15, n. 6, p. 385-403, 2016.

FERRARA, N.; DAVIS-SMYTH, T. The Biology of Vascular Endothelial Growth Factor. Endocrine reviews, v. 18, n. 1, p. 4-25, fev. 1997.

FERRARA, N. et al. Heterozygous embryonic lethality induced by targeted inactivation of the VEGF gene. Nature, v. 380, p. 439-442, 1996.

FERRARA, N.; GERBER, H. P.; LECOUTER, J. The biology of VEGF and its receptors. Nature Medicine, v. 9, n. 6, p. 669-676, 2003.

FOLKMAN, J. Angiogenesis in Psoriasis: Therapeutic Implications. Journal of Investigative Dermatology, v. 59, n. 1, p. 40-43, 1972.

FRASER, H. M.; DUNCAN, W. C. SRB Reproduction, Fertility and Development Award Lecture 2008: Regulation and manipulation of angiogenesis in the ovary and endometrium. Reproduction, Fertility and Development, v. 21, n. 3, p. 377-392, 2009. 
FRASER, H. M.; LUNN, S. F. Angiogenesis and its control in the female reproductive system. v. 56, n. 3, p. 787-797, 2000.

FRASER, H. M.; WULFF, C. Angiogenesis in the Corpus Luteum. Reproductive biology and endocrinology: RB\&E, v. 1, p. 88, nov. 2003.

FREZZETTI, D. et al. Vascular Endothelial Growth Factor A Regulates the Secretion of Different Angiogenic Factors in Lung Cancer Cells. Journal of Cellular Physiology, v. 231, n. 7, p. 1514-1521, 2016.

GANTA, V. C. et al. VEGF165b Modulates Endothelial VEGFR1-STAT3 Signaling Pathway and Angiogenesis in Human and Experimental Peripheral Arterial Disease. Circulation research, v. 120, n. 2, p. 282-295, jan. 2017.

GARGETT, C. E. et al. 17ß-estradiol up-regulates vascular endothelial growth factor receptor-2 expression in human myometrial microvascular endothelial cells: Role of estrogen receptor- $\alpha$ and $-\beta$. Journal of Clinical Endocrinology and Metabolism, v. 87, n. 9, p. 4341-4349, 2002.

GAUDRY, M. et al. Intracellular Pool of Vascular Endothelial Growth Factor in Human Neutrophils. Blood, v. 90, n. 10, p. 4153-4161, nov. 1997.

GEVA, E.; JAFFE, R. B. Role of vascular endothelial growth factor inovarian physiology and pathology. Fertility and Sterility, v. 58, n. 3, p. S113-S119, 2000. Disponível em: <http://linkinghub.elsevier.com/retrieve/pii/S0085253815474320>.

GIRLING, J. E.; ROGERS, P. A. W. Regulation of Endometrial Vascular Remodelling: Role of the Vascular Endothelial Growth Factor Family and the Angiopoietin-TIE Signalling System. Reproduction (Cambridge, England), v. 138, n. 6, p. 883-893, dez. 2009.

GLUECK, C. J.; GOLDENBERG, N. Characteristics of Obesity in Polycystic Ovary Syndrome: Etiology, Treatment, and Genetics. Metabolism: clinical and experimental, v. 92, p. 108-120, mar. 2019.

GOLDMAN, J. et al. Cooperative and redundant roles of VEGFR-2 and VEGFR-3 signaling in adult lymphangiogenesis. FASEB journal, v. 21, p. 1003-1012, 2007.

GRAM, A. et al. Expression and Localization of Vascular Endothelial Growth Factor A (VEGFA) and Its Two Receptors (VEGFR1/FLT1 and VEGFR2/FLK1/KDR) in the Canine Corpus Luteum and Utero-Placental Compartments during Pregnancy and at Normal and Induced Parturition. General and comparative endocrinology, v. 223, p. 54-65, nov. 2015.

HANNAN, N. J. et al. Analysis of Fertility-Related Soluble Mediators in Human Uterine Fluid Identifies VEGF as a Key Regulator of Embryo Implantation. Endocrinology, v. 152, n. 12, p. 4948-4956, dez. 2011.

HARRIS, S. et al. Do anti-angiogenic VEGF (VEGFxxxb) isoforms exist? a Cautionary Tale. PLoS ONE, v. 7, n. 5, p. 1-14, 2012.

HOEBEN, A. et al. Vascular Endothelial Growth Factor and Angiogenesis. Pharmacological reviews, v. 56, n. 4, p. 549-580, dez. 2004.

HOFFMANN, B. et al. Regulation of Corpus Luteum-Function in the Bitch. 
Reproduction in domestic animals $=$ Zuchthygiene, v. 39, n. 4, p. 232-240, ago . 2004.

HOUCK, K. A. et al. The vascular endothelial growth factor family: Identification of a fourth molecular species and characterization of alternative splicing of rna. Molecular Endocrinology, v. 5, n. 12, p. 1806-1814, 1991.

HUANG, K. et al. Signaling properties of VEGF receptor-1 and -2 homo- and heterodimers. International Journal of Biochemistry and Cell Biology, v. 33, n. 4, p. 315-324, 2001.

HUPPERTZ, B.; PEETERS, L. L. H. Vascular biology in implantation and placentation. Angiogenesis, v. 8, n. 2, p. 157-167, 2005.

HURD, W. W. et al. Comparison of Diabetes Mellitus and Insulin Resistance Screening Methods for Women with Polycystic Ovary Syndrome. Fertility and sterility, v. 96, n. 4, p. 1043-1047, out. 2011.

ILLERA, M. J. et al. A Role for Alphavbeta3 Integrin during Implantation in the Rabbit Model. Biology of reproduction, v. 68, n. 3, p. 766-771, mar. 2003.

ISHIDA, A. et al. Expression of Vascular Endothelial Growth Factor Receptors in Smooth Muscle Cells. Journal of cellular physiology, v. 188, n. 3, p. 359-368, set. 2001.

JELTSCH, M. et al. Hyperplasia of lymphatic vessels in VEGF-C transgenic mice. Science, v. 276, n. 5317, p. 1423-1425, 1997.

JIM, B.; KARUMANCHI, S. A. Preeclampsia: Pathogenesis, Prevention, and LongTerm Complications. Seminars in Nephrology, v. 37, n. 4, p. 386-397, 2017.

JINGJING, L. et al. Vascular endothelial growth factor is increased following coronary artery occlusion in the dog heart. Molecular and Cellular Biochemistry, v. 214, n. 1, p. 23-30, 2000.

JOHNSON, K. E.; WILGUS, T. A. Vascular Endothelial Growth Factor and Angiogenesis in the Regulation of Cutaneous Wound Repair.Advances in wound care, out. 2014. .

JOUKOV, V. et al. A novel vascular endothelial growth factor, VEGF-C, is a ligand for the Flt4 (VEGFR-3) and KDR (VEGFR-2) receptor tyrosine kinases. EMBO Journal, v. 15, n. 2, p. 290-298, 1996.

JOUKOV, $\mathrm{V}$. et al. Proteolytic processing regulates receptor specificity and activity of VEGF-C. EMBO Journal, v. 16, n. 13, p. 3898-3911, 1997.

KABRUN, N. et al. Flk-1 expression defines a population of early embryonic hematopoietic precursors. Development, v. 124, n. 10, p. 2039 LP - 2048, 15 maio 1997.

KACZMAREK, M. M.; SCHAMS, D.; ZIECIK, A. J. Role of Vascular Endothelial Growth Factor in Ovarian Physiology - an Overview. Reproductive biology, v. 5, n. 2, p. 111-136, jul. 2005.

KAIPAINEN, A. et al. Expression of the Fms-like Tyrosine Kinase 4 Gene Becomes 
Restricted to Lymphatic Endothelium during Development. Proceedings of the National Academy of Sciences of the United States of America, v. 92, n. 8, p. 3566-3570, abr. 1995.

KALAGIRI, R. R. et al. Inflammation in Complicated Pregnancy and Its Outcome. American journal of perinatology, v. 33, n. 14, p. 1337-1356, dez. 2016.

KARKKAINEN, M. J. et al. Vascular Endothelial Growth Factor C Is Required for Sprouting of the First Lymphatic Vessels from Embryonic Veins. Nature immunology, v. 5, n. 1, p. 74-80, jan. 2004.

KARKKAINEN, M. J.; MÄKINEN, T.; ALITALO, K. Lymphatic endothelium: A new frontier of metastasis research. Nature Cell Biology, v. 4, n. 1, p. E2-E5, 2002.

KIKUCHI, R. et al. Europe PMC Funders Group An anti-angiogenic isoform of VEGFA contributes to impaired vascularization in peripheral artery disease. v. 20, n. 12, p. 1464-1471, 2015.

KIM, S. O.; TRAU, H. A.; DUFFY, D. M. Vascular endothelial growth factors C and D may promote angiogenesis in the primate ovulatory follicle $\dagger$. v. 96, n. December 2016, p. 389-400, 2017.

$\mathrm{KOCH}$, S.; CLAESSON-WELSH, L. Signal Transduction by VEGFRs.pdf. Cold Spring Harb Perspect Med., v. July, n. 2, p. 7, 2012.

KOWALEWSKI, M. P. et al. Luteal and Placental Function in the Bitch: SpatioTemporal Changes in Prolactin Receptor (PRLr) Expression at Dioestrus, Pregnancy and Normal and Induced Parturition. Reproductive biology and endocrinology: RB\&E, v. 9, p. 109, ago. 2011.

KOWALEWSKI, M. P. Luteal Regression vs. Prepartum Luteolysis: Regulatory Mechanisms Governing Canine Corpus Luteum Function. Reproductive biology, v. 14, n. 2, p. 89-102, abr. 2014.

KRUKIER, I. I.; POGORELOVA, T. N. Production of vascular endothelial growth factor and endothelin in the placenta and umbilical cord during normal and complicated pregnancy. Bulletin of Experimental Biology and Medicine, v. 141, n. 2, p. 216-218, 2006.

LAAKKONEN, P. et al. Vascular Endothelial Growth Factor Receptor 3 Is Involved in Tumor Angiogenesis and Growth. n. 2, p. 593-600, 2007.

LAI, T. H. et al. Expression patterns of VEGF and Flk-1 in human endometrium during the menstrual cycle. Journal of Reproduction and Infertility, v. 16, n. 1, p. 3-9, 2015.

LAL, N.; PURI, K.; RODRIGUES, B. Vascular Endothelial Growth Factor B and Its Signaling. Frontiers in Cardiovascular Medicine, v. 5, n. April, p. 1-9, 2018.

LANGE, T. et al. VEGF162, a new heparin-binding vascular endothelial growth factor splice form that is expressed in transformed human cells. Journal of Biological Chemistry, v. 278, n. 19, p. 17164-17169, 2003.

LEACH, L. Placental Vascular Dysfunction in Diabetic Pregnancies: Intimations of Fetal Cardiovascular Disease? Microcirculation, v. 18, n. 4, p. 263-269, 2011. 
LEI, J.; JIANG, A.; PEI, D. Identification and characterization of a new splicing variant of vascular endothelial growth factor: VEGF1831Accession number: AJ010438 for human VEGF183.1. Biochimica et Biophysica Acta (BBA) - Gene Structure and Expression, v. 1443, n. 3, p. 400-406, 1998.

LESSEY, B. A. Adhesion Molecules and Implantation. Journal of reproductive immunology, v. 55, n. 1-2, p. 101-112, 2002.

LEUNG, D. W. et al. Vascular endothelial growth factor is a secreted angiogenic mitogen. Science, v. 246, n. 4935, p. 1306-1309, 1989.

LI, L. et al. Polymorphisms in the vascular endothelial growth factor gene associated with recurrent spontaneous miscarriage. The Journal of Maternal-Fetal \& Neonatal Medicine, v. 26, n. 7, p. 686-690, 1 maio 2013.

LOMET, D. et al. Anti-angiogenic VEGFAxxxb transcripts are not expressed in the medio-basal hypothalamus of the seasonal sheep. PLoS ONE, v. 13, n. 5, p. 1-23, 2018.

LYTTLE, D. J. et al. Homologs of Vascular Endothelial Growth Factor Are Encoded by the Poxvirus Orf Virus. Journal of virology, v. 68, n. 1, p. 84-92, jan. 1994.

MAJUMDER, S.; ADVANI, A. VEGF and the Diabetic Kidney: More than Too Much of a Good Thing. Journal of diabetes and its complications, v. 31, n. 1, p. 273-279, jan. 2017.

MÄKINEN, T. et al. Inhibition of lymphangiogenesis with resulting lymphedema in transgenic mice expressing soluble VEGF receptor-3. Nature Medicine, v. 7, n. 2, p. 199-205, 2001.

MARIANI, T. C. et al. Immunohistochemical localization of VEGF and its receptors in the corpus luteum of the bitch during diestrus and anestrus. Theriogenology, v. 66, n. 6 , p. 1715-1720, 2006.

MATSUNAGA, Y. et al. VEGF-A and VEGF-F evoke distinct changes in vascular ultrastructure. Biochemical and Biophysical Research Communications, v. 379, n. $4, \quad$ p. 872-875, 2009. Disponível em: <http://dx.doi.org/10.1016/j.bbrc.2008.12.129>.

MAYBIN, J. A.; DUNCAN, W. C. The Human Corpus Luteum: Which Cells Have Progesterone Receptors? Reproduction (Cambridge, England), v. 128, n. 4, p. 423-431, out. 2004.

MAYHEW, T. M.; CHARNOCK-JONES, D. S.; KAUFMANN, P. Aspects of Human Fetoplacental Vasculogenesis and Angiogenesis. III. Changes in Complicated Pregnancies. Placenta, v. 25, n. 2, p. 127-139, 2004.

MAYNARD, S. E. et al. Excess placental soluble fms-like tyrosine kinase 1 (sFlt1) may contribute to endothelial dysfunction, hypertension, and proteinuria in preeclampsia. Journal of Clinical Investigation, v. 111, n. 5, p. 649-658, 2003.

MCFEE, R. M.; CUPP, A. S. Vascular Contributions to Early Ovarian Development: Potential Roles of VEGFA Isoforms. Reproduction, fertility, and development, v. 25, n. 2, p. 333-342, 2013. 
MCFEE, R. M.; ROZELL, T. G.; CUPP, A. S. The balance of proangiogenic and antiangiogenic VEGFA isoforms regulate follicle development. Cell and Tissue Research, v. 349, n. 3, p. 635-647, 2012.

MEYER, M. et al. A novel vascular endothelial growth factor encoded by Orf virus, VEGF-E, mediates angiogenesis via signalling through VEGFR-2 (KDR) but not VEGFR-1 (Flt-1) receptor tyrosine kinases. EMBO Journal, v. 18, n. 2, p. 363-374, 1999.

MÖLLER, B. et al. Expression of the Angiogenic Growth Factors VEGF, FGF-2, EGF and Their Receptors in Normal Human Endometrium during the Menstrual Cycle. Molecular human reproduction, v. 7, n. 1, p. 65-72, jan. 2001.

NADERPOOR, N. et al. Obesity and Polycystic Ovary Syndrome. Minerva endocrinologica, v. 40, n. 1, p. 37-51, mar. 2015.

NEUFELD, G. et al. Vascular Endothelial Growth Factor (VEGF) and Its Receptors. FASEB journal : official publication of the Federation of American Societies for Experimental Biology, v. 13, n. 1, p. 9-22, jan. 1999.

NISHIMOTO, H. et al. Gene Expression of Glucose Transporter (GLUT) 1, 3 and 4 in Bovine Follicle and Corpus Luteum. The Journal of endocrinology, v. 188, n. 1, p. 111-119, jan. 2006.

NISSEN, N. N. et al. Vascular endothelial growth factor mediates angiogenic activity during the proliferative phase of wound healing. American Journal of Pathology, v. 152, n. 6, p. 1445-1452, 1998.

NITTA, A. et al. Possible involvement of IFNT in lymphangiogenesis in the corpus luteum during the maternal recognition period in the cow. Reproduction, v. 142, n. 6 , p. 879-892, 2011.

NORMAN, R. J. et al. Polycystic ovary syndrome. Lancet, v. 370, n. 9588, p. 685697, 2007.

OGAWA, S. et al. A Novel Type of Vascular Endothelial Growth Factor, VEGF-E (NZ7 VEGF), Preferentially Utilizes KDR/Flk-1 Receptor and Carries a Potent Mitotic Activity without Heparin-Binding Domain. The Journal of biological chemistry, v. 273, n. 47, p. 31273-31282, nov. 1998.

$\mathrm{OH}$, S. J. et al. VEGF and VEGF-C: Specific induction of angiogenesis and lymphangiogenesis in the differentiated avian chorioallantoic membrane. Developmental Biology, v. 188, n. 1, p. 96-109, 1997.

OKKENS, A. C. et al. Influence of Hypophysectomy on the Lifespan of the Corpus Luteum in the Cyclic Dog. Journal of reproduction and fertility, v. 77, n. 1, p. 187192, maio 1986.

OKKENS, A. C. et al. Evidence for Prolactin as the Main Luteotrophic Factor in the Cyclic Dog. The veterinary quarterly, v. 12, n. 4, p. 193-201, out. 1990.

ONCLIN, K.; VERSTEGEN, J. P. Secretion Patterns of Plasma Prolactin and Progesterone in Pregnant Compared with Nonpregnant Dioestrous Beagle Bitches. Journal of reproduction and fertility. Supplement, v. 51, p. 203-208, 1997. 
PAAVONEN, K. et al. Novel Human Vascular Endothelial Growth Factor Genes VEGF-B and VEGF-C Localize to Chromosomes $11 q 13$ and 4q34, Respectively. Circulation, v. 93, n. 6, p. 1079-1082, mar. 1996.

PADAVALA, S. et al. An Imbalance Between Vascular Endothelial Growth Factor and Its Soluble Receptor in Placental Villous Explants of Intrauterine Growth-Restricted Pregnancies. The Journal of the Society for Gynecologic Investigation: JSGI, v. 13, n. 1, p. 40-47, 2006.

PALLET, N.; THERVET, E.; TIMSIT, M.-O. Angiogenic Response Following Renal Ischemia Reperfusion Injury: New Players. Progres en urologie: journal de l'Association francaise d'urologie et de la Societe francaise d'urologie, v. 24 Suppl 1, p. S20-5, jun. 2014.

PAPA, P. C.; HOFFMANN, B. The Corpus Luteum of the Dog: Source and Target of Steroid Hormones? Reproduction in domestic animals = Zuchthygiene, v. 46, n. 4, p. 750-756, ago. 2011.

PAPA, P. C.; KOWALEWSKI, M. P. Factors affecting the fate of the canine corpus luteum: Potential contributors to pregnancy and non-pregnancy. Theriogenology, $v$. 150, p. 339-346, 2020.

PAPA, P. de C. et al. Glucose Transporter 1 Expression Accompanies Hypoxia Sensing in the Cyclic Canine Corpus Luteum. Reproduction (Cambridge, England), v. 147, n. 1, p. 81-89, jan. 2014.

PARK, J. E. et al. Placenta Growth Factor. Potentiation of Vascular Endothelial Growth Factor Bioactivity, in Vitro and in Vivo, and High Affinity Binding to Flt-1 but Not to Flk-1/KDR. The Journal of biological chemistry, v. 269, n. 41, p. 2564625654, out. 1994.

PATEL, K. R. et al. VEGFA isoforms play a vital role in oral cancer progression. Tumor Biology, v. 36, n. 8, p. 6321-6332, 2015.

PEACH, C. J. et al. Molecular pharmacology of VEGF-A isoforms: Binding and signalling at VEGFR2. International Journal of Molecular Sciences, v. 19, n. 4, 2018.

POLTORAK, Z. et al. VEGF145, a Secreted Vascular Endothelial Growth Factor Isoform That Binds to Extracellular Matrix. The Journal of biological chemistry, v. 272, n. 11, p. 7151-7158, mar. 1997.

QIU, Y. et al. Ovarian VEGF165b expression regulates follicular development, corpus luteum function and fertility. Reproduction, v. 143, n. 4, p. 501-511, 2012.

RAPISARDA, A.; MELILLO, G. Role of the VEGF/VEGFR Axis in Cancer Biology and Therapy. Advances in cancer research, v. 114, p. 237-267, 2012.

REN, Q. et al. Vascular Endothelial Growth Factor Expression Up-Regulated by Endometrial Ischemia in Secretory Phase Plays an Important Role in Endometriosis. Fertility and sterility, v. 95, n. 8, p. 2687-2689, jun. 2011.

RENNEL, E. S. et al. VEGF121b, a new member of the VEGFxxxb family of VEGF-A splice isoforms, inhibits neovascularisation and tumour growth in vivo. British Journal of Cancer, v. 101, n. 7, p. 1183-1193, 2009. 
ROBINSON, C. J.; STRINGER, S. E. The splice variants of vascular endothelial growth factor (VEGF) and their receptors. Journal of Cell Science, v. 114, n. 5, p. 853-865, 2001.

ROBINSON, R. S. et al. Angiogenesis and Vascular Function in the Ovary. Reproduction (Cambridge, England), v. 138, n. 6, p. 869-881, dez. 2009.

ROY, H.; BHARDWAJ, S.; YLÄ-HERTTUALA, S. Biology of Vascular Endothelial Growth Factors. FEBS letters, v. 580, n. 12, p. 2879-2887, maio 2006.

SARGENT, K. M. et al. Loss of vascular endothelial growth factor a (VEGFA) isoforms in granulosa cells using pDmrt-1-cre or Amhr2-Cre reduces fertility by arresting follicular development and by reducing litter size in female mice. PLoS ONE, v. 10, n. 2, p. 1-20, 2015.

SARGENT, K. M. et al. VEGFA splicing : divergent isoforms regulate spermatogonial stem cell maintenance. p. 31-45, 2016.

SCHAMS, D.; BERISHA, B. Regulation of Corpus Luteum Function in Cattle--an Overview. Reproduction in domestic animals = Zuchthygiene, v. 39, n. 4, p. 241251, ago. 2004.

SCHEIDEGGER, P. et al. Vascular Endothelial Growth Factor (VEGF) and Its Receptors in Tumor-Bearing Dogs. Biological chemistry, v. 380, n. 12, p. 14491454, dez. 1999.

SECKER, G. A.; HARVEY, N. L. VEGFR Signaling During Lymphatic Vascular Development: From Progenitor Cells to Functional Vessels An Overview of Lymphatic Vascular. p. 323-331, 2015.

SENGER, D. R. et al. Tumor Cells Secrete a Vascular Permeability Factor That Promotes Accumulation of Ascites Fluid. Science (New York, N.Y.), v. 219, n. 4587, p. 983-985, fev. 1983.

SHARKEY, A. M. et al. Vascular Endothelial Growth Factor Expression in Human Endometrium Is Regulated by Hypoxia. The Journal of clinical endocrinology and metabolism, v. 85, n. 1, p. 402-409, jan. 2000.

SHIBATA, Y. et al. Balance between Angiogenic and Anti-Angiogenic Isoforms of VEGF-A Is Associated with the Complexity and Severity of Coronary Artery Disease. Clinica chimica acta; international journal of clinical chemistry, v. 478, p. 114119, mar. 2018.

SHIBUYA, M. et al. Nucleotide Sequence and Expression of a Novel Human Receptor-Type Tyrosine Kinase Gene (Flt) Closely Related to the Fms Family. Oncogene, v. 5, n. 4, p. 519-524, abr. 1990.

SHIBUYA, M. Structure and function of VEGF/VEGF-receptor system involved in angiogenesis. Cell Structure and Function, v. 26, n. 1, p. 25-35, 2001.

SHIBUYA, M. Vascular endothelial growth factor receptor-2: Its unique signaling and specific ligand, VEGF-E. Cancer science, v. 52, n. 9, p. 185-197, 2003.

SHIBUYA, M. Vascular Endothelial Growth Factor (VEGF) and Its Receptor (VEGFR) Signaling in Angiogenesis: A Crucial Target for Anti- and Pro-Angiogenic Therapies. 
Genes \& Cancer, v. 2, n. 12, p. 1097-1105, 2011.

SHIBUYA, M. VEGFR and Type-V RTK Activation and Signaling. Cold Spring Harbor perspectives in biology, v. 5, n. 10, p. a009092, out. 2013.

SHIMA, D. T. et al. The Mouse Gene for Vascular Endothelial Growth Factor. Genomic Structure, Definition of the Transcriptional Unit, and Characterization of Transcriptional and Post-Transcriptional Regulatory Sequences. The Journal of biological chemistry, v. 271, n. 7, p. 3877-3883, fev. 1996.

SHIMIZU, T. et al. Follicular microvasculature and angiogenic factors in the ovaries of domestic animals. Journal of Reproduction and Development, v. 49, n. 3, p. 181192, 2003.

SIA, D. et al. VEGF Signaling in Cancer Treatment. Current pharmaceutical design, v. 20, n. 17, p. 2834-2842, 2014.

SOLDI, R. et al. Role of Alphavbeta3 Integrin in the Activation of Vascular Endothelial Growth Factor Receptor-2. The EMBO journal, v. 18, n. 4, p. 882-892, 15 fev. 1999.

SOUSA, L. M. M. C. et al. Vascular endothelial growth factor A (VEGFA) modulates bovine placenta steroidogenesis in vitro. Placenta, v. 33, n. 10, p. 788-794, 2012.

SOUSA, L. M. M. D. C. et al. Is the canine corpus luteum an insulin-sensitive tissue? Journal of Endocrinology, v. 231, n. 3, p. 223-233, 2016.

STEVENS, M.; OLTEAN, S. Modulation of Receptor Tyrosine Kinase Activity through Alternative Splicing of Ligands and Receptors in the VEGF-A/VEGFR Axis. Cells, v. 8, n. 4, p. 288, 2019.

SUN, Y. et al. Association between vascular endothelial growth factor polymorphism and recurrent pregnancy loss: A systematic review and meta-analysis. European Journal of Obstetrics \& Gynecology and Reproductive Biology, v. 211, p. 169176, 2017.

SUTO, K. et al. Crystal structures of novel Vascular Endothelial Growth Factors (VEGF) from snake venoms: Insight into selective VEGF binding to kinase insert domain-containing receptor but not to fms-like tyrosine kinase-1. Journal of Biological Chemistry, v. 280, n. 3, p. 2126-2131, 2005.

SWIFT, M. R.; WEINSTEIN, B. M. Arterial-venous specification during development. Circulation Research, v. 104, n. 5, p. 576-588, 2009.

TAMMELA, T. et al. The biology of vascular endothelial growth factors. Cardiovascular Research, v. 65, n. 3, p. 550-563, 2005.

TAVARES PEREIRA, M. et al. Prostaglandin-Mediated Effects in Early Canine Corpus Luteum: In Vivo Effects on Vascular and Immune Factors. Reproductive biology, v. 19, n. 1, p. 100-111, mar. 2019.

TERMAN, B. I. et al. Identification of the KDR Tyrosine Kinase as a Receptor for Vascular Endothelial Cell Growth Factor. Biochemical and biophysical research communications, v. 187, n. 3, p. 1579-1586, set. 1992.

TISCHER, E. et al. The Human Gene for Vascular Endothelial Growth Factor. 
Multiple Protein Forms Are Encoded through Alternative Exon Splicing. The Journal of biological chemistry, v. 266, n. 18, p. 11947-11954, jun. 1991.

TREMAINE, T. D.; FOULADI-NASHTA, A. A. Immunolocalization of Angiogenic Growth Factors in the Ovine Uterus during the Oestrus Cycle and in Response to Steroids. Reproduction in domestic animals $=$ Zuchthygiene, v. 53, n. 3, p. 667679, jun. 2018.

VANKLOMPENBERG, M. K. et al. Regulation and Localization of Vascular Endothelial Growth Factor within the Mammary Glands during the Transition from Late Gestation to Lactation. Domestic animal endocrinology, v. 54, p. 37-47, jan. 2016.

VAREY, A. H. R. et al. VEGF165b, an antiangiogenic VEGF-A isoform, binds and inhibits bevacizumab treatment in experimental colorectal carcinoma: Balance of proand antiangiogenic VEGF-A isoforms has implications for therapy. British Journal of Cancer, v. 98, n. 8, p. 1366-1379, 2008.

VEIGA, G. A. L. et al. Cystic Endometrial Hyperplasia-Pyometra Syndrome in Bitches: Identification of Hemodynamic, Inflammatory, and Cell Proliferation Changes. Biology of reproduction, v. 96, n. 1, p. 58-69, jan. 2017.

VEIKKOLA, T. et al. Regulation of angiogenesis via vascular endothelial growth factor receptors. Cancer Research, v. 60, n. 2, p. 203-212, 2000.

VIVAR, O. I. et al. Estrogen Receptor Beta Binds to and Regulates Three Distinct Classes of Target Genes. The Journal of biological chemistry, v. 285, n. 29, p. 22059-22066, jul. 2010.

WANG, S. et al. Transplantation of Vascular Endothelial Growth Factor 165-transfected Endothelial Progenitor Cells for the Treatment of Limb Ischemia. Molecular medicine reports, v. 12, n. 4, p. 4967-4974, out. 2015.

WHITTINGTON, C. M. et al. Expression of VEGF (111) and Other VEGF-A Variants in the Rat Uterus Is Correlated with Stage of Pregnancy. Journal of comparative physiology. B, Biochemical, systemic, and environmental physiology, v. 187, n. 2, p. 353-360, fev. 2017.

WISE, L. M. et al. Vascular endothelial growth factor (VEGF)-like protein from orf virus NZ2 binds to VEGFR2 and neuropilin-1. Proceedings of the National Academy of Sciences of the United States of America, v. 96, n. 6, p. 3071-3076, 1999.

WITMER, A. N. et al. Expression of Vascular Endothelial Growth Factor Receptors 1, 2 , and 3 in Quiescent Endothelia. The journal of histochemistry and cytochemistry: official journal of the Histochemistry Society, v. 50, n. 6, p. 767-777, jun. 2002.

WOOLARD, J. et al. VEGF165b, an Inhibitory Vascular Endothelial Growth Factor Splice Variant: Mechanism of Action, in Vivo Effect on Angiogenesis and Endogenous Protein Expression. Cancer research, v. 64, n. 21, p. 7822-7835, nov. 2004.

YAMAZAKI, Y. et al. Identification of the heparin-binding region of snake venom 
vascular endothelial growth factor (VEGF-F) and its blocking of VEGF-A 165. Biochemistry, v. 44, n. 24, p. 8858-8864, 2005.

YERLIKAYA, G. et al. Comprehensive Study of Angiogenic Factors in Women with Endometriosis Compared to Women without Endometriosis. European journal of obstetrics, gynecology, and reproductive biology, v. 204, p. 88-98, set. 2016.

ZACHARY, I.; GLIKI, G. Signaling transduction mechanisms mediating biological actions of the vascular endothelial growth factor family. Cardiovascular Research, v. 49, n. 3, p. 568-581, 2001.

ZHANG, L. et al. $17 \beta$-Estradiol promotes vascular endothelial growth factor expression via the $\mathrm{Wnt} / \beta$-catenin pathway during the pathogenesis of endometriosis. Molecular Human Reproduction, v. 22, n. 7, p. 526-535, 2016.

ZUGAIB, R. Perfil transcricional da infecção crônica pelo vírus da Hepatite C ( VHC ) por sequenciamento de nova geração. 2017. 
APÊNDICE - PROPOSTA DE VALIDAÇÃO DE SEQUÊNCIAS HOMÓLOGAS DE VEGFA CANINO AO VEGFA HUMANO 


\section{DELINEAMENTO}

Objetivou-se determinar os prováveis exons que compõem as isoformas do VEGFA que podem estar presentes no corpo lúteo canino, com base em todas as pesquisas e levantamentos realizados.

Com o auxílio de ferramentas de informática e bioinformática foi realizado um levantamento de publicações e acesso a bases de pesquisa, com intuito de estudar o VEGFA, e quais exons compõem suas isoformas em humanos.

\section{COMPUTADOR E PROGRAMAS}

O computador utilizado para a pesquisa em bancos de dados foi o Samsung rv411, com pacote office 2010 e com acesso à internet Wi-Fi.

Para alinhamento das sequências de isoformas foi utilizado o programa ClustalX2.

\section{LEVANTAMENTO DAS INFORMAÇÕES E ESCOLHA DOS ARTIGOS}

A busca integralizada de artigos relevantes ao estudo do tema foi efetuada utilizando bancos de dados disponíveis, incluindo as bases de dados eletrônicas, sendo a principal base o PubMed.

As palavras-chave escolhidas foram obtidas sob orientação do site "Medical Subject Headings" (MeSH) e selecionadas de acordo com os estudos realizados pelo grupo de pesquisa do Laboratório de Estudos Morfofuncionais e Endocrinologia - LEME, da Faculdade de Medicina Veterinária e Zootecnia da Universidade de São Paulo, no qual estou inserida, bem como por escolha conjunta com a orientadora.

As palavras que direcionaram a pesquisa foram: VEGFA, VEGFA isoforms, isoformas do VEGFA, angiogênese, corpo lúteo, ciclo estral, VEGFA dogs, Canis familiaris, VEGFA dog corpus luteum, VEGFA insulin, VEGFA 121, VEGFA 145, VEGFA 148, VEGFA 189, VEGFA 165, VEGFA 206, VEGFA câncer, VEGFA 2018, VEGFA 2019, VEGFA review, angiogênese.

Esta busca resultou em uma coletânea de mais de 15 mil artigos relacionados às palavras chaves, destes uma média de 500 artigos foram selecionados após leitura e constatação da existência de relação com o tema no que se refere à 
angiogênese, o VEGFA, o VEGFA humano, suas isoformas e a relação com o ciclo estral e o corpo lúteo. Destes, os mais correlacionados ao tema foram escolhidos para embasar o presente estudo.

\section{SELEÇÃO DOS EXONS QUE CONSTITUEM O VEGFA HUMANO}

A busca das sequências dos exons de 1 a 8 que constituem o VEGFA humano foi realizada com o seguinte procedimento:

- Acesso ao site do PubMed, Selecionada a opção Gene, digitar VEGFA human, dentre as opções, clicar em Genome (link para acesso https://preview.ncbi.nlm.nih.gov/gene/7422);

- No item 'Genomic regions, transcripts, and products', foi selecionado em 'Genome Sequence' a opção: RefSeqGene;

- Apareceram os exons com as sequências;

- Com o mouse em cima, clicou-se em Fasta View;

- Aberto o arquivo Fasta, opção em cima selecionada: Send to - File - Create File, salvo em txt o nome do arquivo.

- Com essa sequência dos exons, foi descoberta cada região que representa cada exon, de acordo com Harris et al. (2012).

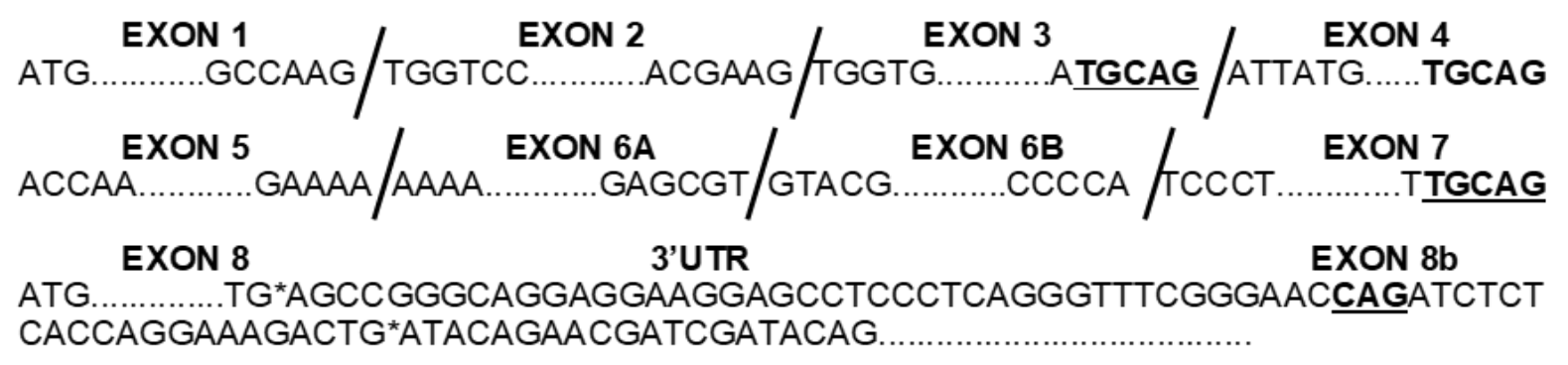

\section{Exon 1 humano}

>NG_008732.1:4994-6097 Homo sapiens vascular endothelial growth factor A (VEGFA), RefSeqGene on chromosome 6 
TTCTCGTTTAAATTATTTTTGCTTGCCATTCCCCACTTGAATCGGGCCGACGGCTTGGGGAGATTGC TCTACTTCCCCAAATCACTGTGGATTTTGGAAACCAGCAGAAAGAGGAAAGAGGTAGCAAGAGCTCCA GAGAGAAGTCGAGGAAGA GAGAGACGGGGTCAGAGAGA GCGCGCGGGCGTGCGAGCAGCGAAAGCGAC AGGGGCAAAGTGAGTGACCTGCTTTTGGGGGTGACCGCCGGAGCGCGGCGTGAGCCCTCCCCCTTGGG ATCCCGCAGCTGACCAGTCGCGCTGACGGACAGACAGACAGACACCGCCCCCAGCCCCAGCTACCACC TCCTCCCCGGCCGGCGGCGGACAGTGGACGCGGCGGCGAGCCGCGGGCAGGGGCCGGAGCCCGCGCCC GGAGGCGGGGTGGAGGGGGTCGGGGCTCGCGGCGTCGCACTGAAACTTTTCGTCCAACTTCTGGGCTG TTCTCGCTTCGGAGGAGCCGTGGTCCGCGCGGGGGAAGCCGAGCCGAGCGGAGCCGCGAGAAGTGCTA GCTCGGGCCGGGAGGAGCCGCAGCCGGAGGAGGGGGAGGAGGAAGAAGAGAAGGAAGAGGAGAGGGGG CCGCAGTGGCGACTCGGCGCTCGGAAGCCGGGCTCATGGACGGGTGAGGCGGCGGTGTGCGCAGACAG TGCTCCAGCCGCGCGCGCTCCCCAGGCCCTGGCCCGGGCCTCGGGCCGGGGAGGAAGAGTAGCTCGCC GAGGCGCCGAGGAGAGCGGGCCGCCCCACAGCCCGAGCCGGAGAGGGAGCGCGAGCCGCGCCGGCCCC GGTCGGGCCTCCGAAACCATGAACTTTCTGCTGTCTTGGGTGCATTGGAGCCTTGCCTTGCTGCTCTA CCTCCACCATGCCAAG

\section{Exon 2 humano}

$>$ NG_008732.1:9126-9177 Homo sapiens vascular endothelial growth factor A (VEGFA), RefSeqGene on chromosome 6

TGGTCCCAGGCTGCACCCATGGCAGAAGGAGGAGGGCAGAATCATCACGAAG

\section{Exon 3 humano}

$>$ NG_008732.1:12254-12450 Homo sapiens vascular endothelial growth factor A (VEGFA), RefSeqGene on chromosome 6

TGGTGAAGTTCATGGATGTCTATCAGCGCAGCTACTGCCATCCAATCGAGACCCTGGTGGACATCTTC CAGGAGTACCCTGATGAGATCGAGTACATCTTCAAGCCATCCTGTGTGCCCCT GATGCGATGCGGGGG

CTGCTGCAATGACGAGGGCCTGGAGTGTGTGCCCACTGAGGAGTCCAACATCACCATGCAG

\section{Exon 4 humano}

$>$ NG_008732.1:13245-13321 Homo sapiens vascular endothelial growth factor A (VEGFA), RefSeqGene on chromosome 6 


\section{Exon 5 humano}

>NG_008732.1:13674-13703 Homo sapiens vascular endothelial growth factor A (VEGFA), RefSeqGene on chromosome 6

ACCAAAGAAAGATAGAGCAAGACAAGAAAA

\section{Exon 6 humano (exon 6A e exon 6B)}

$>$ NG_008732.1:4994-21272 Homo sapiens vascular endothelial growth factor A (VEGFA), RefSeqGene on chromosome 6

TCGCGGAGGCTTGGGGCAGCCGGGTAGC TCGGAGGTCGTGGCGCTGGGGGCTAGCACCAGCGCTCTGT CGGGAGGCGCAGCGGTTAGGTGGACCGGTCAGCGGACTCACCGGCCAGGGCGCTCGGTGCTGGAATTT GATATTCATTGATCCGGGTTTTATCCCTCTTCTTTTTTCTTAAACATTTTTTTTTAAAACTGTATTGT TTCTCGTTTTAATTTATTTTTGCTTGCCATTCCCCACTTGAATCGGGCCGACGGCTTGGGGAGATTGC TCTACTTCCCCAAATCACTGTGGATTTTGGAAACCAGCAGAAAGAGGAAAGAGGTAGCAAGAGCTCCA GAGAGAAGTCGAGGAAGA GAGAGACGGGGTCAGAGAGAGCGCGCGGGCGTGCGAGCAGCGAAAGCGAC AGGGGCAAAGTGAGTGACCTGCTTTTGGGGGTGACCGCCGGAGCGCGGCGTGAGCCCTCCCCCTTGGG ATCCCGCAGCTGACCAGTCGCGCTGACGGACAGACAGACAGACACCGCCCCCAGCCCCAGCTACCACC TCCTCCCCGGCCGGCGGCGGACAGTGGACGCGGCGGCGAGCCGCGGGCAGGGGCCGGAGCCCGCGCCC GGAGGCGGGGTGGAGGGGGTCGGGGCTCGCGGCGTCGCACTGAAACTTTTCGTCCAACTTCTGGGCTG TTCTCGCTTCGGAGGAGCCGTGGTCCGCGCGGGGGAAGCCGAGCCGAGCGGAGCCGCGAGAAGTGCTA GCTCGGGCCGGGAGGAGCCGCAGCCGGAGGAGGGGGAGGAGGAAGAAGAGAAGGAAGAGGAGAGGGGG CCGCAGTGGCGACTCGGCGCTCGGAAGCCGGGCTCATGGACGGGTGAGGCGGCGGTGTGCGCAGACAG TGCTCCAGCCGCGCGCGCTCCCCAGGCCCTGGCCCGGGCCTCGGGCCGGGGAGGAAGAGTAGC TCGCC GAGGCGCCGAGGAGAGCGGGCCGCCCCACAGCCCGAGCCGGAGAGGGAGCGCGAGCCGCGCCGGCCCC GGTCGGGCCTCCGAAACCATGAACTTTCTGCTGTCTTGGGTGCATTGGAGCCTTGCCTTGCTGCTCTA CCTCCACCATGCCAAGGTAAGCGGTCGTGCCCTGCTGGCGCCGCGGGCCGCTGCGAGCGCCTCTCCCG GCTGGGGACGTGCGTGCGAGCGCGCGCGTGGGGGCTCCGTGCCCCACGCGGGTCCATGGGCACCAGGC GTGCGGCGTCCCCCTCTGTCGTCTTAGGTGCAGGGGGAGGGGGCGCGCGCGCTAGGTGGGAGGGTACC CGGAGAGAGGCTCACCGCCCACGCGGGCCCTGCCCACCCACCGGAGTCACCGCACGTACGATCTGGGC CGACCAGCCGAGGGCGGGAGCCGGAGGAGGAGGCCGAGGGGGC TGGGCTTGCGTTGCCGCTGCCGGCT GAAGTTTGCTCCCGGCCGCTGGTCCCGGACGAACTGGAAGTCTGAGCAGCGGGGGCGGGAGCCAGAGA CCAGTGGGCAGGGGGTGCTCGGACCTTGGACCGCGGGA GGGCAGAGAGCGTGGAGGGGGCAGGGCGCA GGAGGGAGAGGGGGCTTGCTGTCACTGCCACTCGGTCTCTTCAGCCCTCGCCGCGAGTTTGGGAAAAG TTTTGGGGTGGATTGCTGCGGGGACCCCCCCTCCCTGCTGGGCCACCTGCGCCGCGCCAACCCCGCCC GTCCCCGCTCGCGTCCCGCTCGGTGCCCGCCCTCCCCCGCCCGGCCGGGTGCGCGCGGCGCGGAGCCG ATTACATCAGCCCGGGCCTGGCCGGCCGCGTGTTCCCGGAGCCTCGGCTGCCCGAATGGGGAGCCCAG 
AGTGGCGAGCGGCACCCCTCCCCCCGCCAGCCCTCCGCGGGAAGGTGACCTCTCGAGGTAGCCCCAGC CCGGGGATCCAGAGAACCATCCCTACCCCTTCCTACTGTCTCCAGACCCTACCTCTGCCCAGTGCTAG GAGGAATTTCCTGACGCCCCTTCTCTTCACCCATTTCCTTTTTAGCCTGGAGAGAAGCCCCTGTCACC CCGCTTATTTTCATTTCTCTCTGCGGAGAAGATCCATCTAACCCCTTTCTGGCCCCAGAGTCCAGGGA AAGGATGATCACTGTCAGAAGTCGTGGCGCGGGAGCCCACTGGGCGCTTTGTCACATTCCACCGAAAG TCCCGACTTGGTGACAGTGTGCTTCCCTTCCCTCGCCAACAGTTCCGAGTGAGCTGTGCTTTAGCTCT CGTGGGGGTGGGTCAAGGGAGGATTTGAAGAGTCATTGCCCCACTTTACCCTTTTGGAGAAATGGCTT GAAATTTGCTGTGACACGGGCAGCATGGGAATAGTCCTTCCTGAACCCTGGAAAGGAGCTCCTGCCAG CCTTGCACACACTTTGTCCTGGTGAAAGGCAGCCCTGGAGCAGGTGTTTTTTTGGAACTCCAAACCTG CCCACCCAACTTGCTTCTGAAAGGGACTCTAAAGGGTCCCTTTCCGCTCCTCTCTGACGCCTTCCCTC AGCCAGAATTCCCTTGGAGAGGAGGCAAGAGGAAAGCCATGGACAGGGGTCGCTGCTAACACCGCAAG TTCCTCAGACCCTGGCACAAAGGCCTTGGCTACAGGCCTCCAAGTAGGGAGGAGGGGGAGGAGTGGCT GCCTGGCCACAGTGTGACCTTCAGAGGCCCCCAGAGAAGGACACCTGGCCCCTGCCTGCCTAGAACCG CCCCTCCTGTGCTCCCTGGCCTTGGAAGGGGTATGAAATTTCCGTCCCCTTTCCTCCTTGGGGCCCAG GAGGAGTGGAGGGTCCCGGGAGAATATTGTCAGGGGGAAGGCAGGGGGTGTCATGGGAATGGGTGAGG GGGCTGAGGTGCAGAATCCAGGGGGTCCCTGCAGGAGCCGCAGTGGTAAGCTGTCCAGCTGGAAGCCT GGTAACTGTTGTTTTCTCTTGAGAGGGGCTTCCTGTGACCTTGGCTGTCTCTGGGAGCAGGGCTGGGG TACCTGAGTGGGGTGCATTTGGGGTGTGTGGGAAGGAGAGGGAAAGAAAGATGGACAGTGGGACTCTC CCCTAGCAGGGTCTGGTGTTCCGTAGGCTAGAGTGCCCCTCTGCTCTGCGAGTGCTGGGCGGGAGGGG AGTTGGTGAGAGCTGGAGACCCCCAGGAAGGGCTGGCAGAAGCCTTTCCTTTTGGGTGCTGTCAGGTC CGCATGTCTTGGCGTGTTGACCTTCACAGCTTCTGGCGAGGGGAGGAATGATCTGATGCGGGTGGGGA GGGTTAGAGGAGGCCTCAGGCCTAAGGTGGTGCAGGGGGCCCCCTAGGGGCTGGGCAGTGCCAAGGCA TAAAAGCCTTCCCTGGTCCCTGGTGGCATTTGAAGGTGCCCAGGTGAGAGGGGCTTGGCACCTCCTCA CCCTGGGAGGGAGAAGAAACCAGGGAACAGGTAGGAGTGGGAGACAGGTGAGGCTTTGGAAATCTATT GAGGCTCTGGAGAGATTTGTGTAGAGAGGAAAATGTGGTTCTCCCCCAGGGTCTCCTCCTGGGTTTTT ACCCTCTAAGCAACCTGTGGGCATGCTGGGTTATTCCTAAGGACTAGAAGAGCTTGGATGGGGGAGGG TGGTTGGTGCCCTTCGGTCCTCGGCACCCCCCTCCGTCTCCAACACCAGCTCACCCTGGTATTTGTCA TGTCAGCAGGAGAAGGTCACCATGTTGTTTTTCTCGCCCCTAGTCCTTCCTTCCTGCCCCAGTCCAAA TTTGTCCTCCTATTTGACCTTAATACTTACCATGGCTTTGGACCAGGGAACTAGGGGGATAGTGAGAG CAGGGAGAGGGAAGTGTGGGGAAGGTACAGGGGACCTCGACAGTGAAGCATTCTGGGGTTTTCCTCCT GCATTTCGAGCTCCCCAGCCCCCAACATCTGGTTAGTCTTTAACTTCCTCGGGTTCATAACCATAGCA GTCCAGGA GTGGTGGGCATATTCTGTGCCCGTGGGGACCCCCGGTTGTGTCCTGTTCGACTCAGAAGA CTTGGAGAAGCCAGAGGCTGTTGGTGGGAGGGAAGTGAGGAGGGAGGAGGGGCTGGGTGGCTGGGCCT GTGCACCCCAGCCCCTGCCCATGCCCATGCCTTGCTCTCTTTCTGTCCTCAGTGGTCCCAGGCTGCAC CCATGGCAGAAGGAGGAGGGCAGAATCATCACGAAGGTGAGTCCCCCTGGCTGTTGGATGGGGTTCCC TGTCCTCTCAGGGGATGGGTGGATGGCCTAATTCCTTTTTCTTCAGAACTGTGGGGAGGAAGGGGAAG GGGCACAGGAATATAAGGATCAAGAAAGAAAGAGCTGGGCACCACGAGGTTCACCCTCAGTTTCGTGA 
GGACTCTCCGCTGTTCAGGTCTCTGCTAGAAGTAGGACTTGTTGCCTTTTTCTTCTGCTCTTTCCAGT AAAATTTTATTTGGAGAAGGAGTCGTGCGCACAGAGCAGGAAGACAGTGTTCAGGGATCCTAGGTGTT GGGGGAAGTGTCCCTTGTTTCCCCTAGCTCCCAGGGGAGAGTGGACATTTAGTGTCATTTCCTATATA GACATGTCCCATTTGTGGGAACTGTGACCCTTCCTGTGTGAGCTGGAGGCACAGAGGGCTCAGCCTAA TGGGATCTCTCCTCCCTTCCCTGGTTTGCATTCCTTTGGGGGTGGAGAAAACCCCATTTGACTATGTT CGGGTGCTGTGAACTTCCCTCCCAGGCCAGCAGAGGGCTGGCTGTAGCTCCCAGGCGCCCCGCCCCCC TGCCCAACCCCGAGTCCGCCTGCCTTTTGTTCCGTTGTGGTTTGGATCCTCCCATTTCTCTGGGGACA CCCTGGCTCTCCCCACCACTGACTGTGGCCTGTGCTCTCCACCTCTGGGGAGGGAAGGCCCTGGGGTC TTCCTTCCCGCGAGTTTCCCTGACCTAAATCTGGCGTGGCTGGGTAGTGGCCAGCAGTGGTGATGCCC AGCCTGTTCTGCCTCCTCCTTCCCCACCCCAGGAGCCCTTTCCTTGGCCTAGGACCTGGCTTCTCAGC CACTGACCGGCCCCCTGCTTCCAGTGCGCCACTTACCCCTTCCAGCTTCCCAGTGGTCTCTGGTCTGG GAGAGGCAGGACAAAGGTCTTTGTTTGCTGGAGAAAAGGTTGTCTGCGATAAATAAGGAAAACCACGA AAGCCTGGTTGTTGGAGTGTACGTGTGTGCTCCCCCAGGCAGTGGAGGCCAGCCCTCCTTGGAGGGGC GGCTGCCTGATGAAGGATGCGGGTGAGGTTCCCCGCCTCCACCTCCCATGGGACTTGGGGATTCATTC CAAGGGGAAGCTTTTTGGGGGAATTCCTACCCCAGGTCTTTTTACCCTCAGTTACCAACCCCTTGCCC AGGCCAGACCTTCCTGCTATCCCCTCCTGGGCCACAAGCCTGGCCCTCCTCTGTCCCAATTGTGATGA AGGGGCAGTTCAAAACTTCTTGATTAGTCATCTTCTCCCCTATCGACTTGGCTTTAAAAAATGACCTT TTCAGACTTCTAGTCTCGTTCACTCTTTTTGATGATGCTTTGCCGTAACCCTTCGTGGGTAGAGAAGG ATtCTGTGCCCATTGGTGGTCTGGATAAAAGAAATAGA GACCTCACAGGAAGCAGTGGACTGGCCTGT TTCCCCACTGTTCTTTCTGTTTTCACACCTGTGGCCTTCTCCCCACCTTCTTCCCAATCAACCTATTG TGTACATAGCCCCCCTCATTGTCCTTTATTCTTCTGGAAAGCAGACCTTGGAGGGAGGAGTGAGGGGG AGGCTCAGCTGTGGTCTCTGGGGGGTGGGGGTTGGGAGCTGGGGTGGAAGTCCACGAAGCATACACTT AAGATGCTTTGGTGAAGTTCTAAACTTCATATTACCCAGGCTGAAAAAAGAGCACTTGTTCCTAGGGC TGGAAATGGAAGCCAAAACACCACCTTTTTCAGCCTGTTTCAGCATCTTTAGAGATCAGCCCAACCCA CTTACACAGTTGAGCAGAGTTGGAGGCCTAGAGAGGGGAGGGACTGGCCCAAGGTCATACCAACTCAT GGCCAGAGCCTGGGCCTCCTCACTGGCCAGGTGTTATTTCTTCCCTCTGGGTAGGGAACCTATTTCAG GGACAGGATTGCTATGTGGTAGTGGTGGTGGGGTGCGATAGGCGTGGCAGGCTGGGCCACAATTTGGA GTAGTCATGCCAGAGTCCTGCATTTATTTATTCTCAAGGGCCCCGCCTCTGTGGCCCAGAATTACCCC TTCATGCTCCAGTGCACCCCAGGCTTCGTGGCCAGCCTGGGAAACTGTCTCTACCCTGGTCTCCCTTC AGATCAGCTTCTAGAAATGTTTCGTGGCTACAGTGGCAGCACTGTTTTTTCCATGATGCAAGCAGTTT GCCCTCTTGGGCGGGGTTATCAGTGGCTGGCAGGGCTGGCACAGCGTGTCCGCCCACTGCCACCTGTG GGTTCCAGGAGGGCCCAGCCCCTGTGCTGATGCCCACCACCTTCTCAGCTCATGTCTGGGGAAGAGGA CTGGCAGGGGGAAAGGTGCCTCCTCCTGAAAGGTGCCTCCTCTGTTTTTGCCTAATATAGGCTTGGGA ACACTTTGATGTCAGCTAATTCTGACTCCTTTACTTACTAGCTGTGCGGCCTTGGGGCAACTTACTTA GCCTCTTTGAGCCTCCTGTTCCCCATCTGTAAAATGGAATCTCAATAGTGTCTAATAGTACCATGTGG AGAAACTTGTGTGAAATGATAGCTGTGGACTACTGTACACAGTACTCAGGATGTAGTAAGTGCTCAAT AAACAGCTGTTGGTATGGTTGACGTTATGGTAGTGGTTGTGGGGAGGACGTAGGAAACTGGAGACTAG 
CTTGGCAAAGCTGGCTCTTCCTCCTTTTAGGGAAAGCTTAGAGCATCCCCATGGGGTATACCCATACT CAGACTGTCCTCTGGCATCGAGGTTGGCCCAGGATTCAGTTCAGCTGTCACAGTGAGGTGGCGGGATC AGATGTGGCAGGCCATGTCCCTTGGAACTTGAGTACATCGTGTGATCTCTGGAATGAAAACAGGCCTT CACCAGTGTTGATGGTGGAAAGCTTAGGGAAGTGCTTCAAACACAGTAGGAGGGACTTACGTTAGATT TTGGAAGGACTTGCCTGATTCGGAAGCTCCAAAGAGTGGCATTACAGAGCTGGGTGGAGAGAGGGGCT AGCCATCTTTTGTGTCGCCCACCGGGCTCATGTGTCATCGCCTCTCATGCAGTGGTGAAGTTCATGGA TGTCTATCAGCGCAGCTACTGCCATCCAATCGAGACCCTGGTGGACATCTTCCAGGAGTACCCTGATG AGATCGAGTACATCTTCAAGCCATCCTGTGTGCCCCTGATGCGATGCGGGGGCTGCTGCAATGACGAG GGCCTGGAGTGTGTGCCCACTGAGGAGTCCAACATCACCATGCAGGTGGGCATCTTTGGGAAGTGGGG CAAGGGGGGGATAGGGAGGGGGGTAACACTTTGGGAACAGGTGGTCCCAGGTCGTTTCCTGGCTAGAT TTGCCTTGTCTGGCTCCTGCCCCTGAGTTGCACAGGGGAGGTATGGTGGGGTCTTGCCTTCTGTGGAG AAGATGCTTCATTCCCAGCCCAGGTTCCCAGCAAGCCCCAACCATCTCCTTCTCCCTGATGGTTGCCC ATGGGCTCAGGAGGGGACAGATGGATGCCTGTGTCAGGAGCCCCTCTCTCCCTCTCTTGGAGAGAGTC CTGAGTGCCCCCCCTTCTTGGGGGCTTTGTTTGGGAAGCTGGATGAGCCTGGTCCATGGAGAGTTTAA AAAGTCTTTTGGTGTTACCTGGTAATGGGGCACATCTCAGCCCAGATAGGGTGGGAGGGAGCTGTGAA ACACAGGGAGGGGGTTGCTTTCGGGTATCTACTAGGAGTCAGGGTGAAGCCTAGAGAGGATGAAAGAA GGGGAGGGGATGGGGAGTGGTAAGAACCTAGGATTTGAATTCCCAGCCTGGCCAACCCTTGCAGCCAT GTCTTGGCCTCAAGTGGAACAAGGGCTCCTTGAGGCCAGCAGGGTTGGGGGAGTTGGGGTGGGCCTGA GCCTCTTTCCTGCTAGAGCTCTTGGTCCTCCCTGCCTCCACCACCCATCCCTGCTCTGCAGAACCCCT GGGTGCTGAGTGGCAGGAGCCCCAGGGTTGTCCCATCTGGGTATGGCTGGCTGGGTCACTAACCTCTG TGATCTGCTTCCTTCCTTTCCAGATTATGCGGATCAAACCTCACCAAGGCCAGCACATAGGAGAGATG AGCTTCCTACAGCACAACAAATGTGAATGCAGGTGAGGATGTAGTCACGGATTCATTATCAGCAAGTG GCTGCAGGGTGCCTGATCTGTGCCAGGGTTAAGCATGCTGTACTTTTTGGCCCCCGTCCAGCTTCCCG CTATGTGACCTTTGGCATTTTACTTCAATGTGCCTCAGTTTCTACATCTGTAAAATGGGCACAATAGT AGTATACTTCATAGCATTGTTATAATGATTAAACAAGTTATATATGAAAAGATTAAAACAGTGTTGCT CCATAATAAATGCTGTTTTACTGTGATTATTATTGTTGTTATCCCTATCATTATCATCACCATCTTA ACССTTCCCTGTTTTGCTCTTTTCTCTCTCCCTACCCATTGCAGACCAAAGAAAGATAGAGCAAGACA AGAAAAGTAAGTGGCCCTGACTTTAGCACTTCTCCCTCTCCATGGCCGGTTGTCTTGGTTTGGGGCTC TTGGCTACCTCTGTTGGGGGCTCCCATAGCCTCCCTGGGTCAGGGACTTGGTCTTGTGGGGGACTTGT GGTGGCAGCAACAATGGGATGGAGCCAACTCCAGGATGATGGCTCTAGGGCTAGTGAGAAAACATAGC CAGGAGCCTGGCACTTCCTTTGGAAGGGACAATGCCTTCTGGGTCTCCAGATCATTCCTGACCAGGAC TTGCTGTTTCGGTGTGTCAGGGGGCACTGTGGACACTGGCTCACTGGCTTGCTCTAGGACACCCACAG TGGGGAGAGGGAGTGGGTGGCAGAGAGGCCAGCTTTTGTGTGTCAGAGGAAATGGCCTCTTTTGGTGG CTGCTGTGACGGTGCAGTTGGATGCGAGGCCGGCTGGAGGGTGGTTTCTCAGTGCATGCCCTCCTGTA GGCGGCAGGCGGCAGACACACAGCCCTCTTGGCCAGGGAGAAAAAGTTGAATGTTGGTCATTTTCAGA GGCTTGTGAGTGCTCCGTGTTAAGGGGCAGGTAGGATGGGGTGGGGGACAAGGTCTGGCGGCAGTAAC CCTTCAAGACAGGGTGGGCGGCTGGCATCAGCAAGAGCTTGCAGGGAAAGAGA GACTGAGAGAGAGCA 
СCTGTGCCCTGCCCTTTCCCCCACACCATCTTGTCTGCCTCCAGTGCTGTGCGGACATTGAAGCCCCC ACCAGGCCTCAACCCCTTGCCTCTTCCCTCAGCTCCCAGCTTCCAGAGCGAGGGGATGCGGAAACCTT CCTTCCACCCTTTGGTGCTTTCTCCTAAGGGGGACAGACTTGCCCTCTCTGGTCCCTTCTCCCCCTCC TTTCTTCCCTGTGACAGACATCCTGAGGTGTGTTCTCTTGGGCTTGGCAGGCATGGAGAGCTCTGGTT CTCTTGAAGGGGACAGGCTACAGCCTGCCCCCCTTCCTGTTTCCCCAAATGACTGCTCTGCCATGGGG AGAGTAGGGGGCTCGCCTGGGCTCGGAAGAGTGTCTGGTGAGATGGTGTAGCAGGCTTTGACAGGCTG GGGAGAGAACTCCCTGCCAAGTACCGCCCAAGCCTCTCCTCCCCAGACCTCCTTAACTCCCACCCCAT CCTGCTGCCTGCCCAGGGCTCCAGGACACCCAGCCCTGCCTCCCAGTCCAGGTCGTGCTGAGCAGGCT GGTGTTGCTCTTGGTTCCGTGCCAGCTCCCAAGGTAGCCGCTTCCCCCACACCGGGATTCCCAGAGGT TCTGTCGCAGTTGCAAATGAAGGCACAAGGCCTGATACACAGCCCTCCCTCCCACTCCTGCTCCCCAT CCAGGCAGGTCTCTGACCTTCTCCCCAAAGTCTGGCCTACCTTTTATCACCCCCGGACCTTCAGGGTC AGACTTGGACAGGGCTGCTGGGCAAAGAGCCTTCCCTCAGGCTTTGCCCCCTGCCGGGGACTGGGAGC CACTGTGA GTGTGGAGACCTTTGGGTCCTGTGCCCTCCACCCAGTCTCGGCTTCCCACCAAAGCCTTG TCAGGGGCTGGGTTTGCCATCCCATGGTGGGCAGCGTGAGGAGAAGAAAGAGCCATCGAGTGCTTGCT GCCCAGACACGCCTGTGTGCGCCCGCGCATGCCTCCCCAGAGACCACCTGCCTCCTGACACTTCCTCC GGGAAGCGGCCCTGTGTGGCTTTGCTTTGGTCGTTCCCCCATCCCTGCCCACCTTACCACTTCTTTTA стCCCCCCACCGCCCCCGCTCTCTCTCTGTCTCTGTTTTTTTATTTTCCAGAAAATCAGTTCGAGGAA AGGGAAAGGGGCAAAAACGAAA GCGCAAGAAA TCCCGGTATAAGTCCTGGAGCGTGTACGTTGGTGCC CGCTGCTGTCTAATGCCCTGGAGCCTCCCTGGCCCCCAGTACAACCTCCGCCTGCCATTCCCTGTAAC сCTGCCTCCCTCCCCTGGTCCTTCCCTGGCTCTCATCCTCCTGGCCCGTGTCTCTCTCTCACTCTCTC АстCCACTAATtGGCACCAACGGGTAGATTTGGTGGTGGCATTGCTGGTCCAGGGTTGGGGTGAATGG GGGTGCCGACTTGGCCTGGAGGATTAAGGGAGGGGACCCTGGCTTGGCTGGGCACCGATTTTCTCTCA CCCACTGGGCACTGGTGGCGGGCCCATGTTGGCACAGGTGCCTGCTCACCCAACTGGTTTCCATTGCT CTAGGCTTCTGCACTCGTCTGGAAGCTGAGGGTGGTGGGGAGGGCAGACATGGCCCAAGAAGGGCTGT GAATGACTGGAGGCAGCTTGCTGAATGACTCCTTGGCTGAAGGAGGAGCTTGGGTGGGATCAGACACC ATGTGGCGGCCTCCCTTCATCTGGTGGAAGTGCCCTGGCTCCTCACGGAGGTGGGGCCTCTGGAGGGG AgCCCCCTATTCCGGCCCAACCCATGGCACCCACAGAGGCCTCCTTGCAGGGCAGCCTCTTCCTCTGG GTCGGAGGCTGTGGTGGGCCCTGCCCTGGGCCCTCTGGCCACCAGCGGCCTGGCCTGGGGACACCGCC TCCGGGCTTAGCCTCCCATCACACCCTACTTTAGCCCACCTTGGTGGAAGGGCCTGGACATGAGCCTT GCACGGGGAGAAGGTGGCCCCTGATTGCCATCCCCAGCAGGTGAAGAGTCAAGGCGTGCTCCGATGGG GGCAACAGCAGTTGGGTCCCTGTGGCCTGAGACTCACCCTTGTCTCCCAGAGACACAGCATTGCCCCT TATGGCAGCCTCTCCCTGCACTCTCTGCCCGTCTGTGCCCGCC TCTTCCTGCGGCAGGTGTCCTAGCC AGTGCTGCCTCTTTCCGCCGCTCTCTCTGTCTTTTGCTGTAGCGCTCGGATCCTTCCAGGGCCTGGGG GCTGACCGGCTGGGTGGGGGTGCAGCTGCGGACATGTTAGGGGGTGTTGCATGGTGATTTTTTTCTC тCTCTCTGCTGATGCTCTAGCTTAGATGTCTTTCCTTTTGCCTTTTTGCAGTCCCTGTGGGCCTTGCT CAGAGCGGAGAAAGCATTTGTTTGTACAAGATCCGCAGACGTGTAAATGTTCCTGCAAAAACACAGAC TCGCGTTGCAAGGCGAGGCAGCTTGAGTTAAACGAACGTACTTGCAGGTTGGTTCCCAGAGGGCAAGC 
AAGTCAGA GAGGGGCATCACACAGAGATGGGGAGAGAGAGAGAGAAAGAGAGTGAGCGAGCGAGCGAG CGGGAGAGCGCCTGAGAGGGGCCAGCTGCTTGCTCAGTTTCTAGCTGCCTGCCTGGTGACTGCTGCCT TCTCTGCTTTTAAGGCCCCTGTGGTGGGCTGCAGGCACTGGTCCAGCCTGGCGGGGCCTGTTCCGAGG TTGCCCTGGTTGCCTGAGTGGTAGGCTGGTGTGGCTTAGTGTAGTGGTGTGGACGCAAGCTGTGTGTT GTGTCCTGTGGTCCTTCTGCTCATAGTGGCTGTTGGTCCTGATGTTATTACTACCTCTGGTAGTAATG CTGAGAAGCTGAAAGCCGATTCCAGGTGTGGACAATGTCAACAAAGCACAGATGCTCTCGCTGGGGCC TTGCCTCGGCCCTTTGAAGTCTGCATGGCTGGGCTTCTCACTCACTCAGTGTTTCTTGCTGGGGGAAG GAATTGAGTCTCCCACTTCAGACTGGGCCTCCCTGAGGAAAGGGTTGTGTCTCCCCACTCAGACTGAG GTTCCCTGAGGGTAGGGCTGTGTCTCTCCCCTCCGACCTGGGCTCCCTGATAGGGCTGTCTCCCCGCT CAGACTGAGGCTCCCTCAGGCCAGGGCTATGTCTCCCTCCTCAGACTGGGGCTCTGAGGGCAAGGGGT CTGGCTGTTCGTTTAGGATGGGGCACTTTTGCCTACACACTGAAGGAGCTGTAGCATCCAAGAATACT AGATACCTTTAATCCTCCACCAGTCATGGTGACAACCCCAAGCAGCCCACACATTTTCAAGTGCCCCC AGGATGCGTGGAGGGAGGGGTCTGTGCCCATTCTCCTGACATTAGCCTGTGAGCTCCGTAAGCCCGGG CCTCGTTTACGTACCTTTGTGAGCCCCGGGCATCTGTACCTCTTTCCTTTGCCCATACTGGGGACCAA GGAAGTGTCAAGTGCATGAGTGAATGTGTGACTCAGTTCAGAGGGTGAGGTCAGGAGCACAGGGTCGG GACAGGTGGCTGGCATCTTTTAATGCCTTAGCTTATGTTCTTTATACCAACTTGGCCTGTGCTCAGAG TGAGGGAGGCCCTGGGGGTCAGGGTAAGCGTCAGTCAGGGAGGCAAGACTTTGTGGGGATTTCCTAGA CAGGGCCAAGGCACCCCCAGCTCACCCCGAGGCTGTGTTAGGGAAGTCCTTGGAGTG TCTCCCCTCCC CCAGCAATGTTCTTGTGGCTTGTGTGTGCTCAGGGGATGCTGGGAACCAGGCCTGGGTAGTTGGTGTG GGGTGCTGTCTGTCTTGGCCCTATGTGAAACCAAGAGGGCGTATATTAGTGCTGGGGTGGGGGCTCTG CCTAACTTCAGGGCTGGATGAGGGGAGTCTCAGTTCCCCAGGGGTCCTTGGGAAAGATAAGGGACTTG ACATTTTAGGGTTTTTAGGTGATTATTCTGCTGATGGGGGTTTGTGTGAAGTGACCTGGGAGCTAACT GAAGTTACTCTAACCTCCCAATACCTTTACCCAACCCCCAAGCTGGCTGTATCTGGGAATATCAGTTT CCAAAATTGGAGGCTTAGGACTCCGTTTCGGGGCTCCCCAGAAGGGTAGGGCCTGTTCTGCCTCCTTC TCACAATCACCCAGGGGCAGGGGCATGCTGAGAAAGTTCTTGGAGGCCCCCTTTGCTTCAGCTGGAGT AGTGAAGCCGCCGAATTGTCTCTCCCCATCCTAAGTGAAGCAGCATATTTGAAAGGAAAGACAACCTG TTACCTGGGCCTGCAACCTCCAGGCAGCTCAAGAGAGA TGAGGCCTACAGCCACAGTGGGAGGGGACA TGGGGAATGGAGATGGTCCCTCACCTTCCTGGGGCCTCCTGCTCTACGCTACCCCCTCGGGAGCCTCC TGTCCCCAGGGCAGGCCCTTGCCATTGTTGGTCACCCGGCCAAGCCTCTCTGCCTCAGGCGTTCTCCC AGAAGATCTGCCCACTCTCTTCCCCACACCAGCCCCTAGAGACTGAACTGAAAACCCTCCTCAGCAGG GAGCCTCTTCTGATTAACTTCATCCAGCTCTGGTCACCCATCAGCTCTTAAAATGTCAAGTGGGGACT GTTCTTTGGTATCCGTTCATTTGTTGCTTTGTAAAGTGTTCCCATGTCCTTGTCTTGTCTCAAGTAGA TTGCAAGCTCAGGAGGGTAGACTGGGAGCCCCTGAGTGGAGCTGCTGCTCAGGCCGGGGCTCCCTGAG GGCAGGGCTGGGGCTGTTCTCATACTGGGGCTTTCTGCCCCAGGACCACACCTTCCTGTCCTCTCTGC TCTTATGGTGCCGGAGGCTGCAGTGACCCAGGGGCCCCCAGGAATGGGGAGGCCGCCTGCCTCATCGC CAGGCCTCCTCACTTGGCCCTAACCCCAGCCTTTGTTTTCCATTTCCCTCAGATGTGACAAGCCGAGG CGGTGAGCCGGGCAGGAGGAAGGAGCCTCCCTCAGGGTTTCGGGAACCAGATCTCTCACCAGGAAAGA 
CTGATACAGAACGATCGATACAGAAACCACGCTGCCGCCACCACACCATCACCATCGACAGAACAGTC CTTAATCCAGAAACCTGAAATGAAGGAAGAGGAGACTCTGCGCAGAGCACTTTGGGTCCGGAGGGCGA GACTCCGGCGGAAGCATTCCCGGGCGGGTGACCCAGCACGGTCCCTCTTGGAATTGGATTCGCCATTT TATTTTTCTTGCTGCTAAATCACCGAGCCCGGAAGATTAGAGAGTTTTATTTCTGGGATTCCTGTAGA CACACCCACCCACATACATACATTTATATATATATATATTATAтAтAтATAAAAATAAATATCTCTAT TTTATATATATAAAATATATATATTCTTTTTTTAAATTAACAGTGCTAATGTTATTGGTGTCTTCACT GGATGTATTTGACTGCTGTGGACTTGAGTTGGGAGGGGAATGTTCCCACTCAGATCCTGACAGGGAAG AGGAGGAGATGAGAGACTCTGGCATGATCTTTTTTTTGTCCCACTTGGTGGGGCCAGGGTCCTCTCCC CTGCCCAGGAATGTGCAAGGCCAGGGCATGGGGGCAAATATGACCCAGTTTTGGGAACACCGACAAAC CCAGCCCTGGCGCTGAGCCTCTCTACCCCAGGTCAGACGGACAGAAAGACAGATCACAGGTACAGGGA TGAGGACACCGGCTCTGACCAGGAGTTTGGGGAGCTTCAGGACATTGCTGTGCTTTGGGGATTCCCTC CACATGCTGCACGCGCATCTCGCCCCCAGGGGCACTGCCTGGAAGATTCAGGAGCCTGGGCGGCCTTC GCTTACTCTCACCTGCTTCTGAGTTGCCCAGGAGACCACTGGCAGATGTCCCGGCGAAGAGAAGAGAC ACATTGTTGGAAGAAGCAGCCCATGACAGCTCCCCTTCCTGGGACTCGCCCTCATCCTCTTCCTGCTC CCCTTCCTGGGGTGCAGCCTAAAAGGACCTATGTCCTCACACCATTGAAACCACTAGTTCTGTCCCCC CAGGAGACCTGGTTGTGTGTGTGTGAGTGGTTGACCTTCCTCCATCCCCTGGTCCTTCCCTTCCCTTC CCGAGGCACAGAGAGACAGGGCAGGATCCACGTGCCCATTGTGGAGGCAGAGAAAAGAGAAAGTGTTT TATATACGGTACTTATTTAATATCCCTTTTTAATTAGAAATTAAAACAGTTAATTTAATTAAAGAGTA GGGTTTTTTTTCAGTATTCTTGGTTAATATTTAATTTCAACTATTTATGAGATGTATCTTTTGCTCTC TCTTGCTCTCTTATTTGTACCGGTTTTTGTATATAAAATTCATGTTTCCAATCTCTCTCTCCCTGATC GGTGACAGTCACTAGCTTATCTTGAACA GATATTTAATTTTGCTAACACTCAGCTCTGCCCTCCCCGA TCCCCTGGCTCCCCAGCACACATTCCTTTGAAATAAGGTTTCAATATACATCTACATACTATATATAT ATTTGGCAACTTGTATTTGTGTGTATATATATATATATATGTTTATGTATATATGTGATTCTGATAAA ATAGACATTGCTATTCTGTTTTTTATATGTAAAAACAAAACAAGAAAAAATAGAGAATTCTACATACT AAATCTCTCTCCTTTTTTAATTTTAATATTTGTTATCATTTATTTATTGGTGCTACTGTTTATCCGTA ATAATTGTGGGGAAAAGATATTAACATCACGTCTTTGTCTCTAGTGCAGTTTTTCGAGATATTCCGTA GTACATATTTATTTTTAAACAACGACAAAGAAATACAGATATATCTTAAAAAAAAAAAAGCATTTTGT ATTAAAGAATTTAATTCTGATCTCAAA

\section{Exon 7 humano}

\section{>NG_008732.1:16741-16872 Homo sapiens vascular endothelial growth factor A (VEGFA), RefSeqGene on chromosome 6}

\footnotetext{
TCCCTGTGGGCCTTGCTCAGAGCGGAGAAAGCATTTGTTTGTACAAGATCCGCAGACGTGTAAATGTT ССTGCAAAAACACAGACTCGCGTTGCAAGGCGAGGCAGCTTGAGTTAAACGAACGTACT TGCAG
} 


\section{Exon 8 humano (exon $8 \mathrm{~A} \mathrm{e}$ exon $8 \mathrm{~B}$ )}

>NG_008732.1:19326-21272 Homo sapiens vascular endothelial growth factor A (VEGFA), RefSeqGene on chromosome 6

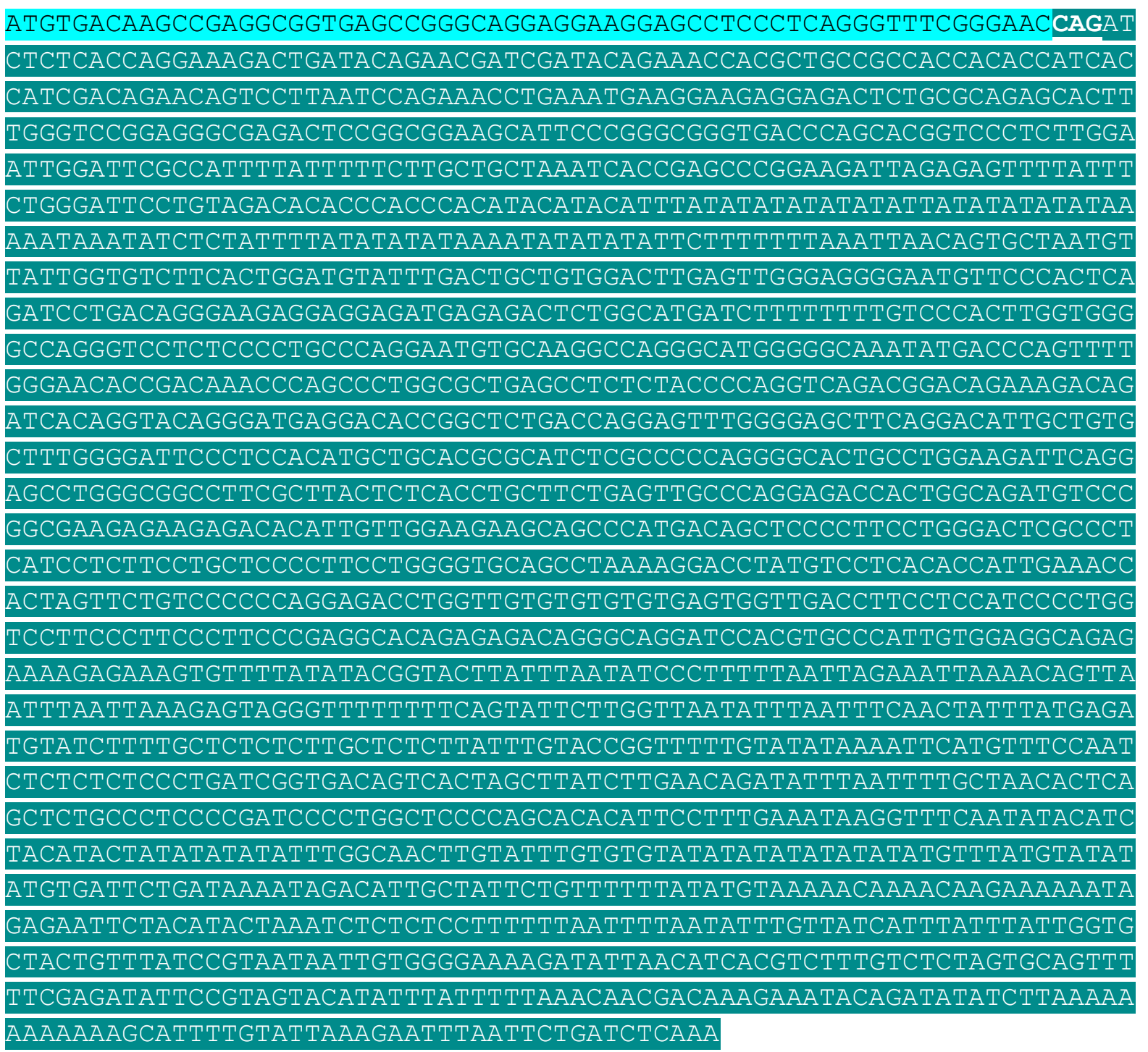


Os pares de base que equivalem ao tamanho de cada exon foram retirados da figura 3 do link https://www.researchgate.net/publication/249320031 VEGFA mRNA processing stability and translation A paradigm for intricate regulation of gene expression at the post-transcriptional level/figures?lo=1

- Os exons de 1 a 8 do VEGFA foram unidos e para cada sequência de exon foi atribuída um formato (Figura 3).

- Em seguida, esses exons foram alinhados à sequência completa do VEGFA humano.

Figura 3 - Sequência nucleotídica dos exons do VEGFA humano. As sequências de 1 a 5 correspondem aos exons estruturais, a sequência em MAIÚSCULA e NEGRITO representa o exon 1, em MAIÚSCULA e realce cinza o exon 2, em MAIÚSCULA e SUBLINHADO o exon 3, em MAIÚSCULA, negrito e itálico o exon 4, em MAIÚSCULA e realce preto o exon 5. O exon $6 \mathrm{~A}$ é representado em letra MAIÚSCULA, sem negrito e sublinhado, 0 exon 6B por letra MAIÚSCULA e itálico, o exon 7 por letra minúscula e negrito, o exon 8A em letra minúscula e o exon 8B em letra MAIÚSCULA.

\footnotetext{
ATGGACGGGTGAGGCGGCGGTGTGCGCAGACAGTGCTCCAGCCGCGCGCGCTCCCCAGGCCCTGGCCC GGGCCTCGGGCCGGGGAGGAAGAGTAGCTCGCCGAGGCGCCGAGGAGAGCGGGCCGCCCCACAGCCCG AGCCGGAGAGGGAGCGCGAGCCGCGCCGGCCCCGGTCGGGCCTCCGAAACCATGAACTTTCTGCTGTC TTGGGTGCATTGGAGCCTTGCCTTGCTGCTCTACCTCCACCATGCCAAGTGGTCCCAGGCTGCACCCA TGGCAGAAGGAGGAGGGCAGAATCATCACGAAGTGGTGAAGTTCATGGATGTCTATCAGCGCAGCTAC TGCCATCCAATCGAGACCCTGGTGGACATCTTCCAGGAGTACCCTGATGAGATCGAGTACATCTTCAA GCCATCCTGTGTGCCCCTGATGCGATGCGGGGGCTGCTGCAATGACGAGGGCCTGGAGTGTGTGCCCA CTGAGGAGTCCAACATCACCATGCAGATTATGCGGATCAAACCTCACCAAGGCCAGCACATAGGAGAG ATGAGCTTCCTACAGCACAACAAATGTGAA TGCAGACCAAAGAAAGATAGAGCAAGACAAGAAAAAAA ATCAGTTCGAGGAAAGGGAAAGGGGCAAAAACGAAAGCGCAAGAAATCCCGGTATAAGTCCTGGAGCG TGTACGTTGGTGCCCGCTGCTGTCTAATGCCCTGGAGCCTCCCTGGCCCCCAtccctgtgggccttgc tcagagcggagaaagcatttgtttgtacaagatccgcagacgtgtaaatgttcctgcaaaaacacaga ctcgcgttgcaaggcgaggcagcttgagttaaacgaacgtacttgcagatgtgacaagccgaggcggt gagccggg caggaggaaggagcctccctcagggtttcgggaacCAGATCTCTCACCAGGAAAGACTGA TACAGAACGATCGATACAGAAACCACGCTGCCGCCACCACACCATCACCATCGACAGAACAGTCCTTA ATCCAGAAACCTGAAATGAAGGAAGAGGAGACTCTGCGCAGAGCACTTTGGGTCCGGAGGGCGAGACT CCGGCGGAAGCATTCCCGGGCGGGTGACCCAGCACGGTCCCTCTTGGAATTGGATTCGCCATTTTATT TTTCTTGCTGCTAAATCACCGAGCCCGGAAGATTAGAGAGTTTTATTTCTGGGATTCCTGTAGACACA CCCACCCACATACATACATTTATATATATATATATTATATATATATAAAAATAAATATCTCTATTTTA TATATATAAAATATATATATTCTTTTTTTAAATTAACAGTGCTAATGTTATTGGTGTCTTCACTGGAT GTATTTGACTGCTGTGGACTTGAGTTGGGAGGGGAATGTTCCCACTCAGATCCTGACAGGGAAGAGGA GGAGATGAGAGACTCTGGCATGATCTTTTTTTTGTCCCACTTGGTGGGGCCAGGGTCCTCTCCCCTGC CCAGGAATGTGCAAGGCCAGGGCATGGGGGCAAATATGACCCAGTTTTGGGAACACCGACAAACCCAG CCCTGGCGCTGAGCCTCTCTACCCCAGGTCAGACGGACAGAAAGACAGATCACAGGTACAGGGATGAG GACACCGGCTCTGACCAGGAGTTTGGGGAGCTTCAGGACATTGCTGTGCTTTGGGGATTCCCTCCACA TGCTGCACGCGCATCTCGCCCCCAGGGGCACTGCCTGGAAGATTCAGGAGCCTGGGCGGCCTTCGCTT АСTCTCACCTGCTTCTGA GTTGCCCAGGAGACCACTGGCAGATGTCCCGGCGAAGAGAAGAGACACAT TGTTGGAAGAAGCAGCCCATGACAGCTCCCCTTCCTGGGACTCGCCCTCATCCTCTTCCTGCTCCCCT TCCTGGGGTGCAGCCTAAAAGGACCTATGTCCTCACACCATTGAAACCACTAGTTCTGTCCCCCCAGG AGACCTGGTTGTGTGTGTGTGAGTGGTTGACCTTCCTCCATCCCCTGGTCCTTCCCTTCCCTTCCCGA GGCACAGA GAGACAGGGCAGGATCCACGTGCCCATTGTGGAGGCAGAGAAAAGAGAAAGTGTTTTATA
} 
TACGGTACTTATTTAATATCCCTTTTTAATTAGAAATTAAAACAGTTAATTTAATTAAAGAGTAGGGT TTTTTTTCAGTATTCTTGGTTAATATTTAATTTCAACTATTTATGAGATGTATCTTTTGCTCTCTCTT GCTCTCTTATTTGTACCGGTTTTTGTATATAAAATTCATGTTTCCAATCTCTCTCTCCCTGATCGGTG ACAGTCACTAGCTTATCTTGAACAGATATTTAATTTTGCTAACACTCAGCTCTGCCCTCCCCGATCCC CTGGCTCCCCAGCACACATTCCTTTGAAATAAGGTTTCAATATACATCTACATACTATATATATATTT GGCAACTTGTATTTGTGTGTATATATATATATATATGTTTATGTATATATGTGATTCTGATAAAATAG ACATTGCTATTCTGTTTTTTATATGTAAAAACAAAACAAGAAAAAATAGAGAATTCTACATACTAAAT СTCTCTCCTTTTTTAATTTTAATATTTGTTATCATTTATTTATTGGTGCTACTGTTTATCCGTAATAA TTGTGGGGAAAAGATATTAACATCACGTCTTTGTCTCTAGTGCAGTTTTTCGAGATATTCCGTAGTAC ATATTTATTTTTAAACAACGACAAAGAAATACAGATATATCTTAAAAAAAAAAAAGCATTTTGTATTA AAGAATTTAATTCTGATCTCAAA

Fonte: D'APRILE, 2021.

\section{ALINHAMENTO DAS ISOFORMAS DO VEGFA}

Foram obtidas no banco de dados do National Center for Biotechnology Information (NCBI) dos Institutos Nacionais de Saúde, as sequências das isoformas do VEGFA de humano:

VEGFA121 (https://www.ncbi.nlm.nih.gov/nuccore/AF214570.1)

VEGFA148 (https://www.ncbi.nlm.nih.gov/nuccore/AF091352.1)

VEGFA165a (https://www.ncbi.nlm.nih.gov/nuccore/AB021221.1)

VEGFA165b (https://www.ncbi.nIm.nih.gov/nuccore/AF430806.1)

VEGFA189 (https://www.ncbi.nlm.nih.gov/nuccore/M27281.1)

VEGFA206 (https://www.ncbi.nIm.nih.gov/nuccore/S85192.1)

As sequências das isoformas do VEGFA foram alinhadas na sequência gênica do VEGFA humano para validação. Posteriormente, as sequências das isoformas do VEGFA e a sequência de referência do VEGFA canino foram alinhadas pelo programa Clustal X2 (http://www.clustal.org) para identificação das isoformas na espécie canina.

A sequência do VEGFA canino foi obtida através do link http://www.ensembl.org/Canis familiaris/Gene/Sequence?db=core;g=ENSCAFG000 00001938; $r=12: 12207947-12225072 ; t=E N S C A F T 00000049819$ 
EXONS DAS ISOFORMAS DO VEGFA CANINO

Após a caracterização das oito isoformas caninas, foi realizado o processo de identificação dos exons utilizando o programa Clustal X2. As isoformas da espécie canina foram alinhadas na sequência do VEGFA (CanFam3.1) e na sequência correspondente a cada um dos exons, sendo descritas as regiões codificantes das isoformas caninas.

Os exons foram encontrados e unidos, assim como no VEGFA humano, com a estruturação dos exons 1 a 8.

Figura 4. Sequência nucleotídica dos exons do VEGFA canino. As sequências de 1 a 5 correspondem aos exons estruturais, a sequência em MAIÚSCULA e NEGRITO representa o exon 1, em MAIÚSCULA e realce cinza ao exon 2, em MAIÚSCULA e sublinhado ao exon 3, em MAIÚSCULA, negrito e itálico ao exon 4, em MAIÚSCULA e realce preto ao exon 5. O exon 6A é representado em MAIÚSCULA, sem negrito e sublinhado, o exon 6B por MAIÚSCULA e itálico, o exon 7 por minúscula e negrito, o exon 8A em minúscula e o exon 8B em MAIÚSCULA.

CCCCCAAGGCCGCGCGGGCGCGTGTGTGTCTGGGCAGAGGGGGGCGGGGGGGCAATTTTCAGGCTGTG AACCGGGGAGGGGGTCGAGGTCCCCTTCGCTCGGGAGGGAGGGCAGGCTTCGCTCCACGTCCCGGGGG AAGGCCCGAGGGGCGCGCGGGGCAGTTGGCGGAGAGGCTGGAGCCCGGGCCCGTCCCCGCCCCCAGGG CGTGCCAAGGGCGGGTCCGGGCGGGGCCTGCCTTGGTTTTAAGCGGCCGCTAGTGGTAGGAGCGCAGA GGCTTGGGGCAGCCGGGCTGCGAGGAGGCCGCGGCGCGGGGGGCGAGTGGAGCCGGCGGCGGCGGCGC TGGGTCGGGAGGCAGCGGCTAGGCGGACGAACCGGCGGGGTCACCGGCCAGGGGTCTCCGCACTGGAA TCCGAATTCATTTATCCAGGGCTTACССTССТССTTTTTTTTСTTAAGCAATTTTAAAACCCACATTC TTTCCCGTTTTAATTTATTTTTTGCTTCCCATTCCCCGCTTAAACCGGGCCGACCGTTTGGGGGAGAT TGCGCCTTTACTTCCCCAAATCACTTCGGATTTTGGAAACCAGCAGAGAGAAGAAGGAGGTAGCAAGA GCTCCAGAGAGAAGTCGAGGAAGAGAGAGAGAGAGAGGAGAGAGAGAGGGGGAGAGAGAGGGAGACGG GGTCAGAGAGCGCGCGCGGGCGAGCGAGCGACGACAGGGCAGGGGCAGAGTGAGTGACCTGCTTTCGG GGGTGCCCGCCCGAGCGCGGCGTGAGCCCTCCCCGTCGGGACCCCGCACCGGACCAGCCGCGCTGACG GACAGACCGACAGACACCGCCCCCCGCCCCAGCGCCCACCTCCTCCCCGGCCGGCGGCCGAGGGTGGC CGCGGCGGCGAGCCGCGGGCAGGAGCCGGAGCCCGCGCCTGGAGGCGGGGTGGAGGGGGTCGGGGCTC GCGGCGTTGCGGTGAAACTTTTCGTCCAACTTCTGGGCTGTTCTCGCTCCGGAGGAGCCGTGGTCCGC GCCGGGGCAGCAGAGCCGAGCGGAGCCGGGAGAAGTGCGAGCCCGGGCCGGGAGGAGCCGCAGTCGGA GGAGGGGGAGGAGGAAGAAGAGAAGGAAGAGGAGAGGGGGCCGCGGTGGCGACTCGGCGTTCGGGAGC CGGGCTCATGGACGGGTGAGGCGGCTGTGTGCGCAGACAGAGCTCCAGCCGCGCGCGCGCCCCAGGCC CCGGCCCCGGCCCCGGCCCGGGCCTCGGCTCCGGGAGGAAGAGGAGCCCGCCTAGGCGCCGAGGAGAG CGGGCCGCCCCGCAGCCCGAGCGGGAGAGGGAGCGCGAGCCGCGCCGGCCCCGGCCGGGCCTCCGAAA CCATGAACTTTCTGCTCTCCTGGGTGCATTGGAGCCTTGCCTTGCTGCTCTACCTCCACCATGCCAAG TGGTCCCAGGCTGCGCCTATGGCAGGAGGA GAGCACAAACCCCACGAAGTGGTGAAGTTCATGGACGT CTACCAGCGCAGCTACTGCCGTCCCATTGA GACCCTGGTGGACATCTTCCAGGAGTACCCTGACGAGA TCGAGTACATCTTCAAGCCATCCTGCGTGCCCCTGATGCGGTGTGGGGGCTGCTGTAATGATGAGGGC CTAGAGTGCGTGCCCACTGAGGAGTTCAACATCACCATGCAGATTATGCGGATCAAACCTCATCAAGG CCAGCACATAGGGGAGATGAGTTTCCTGCAGCATAGCAAATGTGAATGCAGACCAAAGAAAGATAGAG CAAGGCAAGAAAAAAAATCAATTGAGGAAAGGGGAAGGGGCAAAAAAGAAAGCGCAAGAAATCCCGG TATAAACCCTGGAGCGTGTACGTG TGCCTCCGCTGTTTCATTGCCTGGAGCCTCCCTGGCCCCCAtcC ctgtgggccttgctcagagcggagaaagcatttgtttgtacaagatccgcagacgtgtaaatgttcct gcaaaacacagactcgcgttgcaaggcgaggcagcttgagttaaacgaacgtacttgcagatgtga c aagcccaggcggtgagccgggctggaagaaggagcctccctcagggtttcgggaaccagACCTCTCAC CAGGAAAGCCTGATTCAGAATGACCGCTACAGAAACCACGCCGCCGCCACCACCACCACACCACCATC ACCAGAACAATCCTTAATCCAGAAACCTGAAATGAAGGAAGAGGAGACTCTGCGCAGAGCACTTTGGG 
TCCGGAGGGCGCAACTCCGGCAGAAGCATTCCCGGGCAGGTGACCAAGCACGGTCCCTCTTGGAATTG GATCGCCATTGTATTTTTCTTGCTGCTAAATCACCGAGCCCGGAAGATTAGAGAGTTTTATTTCTGGG ATTCCTGTAGACACACCCACCCACATACATACTTTTATATATATATATAAAATATATATATAAAAATA

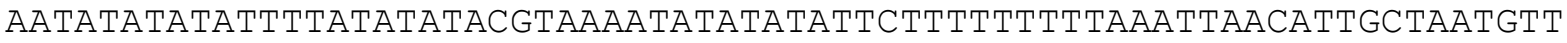
ATTGGTGTCTTCACTGGATATATTTGACTGCTGTGGACTTAAGTTGGGAGGAGGCTGTCCCCACCCAG ATCCCAACAGGGAAGAGGATGGGA GGGGAGACTCTGGCATGATCTTTTGGTCCCTCGTAGGAAGGCCA GGGTCCCCTTCCCTGCCCAGGAACGTGCTTGGCCAGGGCACGGGGGCAAATTTGGCCTGCTTTTGGGG ACACTGACAAACCCAGCCCTGGCCCCAAGCCTCTACCCCGAGTCAAATGGACAGACGACAGGTACAGG GACGAGGACACTGGCTCTGACTAGGAGTTCGGGGAGCCTCAGGACACTGCTGTACTTTGAGGATCCTC TCCACATGCTGCACGGACGGGCATCTTGCCCCCAGGGGCACTGCCTGGAAGATTCAGGAGACTGGGCA GCCTTCACCTACTCTTCACTTGCTCCTGACAAGCCCAGGGTGCCGCCAACAGAGGTCTTGGCGAAAAG AAGAGAGACATTGGTGGA GGAAGGGCCGCCTGGTGGCA GCTTGTCCTCCGAGGGAAGGGCCCCCTGCC TTGGCCATCTCCCAGCTCTCCTTCCCTGGTGCAGCCCAGGAGGGCCTGACGTCCTCAGACCATTGAAA CCACTAGTTCTGTCCCCCCAGGAGACCTGGCTGCGTGTGTGTGAGTGGTTCACCCTCCTCTGTCCCCA GACCCGACCCTTCCCGCGGCACAGAGAGACAGGGCAGGATCCACGTGCCCACCATGGAGGCAGAGAAA GTGTTTTATATACGATAATTATTTAATATCCCTTTTTAATTAGAAATTAAAACAGTTAATTTAATTAA AGAGTAGGGTTTTTTTCAGTATTCTTGGTTAATATTTAATTTCAACTATTTATGAGATGTATCTCTCT ATTGCTCTCTCTTGCGCTCTTATATGTACCGGTCTTTGTGTTTAAGATTCATGTTTCCAATCTCTCTC TCCCTGATCGGTGACAGTCACTAGCTTGTCCTGAGCAGATATTTAATTTTGCTAACACTCAGCTCTGC CCTCCCCTTGCCCCCGGCTCCCCACCACACATTCCTTTGAAATAAGGTTTCAATATACATCTACAGAC TATATATATATTTGGCAACTTGCGTTTGTGTGTATATATATATATATATATATATATATATATGTTTA TGTATATATGTGATTCTGATAAAATAGACATTGCTATTCTGTTTTTTATATGTAAAAACAAAACAAGA AAAAATAGAGAATTCTACATACTAAATCTCTCTCCTTTTTTAATTTTAATATTTGTTATCATTTATTT ATTGGTGCTACTGTTTATCCGTAATAATTGTGGGGGAAAAAGATATTAACATCACATCTTTGTCTCTA GTACAGTTTTTCGAGATATTCCGTAGTACATATTTATTTTTAAACAACAACAAAGAAATACAGATATA TCTTAAAAAAAAAAAAAGCATTTTGTATTAAAGAATTTAATTCTGATCTCAAAGCTCCTCCTGGTTTC TCCTTCTCCATTGGGTCTTTGTTCCAGACTCCCTCCTGCTTCC

Fonte: D’APRILE, 2021

\section{RESULTADOS ENCONTRADOS E CONSIDERAÇÕES}

Os resultados obtidos caracterizam as possíveis estruturações de exons das isoformas do VEGFA canino, baseados nos exons das isoformas do VEGFA humano.

\section{ISOFORMA 165A}

\section{Esta isoforma é composta pelos exons estruturais 1 - 5 e pelos exons 7 e 8a.}


TGCGCCTTTACTTCCCCAAATCACTTCGGATTTTGGAAACCAGCAGA GA GAAGAAGGAGGTAGCAAGA GCTCCAGA GAGAAGTCGAGGAAGAGAGA GA GAGAGAGGAGAGAGAGAGGGGGAGA GAGAGGGAGACGG GGTCAGAGAGCGCGCGCGGGCGAGCGAGCGACGACAGGGCAGGGGCAGAGTGAGTGACCTGCTTTCGG GGGTGCCCGCCCGAGCGCGGCGTGAGCCCTCCCCGTCGGGACCCCGCACCGGACCAGCCGCGCTGACG GACAGACCGACAGACACCGCCCCCCGCCCCAGCGCCCACCTCCTCCCCGGCCGGCGGCCGAGGGTGGC CGCGGCGGCGAGCCGCGGGCAGGAGCCGGA GCCCGCGCCTGGAGGCGGGGTGGAGGGGGTCGGGGCTC GCGGCGTTGCGGTGAAAC TTTTCGTCCAACTTCTGGGC TGTTCTCGCTCCGGA GGAGCCGTGGTCCGC GCCGGGGCAGCAGAGCCGAGCGGAGCCGGGAGAAGTGCGAGCCCGGGCCGGGAGGAGCCGCAGTCGGA GGAGGGGGAGGAGGAAGAAGAGAAGGAAGA GGAGAGGGGGCCGCGGTGGCGACTCGGCGTTCGGGAGC CGGGCTCATGGACGGGTGAGGCGGCTGTGTGCGCAGACAGAGCTCCAGCCGCGCGCGCGCCCCAGGCC CCGGCCCCGGCCCCGGCCCGGGCCTCGGCTCCGGGAGGAAGAGGAGCCCGCCTAGGCGCCGAGGA GAG CGGGCCGCCCCGCAGCCCGAGCGGGAGA GGGAGCGCGA GCCGCGCCGGCCCCGGCCGGGCCTCCGAAA CCATGAACTTTCTGCTCTCCTGGGTGCATTGGAGCCTTGCCTTGCTGCTCTACCTCCACCATGCCAAG TGGTCCCAGGCTGCGCCTATGGCAGGAGGA GAGCACAAACCCCACGAAGTGGTGAAGTTCATGGACGT CTACCAGCGCAGCTACTGCCGTCCCATTGAGACCCTGGTGGACATCTTCCAGGAGTACCCTGACGAGA TCGAGTACATCTTCAAGCCATCCTGCGTGCCCCTGATGCGGTGTGGGGGCTGCTGTAATGATGAGGGC CTAGAGTGCGTGCCCACTGAGGAGTTCAACATCACCATGCAGATTATGCGGATCAAACCTCATCAAGG CCAGCACATAGGGGAGATGAGTTTCCTGCAGCATAGCAAATGTGAATGCAGACCAAAGAAAGATAGAG CAAGGCAAGAAAATCCCTGTGGGCCTTGCTCAGAGCGGAGAAAGCATTTGTTTGTACAAGATCCGCAG ACGTGTAAATGTTCCTGCAAAAACACAGACTCGCGTTGCAAGGCGAGGCAGCTTGAGTTAAACGAACG TACTTGCA GATGTGACAAGCCCAGGCGGTGAGCCGGGCTGGAAGAAGGAGCCTCCCTCAGGGTTTCGG GAACCAG

\section{ISOFORMA 165B}

\section{Esta isoforma é composta pelos exons estruturais 1 - 5 e pelos exons 7 e 8b.}

CCCCCAAGGCCGCGCGGGCGCGTGTGTGTCTGGGCAGAGGGGGGCGGGGGGGCAATTTTCAGGCTGTG AACCGGGGAGGGGGTCGA GGTCCCCTTCGC TCGGGAGGGAGGGCAGGCTTCGCTCCACGTCCCGGGGG AAGGCCCGAGGGGCGCGCGGGGCAGTTGGCGGAGAGGC TGGAGCCCGGGCCCGTCCCCGCCCCCAGGG CGTGCCAAGGGCGGGTCCGGGCGGGGCCTGCCTTGGTTTTAAGCGGCCGCTAGTGGTAGGAGCGCAGA GGCTTGGGGCAGCCGGGCTGCGAGGAGGCCGCGGCGCGGGGGGCGAGTGGAGCCGGCGGCGGCGGCGC TGGGTCGGGAGGCAGCGGCTAGGCGGACGAACCGGCGGGGTCACCGGCCAGGGGTCTCCGCACTGGAA TCCGAATTCATTTATCCAGGGCTTACCCTCCTCCTTTTTTTTCTTAAGCAATTTTAAAACCCACATTC TTTCCCGTTTTAATTTATTTTTTGCTTCCCATTCCCCGCTTAAACCGGGCCGACCGTTTGGGGGAGAT TGCGCCTTTACTTCCCCAAATCACTTCGGATTTTGGAAACCAGCAGAGAGAAGAAGGAGGTAGCAAGA GCTCCAGA GAGAAGTCGAGGAAGAGAGAGAGAGAGAGGAGAGA GAGAGGGGGAGA GAGAGGGAGACGG GGTCAGAGAGCGCGCGCGGGCGAGCGAGCGACGACAGGGCAGGGGCAGAGTGAGT GACCTGCTTTCGG GGGTGCCCGCCCGAGCGCGGCGTGAGCCCTCCCCGTCGGGACCCCGCACCGGACCAGCCGCGCTGACG GACAGACCGACAGACACCGCCCCCCGCCCCAGCGCCCACCTCC TCCCCGGCCGGCGGCCGAGGGTGGC CGCGGCGGCGAGCCGCGGGCAGGAGCCGGAGCCCGCGCCTGGAGGCGGGGTGGAGGGGGTCGGGGCTC GCGGCGTTGCGGTGAAACTTTTCGTCCAACTTCTGGGCTGTTCTCGCTCCGGAGGAGCCGTGGTCCGC GCCGGGGCAGCAGAGCCGAGCGGAGCCGGGAGAAGTGCGAGCCCGGGCCGGGAGGAGCCGCAGTCGGA 
GGAGGGGGAGGAGGAAGAAGAGAAGGAAGAGGAGAGGGGGCCGCGGTGGCGACTCGGCGTTCGGGAGC CGGGCTCATGGACGGGTGAGGCGGCTGTGTGCGCAGACAGAGCTCCAGCCGCGCGCGCGCCCCAGGCC CCGGCCCCGGCCCCGGCCCGGGCCTCGGCTCCGGGAGGAAGAGGAGCCCGCCTAGGCGCCGAGGAGAG CGGGCCGCCCCGCAGCCCGAGCGGGAGAGGGAGCGCGAGCCGCGCCGGCCCCGGCCGGGCCTCCGAAA CCATGAACTTTCTGCTCTCCTGGGTGCATTGGAGCCTTGCCTTGCTGCTCTACCTCCACCATGCCAAG TGGTCCCAGGCTGCGCCTATGGCAGGAGGAGAGCACAAACCCCACGAAGTGGTGAAGTTCATGGACGT CTACCAGCGCAGCTACTGCCGTCCCATTGAGACCCTGGTGGACATCTTCCAGGAGTACCCTGACGAGA TCGAGTACATCTTCAAGCCATCCTGCGTGCCCCTGATGCGGTGTGGGGGCTGCTGTAATGATGAGGGC CTAGAGTGCGTGCCCACTGAGGAGTTCAACATCACCATGCAGATTATGCGGATCAAACCTCATCAAGG CCAGCACATAGGGGAGATGAGTTTCCTGCAGCATAGCAAATGTGAATGCAGACCAAAGAAAGATAGAG CAAGGCAAGAAAATCCCTGTGGGCCTTGCTCAGAGCGGAGAAAGCATTTGTTTGTACAAGATCCGCAG ACGTGTAAATGTTCCTGCAAAAACACAGACTCGCGTTGCAAGGCGAGGCAGCTTGAGTTAAACGAACG TACTTGCA GACCTCTCACCAGGAAAGCCTGATTCAGAATGACCGCTACAGAAACCACGCCGCCGCCAC CACCACCACACCACCATCACCAGAACAATCCTTAATCCAGAAACCTGAAATGAAGGAAGAGGAGACTC TGCGCAGAGCACTTTGGGTCCGGAGGGCGCAACTCCGGCAGAAGCATTCCCGGGCAGGTGACCAAGCA CGGTCCCTCTTGGAATTGGATCGCCATTGTATTTTTCTTGCTGCTAAATCACCGAGCCCGGAAGATTA GAGAGTTTTATTTCTGGGATTCCTGTAGACACACCCACCCACATACATACTTTTATATATATATATAA

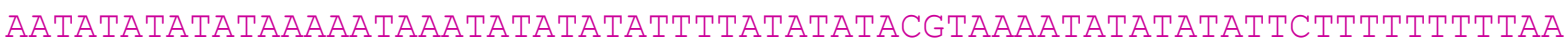
ATTAACATTGCTAATGTTATTGGTGTCTTCACTGGATATATTTGACTGCTGTGGACTTAAGTTGGGAG GAGGCTGTCCCCACCCAGATCCCAACAGGGAAGAGGATGGGAGGGGAGACTCTGGCATGATCTTTTGG TCCCTCGTAGGAAGGCCAGGGTCCCCTTCCCTGCCCAGGAACGTGCTTGGCCAGGGCACGGGGGCAAA TTTGGCCTGCTTTTGGGGACACTGACAAACCCAGCCCTGGCCCCAAGCCTCTACCCCGAGTCAAATGG ACAGACGACAGGTACAGGGACGAGGACACTGGCTCTGACTAGGAGTTCGGGGAGCCTCAGGACACTGC TGTACTTTGAGGATCCTCTCCACATGCTGCACGGACGGGCATCTTGCCCCCAGGGGCACTGCCTGGAA GATTCAGGAGACTGGGCAGCCTTCACCTACTCTTCACTTGCTCCTGACAAGCCCAGGGTGCCGCCAAC AGAGGTCTTGGCGAAAAGAAGAGAGACATTGGTGGAGGAAGGGCCGCCTGGTGGCAGCTTGTCCTCCG AGGGAAGGGCCCCCTGCCTTGGCCATCTCCCAGCTCTCCTTCCCTGGTGCAGCCCAGGAGGGCCTGAC GTCCTCAGACCATTGAAACCACTAGTTCTGTCCCCCCAGGAGACCTGGCTGCGTGTGTGTGAGTGGTT CACCCTCCTCTGTCCCCAGACCCGACCCTTCCCGCGGCACAGAGAGACAGGGCAGGATCCACGTGCCC ACCATGGAGGCAGAGAAAGTGTTTTATATACGATAATTATTTAATATCCCTTTTTAATTAGAAATTAA AACAGTTAATTTAATTAAAGAGTAGGGTTTTTTTCAGTATTCTTGGTTAATATTTAATTTCAACTATT TATGAGATGTATCTCTCTATTGCTCTCTCTTGCGCTCTTATATGTACCGGTCTTTGTGTTTAAGATTC ATGTTTCCAATCTCTCTCTCCCTGATCGGTGACAGTCACTAGCTTGTCCTGAGCAGATATTTAATTTT GCTAACACTCAGCTCTGCCCTCCCCTTGCCCCCGGCTCCCCACCACACATTCCTTTGAAATAAGGTTT CAATATACATCTACAGACTATATATATATTTGGCAACTTGCGTTTGTGTGTATATATATATATATATA

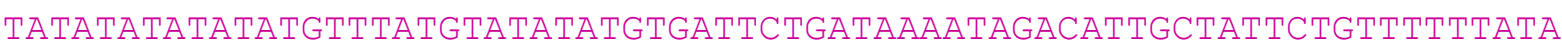
TGTAAAAACAAAACAAGAAAAAATAGAGAATTCTACATACTAAATCTCTCTCCTTTTTTAATTTTAAT 


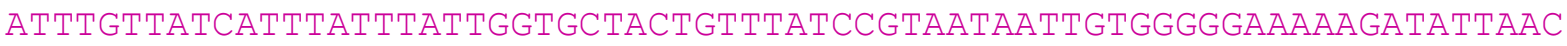

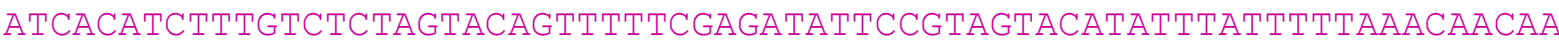
CAAAGAAATACAgATATA TCTTAAAAAAAAAAAAAGCATTTTGATTAAAgAATTTAATTCTGATCTC AAAgCTCCTCCTGGTTTCTCCTTCTCCATTGGGTCTTTGTTCCAGACTCCCTCCTGCTTCC

\section{ISOFORMA $121 \mathrm{~A}$}

\section{Esta isoforma é composta pelos exons estruturais 1-5 e pelo exon 8A.}

CCCCCAAGGCCGCGCGGGCGCGTGTGTGTCTGGGCAGAGGGGGGCGGGGGGGCAATTTTCAGGCTGTG AACCGGGGAGGGGGTCGAGGTCCCCTTCGCTCGGGAGGGAGGGCAGGCTTCGCTCCACGTCCCGGGGG AAGGCCCGAGGGGCGCGCGGGGCAGTTGGCGGAGAGGCTGGAGCCCGGGCCCGTCCCCGCCCCCAGGG CGTGCCAAGGGCGGGTCCGGGCGGGGCCTGCCTTGGTTTTAAGCGGCCGCTAGTGGTAGGAGCGCAGA GGCTTGGGGCAGCCGGGCTGCGAGGAGGCCGCGGCGCGGGGGGCGAGTGGAGCCGGCGGCGGCGGCGC TGGGTCGGGAGGCAGCGGCTAGGCGGACGAACCGGCGGGGTCACCGGCCAGGGGTCTCCGCACTGGAA TCCGAATTCATTATCCAGGGCTTACCCTCCTCCTTTTTTTCTTAAGCAATTTTAAAACCCACATTC тTтCCCGTTTAATTATTTTTGCTTCCCATTCCCCGCTTAAACCGGGCCGACCGTTTGGGGGAGAT

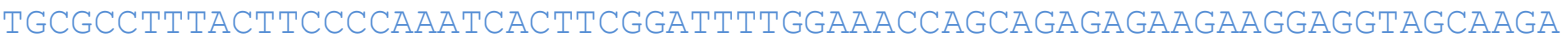
GCTCCAGA GA GAAGTCGA GGAAGAGAGA GA GA GAGAGGAGA GA GA GAGGGGGA GA GAGAGGGA GA CGG GGTCAGAGAGCGCGCGCGGGCGAGCGAGCGACGACAGGGCAGGGGCAGAGTGAGTGACCTGCTTTCGG GGGTGCCCGCCCGAGCGCGGCGTGAGCCCTCCCCGTCGGGACCCCGCACCGGACCAGCCGCGCTGACG GACAGACCGACAGACACCGCCCCCCGCCCCAGCGCCCACCTCCTCCCCGGCCGGCGGCCGAGGGTGGC CGCGGCGGCGAGCCGCGGGCAGGAGCCGGA GCCCGCGCCTGGAGGCGGGGTGGAGGGGGTCGGGGCTC GCGGCGTTGCGGTGAAACTTTTCGTCCAACTTCTGGGCTGTTCTCGCTCCGGAGGAGCCGTGGTCCGC GCCGGGGCAGCAGAGCCGAGCGGAGCCGGGAGAAGTGCGAGCCCGGGCCGGGA GGAGCCGCAGTCGGA GGAGGGGGAGGAGGAAGAAGAGAAGGAAGAGGAGAGGGGGCCGCGGTGGCGACTCGGCGTTCGGGAGC CGGGCTCATGGACGGGTGAGGCGGCTGTGTGCGCAGACAGAGCTCCAGCCGCGCGCGCGCCCCAGGCC CCGGCCCCGGCCCCGGCCCGGGCCTCGGCTCCGGGAGGAAGAGGAGCCCGCCTAGGCGCCGAGGAGAG CGGGCCGCCCCGCAGCCCGAGCGGGAGA GGGAGCGCGAGCCGCGCCGGCCCCGGCCGGGCCTCCGAAA CCATGAACTTTCTGCTCTCCTGGGTGCATTGGAGCCTTGCCTTGCTGCTCTACCTCCACCATGCCAAG TGGTCCCAGGCTGCGCCTATGGCAGGAGGAGA GCACAAACCCCACGAAGTGGTGAAGTTCATGGACGT CTACCAGCGCAGCTACTGCCGTCCCATTGA GACCCTGGTGGACATCTTCCAGGAGTACCCTGACGAGA TCGAGTACATCTTCAAGCCATCCTGCGTGCCCCTGATGCGGTGTGGGGGCTGCTGTAATGATGAGGGC CTAGAGTGCGTGCCCACTGAGGAGTTCAACATCACCATGCAGATTATGCGGATCAAACCTCATCAAGG CCAGCACATAGGGGAGATGA GTTTCCTGCAGCATAGCAAATGTGAATGCAGACCAAAGAAAGATAGAG CAAGGCAA GAAAAATGTGACAAGCCCAGGCGGTGAGCCGGGCTGGAAGAAGGAGCCTCCCTCAGGGTT TCGGGAACCAG 
ISOFORMA 145A

Esta isoforma é composta pelos exons estruturais 1 - 5 e pelos exons 6A e 8A.

CCCCCAAGGCCGCGCGGGCGCGTGTGTGTCTGGGCAGAGGGGGGCGGGGGGGCAATTTTCAGGCTGTG AACCGGGGAGGGGGTCGAGGTCCCCTTCGCTCGGGAGGGAGGGCAGGCTTCGCTCCACGTCCCGGGGG AAGGCCCGAGGGGCGCGCGGGGCAGTTGGCGGAGAGGCTGGAGCCCGGGCCCGTCCCCGCCCCCAGGG CGTGCCAAGGGCGGGTCCGGGCGGGGCCTGCCTTGGTTTTAAGCGGCCGCTAGTGGTAGGAGCGCAGA GGCTTGGGGCAGCCGGGCTGCGAGGAGGCCGCGGCGCGGGGGGCGAGTGGAGCCGGCGGCGGCGGCGC TGGGTCGGGAGGCAGCGGCTAGGCGGACGAACCGGCGGGGTCACCGGCCAGGGGTCTCCGCACTGGAA TCCGAATTCATTTATCCAGGGCTTACCCTCCTCCTTTTTTTTCTTAAGCAATTTTAAAACCCACATTC TTTCCCGTTTTAATTTATTTTTTGCTTCCCATTCCCCGCTTAAACCGGGCCGACCGTTTGGGGGAGAT TGCGCCTTTACTTCCCCAAATCACTTCGGATTTTGGAAACCAGCAGAGAGAAGAAGGAGGTAGCAAGA GCTCCAGA GAGAAGTCGA GGAAGAGAGA GA GAGAGAGGAGAGA GAGAGGGGGA GA GAGAGGGAGACGG GGTCAGAGAGCGCGCGCGGGCGAGCGAGCGACGACAGGGCAGGGGCAGAGTGA GTGACCTGCTTTCGG GGGTGCCCGCCCGAGCGCGGCGTGAGCCCTCCCCGTCGGGACCCCGCACCGGACCAGCCGCGCTGACG GACAGACCGACAGACACCGCCCCCCGCCCCAGCGCCCACCTCCTCCCCGGCCGGCGGCCGAGGGTGGC CGCGGCGGCGAGCCGCGGGCAGGAGCCGGA GCCCGCGCCTGGAGGCGGGGTGGAGGGGGTCGGGGCTC GCGGCGTTGCGGTGAAACTTTTCGTCCAACTTCTGGGCTGTTCTCGCTCCGGAGGAGCCGTGGTCCGC GCCGGGGCAGCAGAGCCGAGCGGAGCCGGGAGAAGTGCGAGCCCGGGCCGGGAGGAGCCGCAGTCGGA GGAGGGGGAGGAGGAAGAAGAGAAGGAAGAGGAGAGGGGGCCGCGGTGGCGACTCGGCGTTCGGGAGC CGGGCTCATGGACGGGTGAGGCGGCTGTGTGCGCAGACAGAGCTCCAGCCGCGCGCGCGCCCCAGGCC CCGGCCCCGGCCCCGGCCCGGGCCTCGGCTCCGGGAGGAAGAGGAGCCCGCCTAGGCGCCGAGGAGAG CGGGCCGCCCCGCAGCCCGAGCGGGAGAGGGAGCGCGAGCCGCGCCGGCCCCGGCCGGGCCTCCGAAA CCATGAACTTTCTGCTCTCTGGGTGCATTGGAGCCTTGCCTTGCTGCTCTACCTCCACCATGCCAAGT GGTCCCAGGCTGCGCCTATGGCAGGAGGAGAGCACAAACCCCACGAAGTGGTGAAGTTCATGGACGTC TACCAGCGCAGCTACTGCCGTCCCATTGAGACCCTGGTGGACATCTTCCAGGAGTACCCTGACGAGAT CGAGTACATCTTCAAGCCATCCTGCGTGCCCCTGATGCGGTGT GGGGGCTGCTGTAATGATGA GGGCC TAGAGTGCGTGCCCACTGAGGAGTTCAACATCACCATGCAGATTATGCGGATCAAACCTCATCAAGGC CAGCACATAGGGGAGATGAGTTTCCTGCAGCATAGCAAATGTGAATGCAGACCAAAGAAAGATAGAGC AAGGCAAGAAAAAAAATCAATTCGAGGAAAGGGGAAGGGGCAAAAAAGAAAGCGCAAGAAATCCCGGT ATAAACCCTGGAGCGTGTACGTGATGTGACAAGCCCAGGCGGTGAGCCGGGCTGGAAGAAGGAGCCTC CCTCAGGGTTTCGGGAACCAG 
ISOFORMA 189A

\section{Esta isoforma é composta pelos exons estruturais 1-5 e pelos exons, $6 \mathrm{~A}, 7,8 \mathrm{~A}$}

CCCCCAAGGCCGCGCGGGCGCGTGTGTGTCTGGGCAGAGGGGGGCGGGGGGGCAATTTTCAGGCTGTG AACCGGGGAGGGGGTCGA GGTCCCCTTCGCTCGGGAGGGAGGGCAGGCTTCGCTCCACGTCCCGGGGG AAGGCCCGAGGGGCGCGCGGGGCAGTTGGCGGAGAGGCTGGAGCCCGGGCCCGTCCCCGCCCCCAGGG CGTGCCAAGGGCGGGTCCGGGCGGGGCCTGCCTTGGTTTTAAGCGGCCGCTAGTGGTAGGAGCGCAGA GGCTTGGGGCAGCCGGGCTGCGAGGAGGCCGCGGCGCGGGGGGCGAGTGGAGCCGGCGGCGGCGGCGC TGGGTCGGGAGGCAGCGGCTAGGCGGACGAACCGGCGGGGTCACCGGCCAGGGGTCTCCGCACTGGAA TCCGAATTCATTTATCCAGGGCTTACCCTCCTCCTTTTTTTTCTTAAGCAATTTTAAAACCCACATTC TTTCCCGTTTTAATTTATTTTTTGCTTCCCATTCCCCGCTTAAACCGGGCCGACCGTTTGGGGGAGAT TGCGCCTTTACTTCCCCAAATCACTTCGGATTTTGGAAACCAGCAGAGAGAAGAAGGAGGTAGCAAGA GCTCCAGAGAGAAGTCGAGGAAGAGAGAGAGAGAGAGGAGAGAGAGAGGGGGAGA GAGAGGGAGACGG GGTCAGAGAGCGCGCGCGGGCGAGCGAGCGACGACAGGGCAGGGGCAGAGTGA GTGACCTGCTTTCGG GGGTGCCCGCCCGAGCGCGGCGTGAGCCCTCCCCGTCGGGACCCCGCACCGGACCAGCCGCGCTGACG GACAGACCGACAGACACCGCCCCCCGCCCCAGCGCCCACCTCCTCCCCGGCCGGCGGCCGAGGGTGGC CGCGGCGGCGAGCCGCGGGCAGGAGCCGGA GCCCGCGCCTGGAGGCGGGGTGGAGGGGGTCGGGGCTC GCGGCGTTGCGGTGAAACTTTTCGTCCAACTTCTGGGCTGTTCTCGCTCCGGAGGAGCCGTGGTCCGC GCCGGGGCAGCAGAGCCGAGCGGAGCCGGGAGAAGTGCGAGCCCGGGCCGGGAGGAGCCGCAGTCGGA GGAGGGGGAGGAGGAAGAAGAGAAGGAAGAGGAGAGGGGGCCGCGGTGGCGACTCGGCGTTCGGGAGC CGGGCTCATGGACGGGTGAGGCGGCTGTGTGCGCAGACAGAGCTCCAGCCGCGCGCGCGCCCCAGGCC CCGGCCCCGGCCCCGGCCCGGGCCTCGGCTCCGGGAGGAAGAGGAGCCCGCCTAGGCGCCGAGGAGAG CGGGCCGCCCCGCAGCCCGAGCGGGAGAGGGAGCGCGA GCCGCGCCGGCCCCGGCCGGGCCTCCGAAA CCATGAACTTTCTGCTCTCCTGGGTGCATTGGAGCCTTGCCTTGCTGCTCTACCTCCACCATGCCAAG TGGTCCCAGGCTGCGCCTATGGCAGGAGGA GAGCACAAACCCCACGAAGTGGT GAAGTTCATGGACGT CTACCAGCGCAGCTACTGCCGTCCCATTGAGACCCTGGTGGACATCTTCCAGGAGTACCCTGACGAGA TCGAGTACATCTTCAAGCCATCCTGCGTGCCCCTGATGCGGTGTGGGGGCTGCTGTAATGATGAGGGC CTAGAGTGCGTGCCCACTGAGGAGTTCAACATCACCATGCAGATTATGCGGATCAAACCTCATCAAGG CCAGCACATAGGGGAGATGAGTTTCCTGCAGCATAGCAAATGTGAATGCAGACCAAAGAAAGATAGAG CAAGGCAAGAAAAAAAATCAATTCGAGGAAAGGGGAAGGGGCAAAAAAGAAAGCGCAAGAAATCCCGG TATAAACCCTGGAGCGTGTACGTGTCCCTGTGGGCCTTGCTCAGAGCGGAGAAAGCATTTGTTTGTAC AAGATCCGCAGACGTGTAAATGTTCCTGCAAAAACACA GACTCGCGTTGCAAGGCGAGGCAGCTTGAG TTAAACGAACGTACTTGCAGATGTGACAAGCCCAGGCGGTGAGCCGGGCTGGAAGAAGGAGCCTCCCT CAGGGTTTCGGGAACCAG 
ISOFORMA 206A

\section{Esta isoforma é composta pelos exons estruturais 1-5 e pelos exons, $6 \mathrm{~A}, 6 \mathrm{~B}, 7,8 \mathrm{~A}$}

CCCCCAAGGCCGCGCGGGCGCGTGTGTGTCTGGGCAGAGGGGGGCGGGGGGGCAATTTTCAGGCTGTG AACCGGGGAGGGGGTCGAGGTCCCCTTCGCTCGGGAGGGAGGGCAGGCTTCGCTCCACGTCCCGGGGG AAGGCCCGAGGGGCGCGCGGGGCAGTTGGCGGAGAGGCTGGAGCCCGGGCCCGTCCCCGCCCCCAGGG CGTGCCAAGGGCGGGTCCGGGCGGGGCCTGCCTTGGTTTTAAGCGGCCGCTAGTGGTAGGAGCGCAGA GGCTTGGGGCAGCCGGGCTGCGAGGAGGCCGCGGCGCGGGGGGCGAGTGGAGCCGGCGGCGGCGGCGC TGGGTCGGGAGGCAGCGGCTAGGCGGACGAACCGGCGGGGTCACCGGCCAGGGGTCTCCGCACTGGAA TCCGAATTCATTATCCAGGGCTTACCCTCCTCCTTTTTTTCTTAAGCAATTTTAAAACCCACATTC

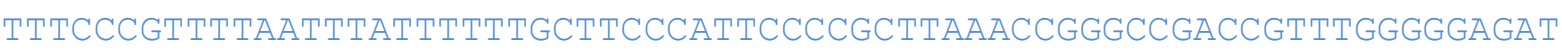

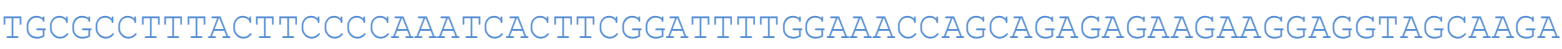

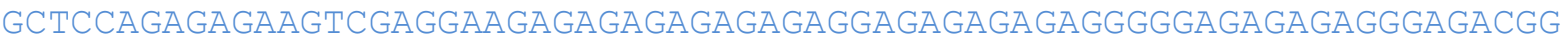
GGTCAGAGAGCGCGCGCGGGCGAGCGAGCGACGACAGGGCAGGGGCAGAGTGAGTGACCTGCTTTCGG GGGTGCCCGCCCGAGCGCGGCGTGAGCCCTCCCCGTCGGGACCCCGCACCGGACCAGCCGCGCTGACG GACAGACCGACAGACACCGCCCCCCGCCCCAGCGCCCACCTCCTCCCCGGCCGGCGGCCGAGGGTGGC CGCGGCGGCGAGCCGCGGGCAGGAGCCGGAGCCCGCGCCTGGAGGCGGGGTGGAGGGGGTCGGGGCTC GCGGCGTTGCGGTGAAACTTTTCGTCCAACTTCTGGGCTGTTCTCGCTCCGGAGGAGCCGTGGTCCGC GCCGGGGCAGCAGAGCCGAGCGGAGCCGGGAGAAGTGCGAGCCCGGGCCGGGA GGAGCCGCAGTCGGA GGAGGGGGAGGAGGAAGAAGAGAAGGAA GA GGAGAGGGGGCCGCGGTGGCGACTCGGCGTTCGGGAGC CGGGCTCATGGACGGGTGAGGCGGCTGTGTGCGCAGACAGAGCTCCAGCCGCGCGCGCGCCCCAGGCC CCGGCCCCGGCCCCGGCCCGGGCCTCGGCTCCGGGAGGAAGAGGAGCCCGCCTAGGCGCCGAGGAGAG CGGGCCGCCCCGCAGCCCGAGCGGGAGAGGGAGCGCGAGCCGCGCCGGCCCCGGCCGGGCCTCCGAAA CCATGAACTTTCTGCTCTCCTGGGTGCATTGGAGCCTTGCCTTGCTGCTCTACCTCCACCATGCCAAG TGGTCCCAGGCTGCGCCTATGGCAGGAGGA GAGCACAAACCCCACGAAGTGGTGAAGTTCATGGACGT CTACCAGCGCAGCTACTGCCGTCCCATTGA GACCCTGGTGGACATCTTCCAGGAGTACCCTGACGAGA TCGAGTACATCTTCAAGCCATCCTGCGTGCCCCTGATGCGGTGTGGGGGCTGCTGTAATGATGAGGGC CTAGAGTGCGTGCCCACTGAGGAGTTCAACATCACCATGCAGATTATGCGGATCAAACCTCATCAAGG CCAGCACATAgGGgAgATGAgTTTCCTGCAGCATAGCAAATGTGAATGCAGACCAAAGAAAGATAGAG CAAGGCAA GAAAAAAAATCAATTCGAGGAAAGGGGAAGGGGCAAAAAAGAAAGCGCAAGAAATCCCGG TATAAACCCTGGAGCGTGTACGTGTGCCTCCGCTGTTTCATTGCCTGGAGCCTCCCTGGCCCCCATCC CTGTGGGCCTTGCTCAGAGCGGAGAAAGCATTTGTTTGTACAAGATCCGCAGACGTGTAAATGTTCCT GCAAAAACACAGACTCGCGTTGCAAGGCGA GGCAGCTTGAGTTAAACGAACGTACTTGCAGATGTGAC AAGCCCAGGCGGTGAGCCGGGCTGGAAGAAGGAGCCTCCCTCAGGGTTTCGGGAACCAG 
O VEGFA canino é constituído de sequências homólogas ao VEGFA humano, formado por oito exons (TISCHER et al., 1991; SHIMA et al., 1996). As isoformas humanas VEGFA121, VEGFA145, VEGFA165A, VEGFA165B, VEGFA189 e VEGFA206 são homólogas às caninas.

A formação e manutenção do CL depende do sistema do VEGFA (FERRARA et al., 1998; NISHIMOTO et al., 2006) e as isoformas podem exercer funções próangiogênicas e anti-angiogênicas (HARRIS et al., 2012).

De acordo com os dados obtidos da homologia, é possível indicar a ação das isoformas no desenvolvimento do corpo lúteo de cadelas, uma vez que a fase inicial do diestro é caracterizada por uma alta taxa de vascularização e uma baixa na fase de regressão do corpo lúteo (HOFFMANN et al., 2004; MARIANI et al., 2006).

Mariani et al. (2006), descrevem que os receptores do VEGF, o FLT-1 e o KDR sofrem pouca variação ao longo do diestro, sugerindo um papel na regulação luteínica e relacionando com a presença de isoformas pró-angiogênicas e antiangiogênicas no CL canino.

Neste sentido, sugere-se que as isoformas caninas do VEGFA aqui apresentadas sejam validadas em experimentos para caracterizar sua a expressão no corpo lúteo canino cíclico e gravídico; além disto, sugere-se validação experimental para caracterizar quais destas isoformas aqui apresentadas possuem maior expressão em quais fases do diestro. 